Universidade de São Paulo

Faculdade de Economia, Administração e Contabilidade de Ribeirão Preto Departamento de EConomia

Programa de Pós-Graduação em Economia - Área: Economia Aplicada

CAIO DE ANGELIS NASCIMENTO

Precificação de ativos via Machine Learning: uma extensão de métodos lineares esparsos

Orientador: Prof. Dr. Márcio Poletti Laurini

Ribeirão Preto

2020 
Prof. Dr. Vahan Agopyan

Reitor da Universidade de São Paulo

Prof. Dr. André Lucirton Costa

Diretor da Faculdade de Economia, Administração e Contabilidade de Ribeirão Preto

Prof. Dr. Sérgio Kannebley Júnior

Chefe do Departamento de Economia

Prof. Dr. Sérgio Naruhiko Sakurai

Coordenador do Programa de Pós-Graduação em Economia 


\title{
Precificação de ativos via Machine Learning: uma extensão de métodos lineares esparsos
}

\author{
Dissertação de mestrado apresentada ao Pro- \\ grama de Pós-Graduação em Economia - \\ Área: Economia Aplicada da Faculdade de \\ Economia, Administração e Contabilidade de \\ Ribeirão Preto da Universidade de São Paulo \\ para obtenção do título de Mestre em Ciên- \\ cias.
}

Orientador: Prof. Márcio Poletti Laurini

\begin{abstract}
Versão Corrigida
(versão original disponível na Faculdade de Economia, Administração e Contabilidade de Ribeirão Preto)
\end{abstract}

Ribeirão Preto 
Autorizo a reprodução e divulgação total ou parcial deste trabalho, por qualquer meio convencional ou eletrônico, para fins de estudo e pesquisa, desde que citada a fonte.

Nascimento, Caio de Angelis.

Precificação de Ativos via Machine Learning: uma extensão de métodos lineares esparsos / Caio de Angelis Nascimento Ribeirão Preto, SP, 2020.

121 p.: il.; $30 \mathrm{~cm}$

Dissertação de mestrado apresentada ao Programa de PósGraduação em Economia - Área: Economia Aplicada da Faculdade de Economia, Administração e Contabilidade de Ribeirão Preto da Universidade de São Paulo, para obtenção do título de Mestre em Ciências. - Universidade de São Paulo

Orientador: Laurini, Márcio

1. Precificação de ativos. 2. Machine Learning. 3. Estrutura a termo do retorno esperado. 4. Gestão de portfólios. 
Aos meus pais. 



\section{Agradecimentos}

Primeiramente, gostaria de expressar minha incomensurável gratidão aos meus pais, Salete e Cassiano, que apostaram em mim sua confiança e apoio, e que tanto sacrificaram para que eu pudesse chegar até aqui. Essa conquista é tão de vocês quanto minha.

Ao meu caro orientador, Márcio Laurini, por todo conhecimento e inspiração que me foram transmitidos durante as disciplinas do mestrado, e pelas valiosas contribuições na qualificação, pré-defesa e defesa. Meu muito obrigado é certamente pouco perante a confiança que vocês depositaram em mim.

Aos professores João Caldeira e Roseli Silva por também terem aceitado meu convite para participar da minha pré-defesa e qualificação e pelas contribuições importantíssimas para o desenvolvimento da dissertação.

Aos professores Marcelo Fernandes e Marcelo Medeiros pelas contribuições valiosas para o desenvolvimento da dissertação.

Aos meus amigos de mestrado, em especial a João Pedro Amaral e Igor Martins pelo apoio no desenvolvimento da pesquisa, conselhos e conhecimentos compartilhados.

A todos os professores do PPGE/FEA-RP/USP, em especial aos professores Sérgio Kannebley Júnior, Sérgio Naruhiko Sakurai e Alex Ferreira que se tornaram além de professores, conselheiros, amigos e parceiros de tênis.

A todos os técnicos e funcionários da FEA-RP/USP, especialmente do Serviço de PósGraduação.

A EESP/FGV pela concessão de vaga regular para estudos em seus cursos de pós-graduação, em especial ao professor Pedro Valls Pereira.

Ao banco BTG Pactual pelo apoio e auxilio para finalização de minha dissertação, em especial a área de Collateral Management.

À CAPES pelo apoio financeiro concedido ao longo do mestrado. O presente trabalho foi realizado com o apoio da Coordenação de Aperfeiçoamento de Pessoal de Nível Superior Brasil (CAPES) - Código de Financiamento 001. 


\section{Resumo}

NASCIMENTO, C. A. Precificação de Ativos via Machine Learning: uma extensão de métodos lineares esparsos. Dissertação (Mestrado) - Faculdade de Economia, Administração e Contabilidade de Ribeirão Preto, Universidade de São Paulo, Ribeirão Preto, 2020.

Neste trabalho utilizamos uma classe de modelos de não arbitragem e métodos de estimação baseados em ferramentas de Machine Learning para prever o prêmio de risco ao longo do tempo. A pesquisa inova em adicionar modelos de alta dimensão esparsos para precificação de ativos, como modelos de vetores autoregressivos esparsos, análise de componentes principais esparsos (SPCA), combinação de métodos de penalização como pré-seleção de variáveis e e outros modelos econométricos baseados em esparsidade. Também consideramos como extensão aos modelos existentes na literatura de alta de dimensão analisados na pesquisa correções nos estimadores de matrizes de covariância, adicionando estimadores considerando dependência de longo prazo. A base de dados utilizada consiste de 630 séries temporais relacionadas ao mercado Brasileiro, contendo variáveis macroeconômicas, setoriais e especificas dos ativos, divididas em quatro diferentes espaços de tempo (dia, mês, trimestre e ano). Como resultado principal foi desenvolvida uma estrutura a termo do prêmio de risco de um conjunto de ativos selecionados, chegando a encontrar um R2 para previsões de fora da amostra de aproximadamente $91 \%$ para o Índice IBOVESPA. Com objetivo de testar a capacidade de geração de alpha dos modelos desenvolvidos na pesquisa, foram desenvolvidas estratégias de Long-Short e Long-Only compostas pelos ativos analisados de 1 de janeiro de 2016 até 31 de dezembro de 2017, apresentando índice de Sharpe de 3,030 e um retorno acumulado de 157,07\% no período.

Palavras-chave: Precificação de ativos. Machine Learning. Estrutura a termo do retorno esperado. Gestão de portfólios. 



\section{Abstract}

NASCIMENTO, C. A. Asset Pricing via Machine Learning: an extension of sparse linear methods. Dissertation (Master Degree) - School of Economics, Business and Accounting at Ribeirão Preto, University of São Paulo, Ribeirão Preto, 2019.

In this work we use a class of non-arbitrage models and estimation methods based on Machine Learning tools to predict the risk premium over time. The research innovates in adding sparse high-dimension models for asset pricing, such as sparse autoregressive vector models, sparse principal component analysis (SPCA), combination of penalty methods such as pre-selection of variables and other sparse based econometric models. We also consider as an extension to the existing models in the high-dimensional literature analyzed in the research, corrections in the covariance matrix estimators, adding estimators considering long-term dependence. The database used consists of 630 time series related to the Brazilian market, containing macroeconomic, sectorial and asset-specific variables, divided into four different time periods (day, month, quarter and year). As a main result, a term structure of the risk premium for a set of selected assets was developed, reaching an R2 for out-of-sample forecasts of approximately $91 \%$ for the IBOVESPA Index. In order to test the alpha generation capacity of the models developed in the research, Long-Short and Long-Only strategies were developed composed of the analyzed assets from January 1, 2016 to December 31, 2017, with a Sharpe index of 3.030 and an accumulated return of $157.07 \%$ in the period.

Keywords: Asset pricing. Machine Learning. Term structure of the expected return. Portfolio management.. 



\section{Lista de ilustrações}

Figura 1 - Divisão do espaço de tempo da pesquisa . . . . . . . . . . . . . . . 54

Figura 2 - Avaliação da Capacidade Preditiva dos Modelos Diários. . . . . . . . . 59

Figura 3 - Análise Diária de Efeitos Marginais Por Ativo. . . . . . . . . . . . . 62

Figura 4 - Análise Mensal de Efeitos Marginais Por Ativo. . . . . . . . . . . . . 65

Figura 5 - Análise Trimestral de Efeitos Marginais Por Ativo. . . . . . . . . . . 67

Figura 6 - Estrutura a termo do retorno esperado: Índice IBOVESPA. . . . . . . . 74

Figura 7 - Estrutura a termo do retorno esperado: Taxa de Câmbio Real/Dólar. 75

Figura 8 - Estrutura a termo do retorno esperado: Taxa CDI. . . . . . . . . . 75

Figura 9 - Estrutura a termo do retorno esperado: ABEV3.SA. . . . . . . . 76

Figura 10 - Estrutura a termo do retorno esperado: CMIG4.SA . . . . . . . . . 76

Figura 11 - Estrutura a termo do retorno esperado: ITUB4.SA . . . . . . . . . . 77

Figura 12 - Estrutura a termo do retorno esperado: PETR4.SA . . . . . . . . . . 77

Figura 13 - Estrutura a termo do retorno esperado: VALE3.SA . . . . . . . . . 78

Figura 14 - Avaliação da Capacidade Preditiva Para o Retorno Acumulado por Ativo. 79

Figura 15 - Retorno Acumulado Carteiras Reduzidas. . . . . . . . . . . . . . 84

Figura 16 - Retorno Acumulado Carteiras Completas . . . . . . . . . . . . . 86 


\section{Lista de tabelas}

Tabela 1 - Total de séries temporais. . . . . . . . . . . . . . . 52

Tabela 2 - Apresentação dos modelos estimados. . . . . . . . . . . . 56

Tabela 3 - Resultados para cada um dos modelos de predição diária. . . . . . . . 58

Tabela 4 - Teste de Diebold e Mariano. . . . . . . . . . . . . . . . . 61

Tabela 5 - Resultados dos modelos mensais. . . . . . . . . . . . . . . . 64

Tabela 6 - Resultados dos modelos trimestrais. . . . . . . . . . . . . . . 66

Tabela 7 - Resultados dos modelos anuais. . . . . . . . . . . . . . . . 69

Tabela 8 - Resumo dos modelos selecionados. . . . . . . . . . . . 72

Tabela 9 - Horizonte de previsão. . . . . . . . . . . . . . 73

Tabela 10 - Médias da confiança em relação as priores e posteriores por ativo analisado. 83

Tabela 11 - Principais resultados encontrados. . . . . . . . . . . . . . . . 85

Tabela 12 - Principais resultados encontrados nas carteiras completas . . . . . . . 87

Tabela 13 - Variáveis incluídas na pesquisa (1) . . . . . . . . . . . . . . 97

Tabela 14 - Variáveis incluídas na pesquisa $(2) \ldots \ldots$. . . . . . . . . . . 98

Tabela 15 - Variáveis incluídas na pesquisa (3) . . . . . . . . . . . . . . . . 99

Tabela 16 - Variáveis incluídas na pesquisa (4) . . . . . . . . . . . . . . . 100 


\section{Sumário}

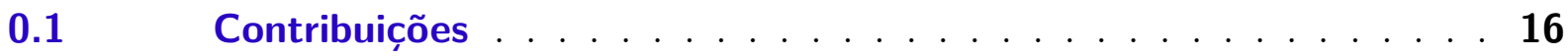

$0.2 \quad$ Machine Learning $\ldots \ldots \ldots \ldots$

$0.3 \quad$ Literatura . . . . . . . . . . . . . . . . 21

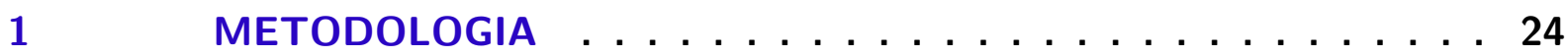

1.1 Precificação de ativos com não arbitragem . . . . . . . . . 25

1.2 Ajuste via validação e divisão da amostra . . . . . . . . . . . 26

1.3 Penalização Linear . . . . . . . . . . . . . . . . . . . 27

1.4 Vetor Autoregressivo (VAR) $\ldots \ldots \ldots \ldots$

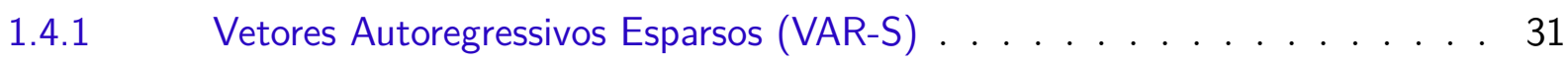

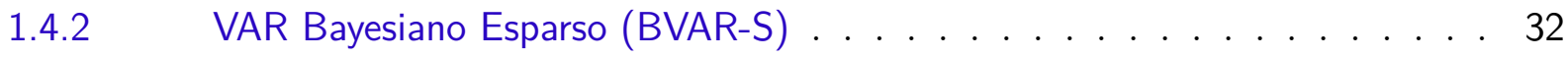

1.4.3 Métodos de Redução de Dimensionalidade Para o Conjunto Informacional $\Omega 34$

1.5 Estimação da Matriz de Covariâncias . . . . . . . . . . . 40

1.5.1 Matriz de Covariâncias de Longo Prazo (LRCM) . . . . . . . . . . . . 40

1.5.2 Modelo fatorial de volatilidade estocástica . . . . . . . . . . . . . 42

$1.6 \quad$ Avaliação do desempenho preditivo . . . . . . . . . . . 43

$1.7 \quad$ Alocação de Carteiras . . . . . . . . . . . . . . . 45

$1.8 \quad$ Interpolação de dados e preenchimento de curvas . . . . . . . 50

1.9 Relevância das variáveis e relacionamento marginal . . . . . . . . 51

2 UM ESTUDO EMPÍRICO PARA ATIVOS BRASILEIROS . . . . 52

$2.1 \quad$ Base de dados $\ldots \ldots \ldots \ldots \ldots \ldots$

$2.2 \quad$ Estruturas dos Modelos Preditivos . . . . . . . . . . . . . . . 54

3 APLICAÇÃO:DESENVOLVIMENTO DA ESTRUTURA A TERMO

DO RETORNO ESPERADO . . . . . . . . . . . . . 72

4 APLICAÇÃO: ALOCAÇÃO DE PORTFÓLIOS VIA EXTENSÃO

DO MODELO BLACK E LITTERMAN . . . . . . . . . . . 81 
CONCLUSÃO . . . . . . . . . . . . . . . 89

REFERÊNCIAS ....................... 92

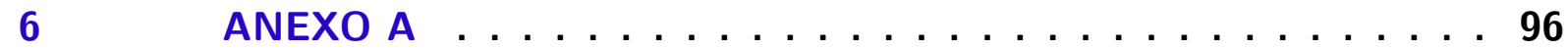

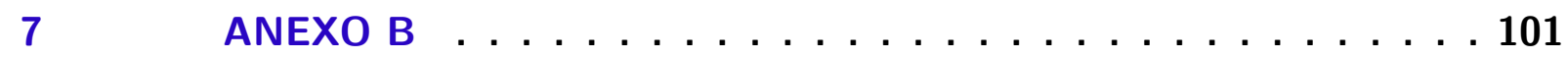

$7.1 \quad$ Modelos de Penalização Linear . . . . . . . . . . . . . . . . . . 101

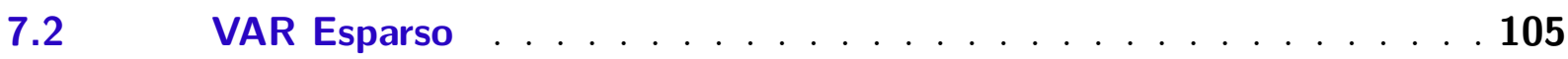

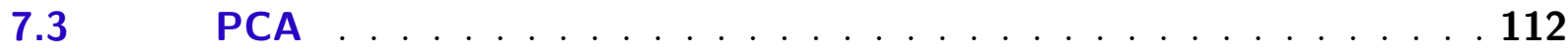

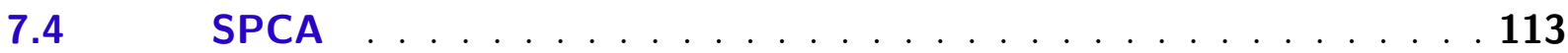

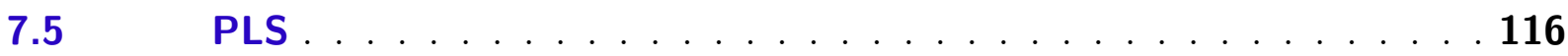




\section{Introdução}

A previsão dos retornos de ativos é um valor central em finanças e na macroeconomia. A questão fundamental na precificação de ativos é entender o comportamento dos prêmios de risco ao longo do tempo. A eficiência de mercado impõe que todas as informações dos preços sejam resumidas no Fator de Desconto Estocástico (FDS) ou no operador de núcleo dos preços. Entretanto, a variação do retorno tende a ser dominada por informações imprevisíveis que obscurecem tais fatores ao longo do tempo. Esse processo muitas vezes é denominado na literatura como ruído ou efeito das incertezas, podendo surgir da incapacidade dos modelos existentes e dos agentes de capturar com fidedignidade o efeito real e o sinal que cada nova informação tem sobre o prêmio de risco.

Nos últimos 50 anos, a busca empírica por explicar o fator de desconto estocástico e o núcleo de preços para o processo de precificação de ativos foi incessante e extensa. Com o objetivo de explicar o prêmio de risco dos ativos, mais de 400 fatores já foram desenvolvidos na literatura como pode ser visto em Harvey e Liu (2019). Contudo, o trabalho de Gu, Kelly e Xiu (2018) elucidou que estimar um fator de desconto estocástico comum que possa explicar o retorno esperado de todos os ativos é uma tarefa complexa. O fator de desconto estocástico de determinado ativo depende de um enorme conjunto informacional específico para o ativo em questão e de um conjunto ainda maior de informações comuns entre os ativos. De forma reincidente, as pesquisas de Gu, Kelly e Xiu (2018) e Chen, Pelger e Zhu (2019) encontraram quatro grandes desafios: (1) O FDS poderia, por construção, depender de todas as informações disponíveis, o que significa que o FDS é uma função de um conjunto potencialmente muito grande de variáveis e não incluído nos trabalhos até então realizados. (2) A forma funcional do FDS não é conhecida ex-ante, e ex-post, e por basear-se em seu comportamento histórico não possui capacidade preditiva para o futuro, sendo que sua previsão pode advir de um processo extremamente complexo. (3) O FDS tem uma estrutura dinâmica complexa e a exposição ao risco para ativos individuais varia ao longo do tempo, dependendo das condições econômicas e das mudanças nos atributos 
específicos do ativo. (4) O prêmio de risco de ações individuais tem uma baixa relação entre o sinal e o ruído, o que complica a estimativa de um FDS que explica os retornos esperados de todas as ações.

Nesta dissertação, estimamos cinquenta e três modelos lineares esparsos diferentes para o processo de precificação de um conjunto dos ativos de maior liquidez no mercado brasileiro, com base em um grande conjunto de informações macroeconômicas e específicas dos ativos. Seguindo Chen, Pelger e Zhu (2019), utilizamos da condição de não arbitragem como parte do algoritmo de Machine Learning Linear. Estimamos os fatores de desconto estocástico comuns entre os ativos e preditores específicos de cada ativo analisado, com objetivo de explicar os retornos dos ativos a partir das restrições de momento condicional implícitas pela não arbitragem. O uso de técnicas de Machine Learning, é uma ideia natural para lidar com a alta dimensionalidade do problema. Uma abordagem crucial de nosso trabalho foi incorporar condições econômicas e preditores específicos de cada ativos ao problema de Machine Learning. A inclusão da restrição de não arbitragem no algoritmo melhorou o sinal de prêmio de risco e possibilitou explicar os retornos individuais das ações. Empiricamente, nosso modelo geral superou fora da amostra as principais abordagens de benchmark e forneceu uma visão clara da estrutura de desconto estocástico dos ativos selecionados e das fontes de risco sistemático ao longo do tempo.

A determinação do FDS e do fator de desconto estocástico específico (FDSE) previu retornos futuros esperados que foram incorporados diretamente nas estratégias de negociação via arbitragem presente na dissertação, onde ativos com preços incorretos corresponderam a oportunidades de arbitragem que podem ser exploradas. A condição de não arbitragem identificou os componentes do FDS que carregam um prêmio de risco elevado, mas possuem apenas um sinal de variação fraco. Intuitivamente, a maioria dos métodos de Machine Learning em finanças se encaixa em um modelo que pode explicar o máximo de variação possível, que é essencialmente um objeto de segundo momento. A condição de não arbitragem se baseou na explicação dos prêmios de risco, que, por sua vez, se baseiam no primeiro momento condicional. Podemos decompor o retorno das ações em uma parte de prêmio de risco previsível e um componente de martingale imprevisível. 
A maior parte da variação foi gerada pelo componente imprevisível que não possui um prêmio de risco. Ao considerar retornos médios desagregados, o componente imprevisível foi diversificado ao longo do tempo e o sinal de risco previsível foi reforçado. No entanto, os prêmios de risco de ações individuais variam no tempo e uma média incondicional dos retornos das ações pode não capturar o componente previsível. Portanto, consideramos médias incondicionais de retorno das ações instrumentados com todas as combinações possíveis de características específicas da empresa e informações macroeconômicas. Isso tem o objetivo de elevar o sinal do prêmio de risco e levar em consideração a variação ao longo do tempo do prêmio de risco.

\subsection{Contribuições}

Realizamos uma análise empírica em larga escala, investigando os 8 principais ativos em relação a liquidez do mercado financeiro brasileiro nos últimos 25 anos: Índice IBOVESPA, Certificados de Depósitos Interbancários (CDI) (SWAP), taxa de câmbio Real/Dólar, ABEV3.SA, CMIG4.SA, ITUB4.SA, PETR4.SA e VALE3.SA. utilizando-se de uma base de dados de 23 anos, de 1995 à 2017. Nosso conjunto de preditores inclui um total de 630 séries temporais diárias, mensais, trimestrais e anuais, sendo uma média de 88 características para cada ação, 90 características setoriais e 102 variáveis macroeconômicas. No nível mais amplo, nossa principal descoberta empírica foi que o Machine Learning Linear e Esparso (MLLE) como um todo tem o potencial de melhorar nosso entendimento empírico dos retornos esperados dos ativos. Tal método consolidou o conjunto de dados preditores, que é massivo na perspectiva da literatura existente, em um modelo de previsão de retorno que domina as abordagens tradicionais. A implicação imediata foi que o Machine Learning ajudou a resolver os problemas práticos de investimentos, como escolha de portfólio e gerenciamento de riscos, justificando seu papel na arquitetura de estratégias de investimento no contexto atual.

A evidência de tal contribuição foi divida em dois grupos. No primeiro grupo, fornecemos um conjunto de modelos de referência para a previsão dos prêmios de risco do mercado agregado e dos retornos esperados para os ativos específicos. Essa capacidade 
de previsão foi resumida em um $R^{2}$ preditivo fora da amostra comparativamente alto em relação à literatura anterior e robusto em uma variedade de especificações de Machine Learning. No segundo grupo, fornecemos estratégias de gestão de portfólio desenvolvidas das previsões de retorno geradas pelos modelos Machine Learning que alcançaram índices Sharpe mensais acima de 3,00.

Ao total foram encontradas mais dez contribuições para literatura existente. A primeira destas contribuições advém do encontro dos preditores de maior sucesso nos ativos analisados. Todos os métodos que estudamos produziram uma classificação muito semelhante dos preditores mais informativos em nível de retorno, que se enquadraram em três categorias principais: (1) variáveis de tendência de preços, incluindo o momento dos pares no mercado, o momento da indústria e movimento dos demais índices de mercado; (2) variáveis de liquidez, incluindo valor de mercado, volume de negociações e spread de compra e venda; (3) volatilidade de retorno, índice de volatilidade, beta de mercado e beta ao quadrado que também estão entre os principais preditores em todos os modelos que consideramos. As variáveis específicas dos ativos analisados, como índices dos principais commodities da cadeira produtiva, índice das vendas pelo preço do ativo, ratio do preço em relação aos lucros e variáveis de grau de alavancagem financeira foram os próximos preditores encontrados na escala de importância preditiva.

Seguindo na mesma linha de contribuições da literatura, encontramos os preditores de maior sucesso no nível microeconômico e macroeconômico, considerando que analisamos ativos como Índice IBOVESPA, CDI e taxa de câmbio e obtivermos como resultado o conjunto de variáveis que melhor explicam as variações apresentadas por tais variáveis, contribuindo para literatura de previsão de variáveis econômicas. Os dados macroeconômicos de séries temporais têm uma estrutura de "fator"de baixa frequência, que pode ser capturada pelos modelos desenvolvidos através da pesquisa

Terceiro, ao considerar as características específicas da empresa isoladamente, o FDS depende aproximadamente de forma linear da maioria das características. Isso explica por que fatores de risco lineares funcionam bem em determinadas carteiras de uma única classe de ativos, e fortalece a visão de que cada ativo de determinada classe possui um 
conjunto informacional exclusivo que gera melhores resultados em sua previsão. Desta forma, justificamos a necessidade de um fator de desconto exclusivo para cada um dos ativos analisados.

Em quarto lugar, estimar um modelo de precificação para ações individuais levou a um modelo de precificação superior para carteiras. Nosso modelo explica de forma robusta os retornos esperados dos ativos de teste padrão, por exemplo, Índice IBOVESPA, Taxa de Câmbio Real/Dólar e CDI, possuindo um excelente desempenho de precificação, superior ao benchmark em todas as carteiras analisadas, e um $R^{2}$ fora da amostra superior a $50 \%$ na média para retornos mensais.

Quinto, a estrutura FDS encontrada foi estável ao longo do tempo. Estimamos a forma funcional do FDS com os dados de 1995 a 2015, que apresentaram um excelente desempenho fora da amostra para os dados de teste de 2016 até 2017. A exposição ao FDS do risco para ações individuais pode variar ao longo do tempo, porque as características específicas da empresa e variáveis macroeconômicas variam no tempo. No entanto, a forma funcional do FDS e a exposição ao risco em relação a essas covariáveis não sofrem grandes alterações. Para acrescentar à contribuição, constatamos que os melhores modelos preditivos se alteram ao longo do tempo, com um ciclo de vida médio de 3 meses, o que vai ao encontro aos resultados encontrados nas principais gestoras de fundos quantitativas.

Sexto, utilizamos a literatura de Machine Learning de métodos lineares para precificação de ativos um modelo de não arbitragem, separando o efeito de ruído e tendência presente no FDS. Reforçando tal contribuição, encontramos modelos de alocação de ativos que estruturados sobre não arbitragem possuem melhor performance em todos casos no qual a estratégia de arbitragem não inclui explorar o ruído.

Sétimo, complementamos a literatura de desenvolvimento da estrutura a termo para ativos de risco, fornecendo uma alternativa a modelos de opções e derivativos sobre dividendos e variância. Através da combinação das previsões em diferentes frequências, entregamos uma curva de estrutura a termo do prêmio de risco esperado. Devido à impossibilidade de tempo e dados, as estratégias comparativas não foram desenvolvidas na pesquisa, gerando um benchmark a ser alcançado. Contudo, como analisamos o $R^{2}$ 
preditivo encontramos na média um percentual de $34 \%$ para um ambiente de previsão de dois anos.

Oitavo, adicionamos novas extensões de modelos de alta dimensão, incluindo novas formulações de VAR esparsos, modificações em relação à aplicação posterior ou de préseleção de variáveis em relação aos modelos de análise de componentes principais esparsos. Tais modelos apresentaram resultados semelhantes aos já presentes na literatura em relação à capacidade preditiva fora da amostra. Utilizamos o método de análise do teste de DIEBOLD e MARIANO (1995) para compararmos os modelos e encontramos que os modelos de alta dimensão desenvolvidos na dissertação possuem resultados superiores e significativos em relação aos principais modelos de benchmark.

Nona, adicionamos aos modelos de alta dimensão uma correção em relação as matrizes de covariâncias, utilizando das matrizes de covariância de longo prazo. Desta forma, adicionamos a literatura dois formatos de matrizes de covariância de longo prazo introduzidos aos modelos de alta dimensão: Andrews (1991) e Kiefer e Vogelsang (2005). Uma extensão também adicionada à pesquisa em relação as matrizes de covariância foi sua estimação via volatilidade estocástica fatorial para o modelo de alocação de ativos.

Décima, realizamos uma extensão na metodologia de alocação de carteiras de Black-litterman, onde através da diferenciação entre as priores e posteriores introduzimos um conceito de não arbitragem na pesquisa. Sendo que como priori utilizamos da previsão mensal desagregada e como posterior incluímos a previsão diária para o retorno, o que possibilitou, em conjunto com a correção das matrizes de covariância pela matriz de covariância de longo prazo, decompor o retorno das ações em uma parte de prêmio de risco previsível e um componente de martingale imprevisível para previsão.

\subsection{Machine Learning}

O interesse em métodos de Machine Learning para finanças cresceu tremendamente na pesquisa acadêmica e na indústria. Na área acadêmica livros recentes como Advances in Financial Machine Learning de Prado (2018) se tornaram extremamente utilizados em 
cursos avançados de finanças, concomitantemente a indústria financeira possui excelentes aplicações de tais modelos para gestão de fundos de investimento como no caso da empresa $A Q R$ e dos setores quantitativos emergindo dentro das mesas dos grandes conglomerados financeiros. A definição de Machine Learning é incipiente e geralmente é específica do contexto. Utilizamos o termo para descrever uma coleção diversificada de modelos de alta dimensão para previsão estatística, combinada com os chamados métodos de "regularização" para seleção de modelos e mitigação do super ajuste e algoritmos eficientes para pesquisar entre um grande número de possíveis especificações de modelo. A natureza de alta dimensão dos métodos de Machine Learning aprimora sua flexibilidade em relação às técnicas de previsão econométrica mais tradicionais. Essa flexibilidade traz esperança de uma melhor aproximação do processo de geração de dados desconhecidos e prováveis complexos subjacentes aos prêmios de risco de patrimônio. Vários aspectos do processo de precificação de ativos o tornam um campo particularmente atraente para análise.

O trabalho de Gu, Kelly e Xiu (2018) motivou a utilização do Machine Learning, através de dois principais pontos. (1) Duas agendas de pesquisa monopolizaram a moderna pesquisa empírica de precificação de ativos. A primeira buscou descrever e entender as diferenças nos retornos esperados entre os ativos e é encontrada nos trabalhos de Fama e French (2008) e Jenter e Lewellen (2015). A segunda focou a dinâmica do prêmio agregado ao risco de ações de mercado como o trabalho de Rapach e Zhou (2013). Machine Learning, cujos métodos são amplamente especializados para previsão, é, portanto, ideal para o problema de medição de prêmio de risco. (2) A coleta de variáveis candidatadas para previsão do prêmio de risco é grande. A área acumulou uma lista impressionante de preditores que vários pesquisadores argumentaram possuir poder de previsão para retornos.Com ênfase nas técnicas de seleção de variáveis e redução de dimensão, Machine Learning é adequado para esses problemas de previsão desafiadores, reduzindo graus de liberdade e condensando variações redundantes entre os preditores devido ao alto nível de correlação entre as variáveis.

Selecionamos um conjunto de modelos candidatos potencialmente adequados para enfrentar os dois desafios empíricos descritos acima. Eles constituem o core dos métodos 
encontrados em um livro didático de Machine Learning linear em nível avançado. Isso inclui regressão linear, modelos lineares generalizados com penalização, redução de dimensão via regressão de componentes principais (PCR) e mínimos quadrados parciais (PLS), utilização de critérios de pré-seleção (RIDGE, LASSO, adaLASSO e ELASTICNET), modelos de vetores autoregressivos esparsos (VAR-S) e análise de componentes principais esparsos. Esta não foi uma análise exaustiva de todos os métodos. Por exemplo, excluímos modelos não lineares de Machine Learning. Entretanto, os métodos de Machine Learning por si só não identificam profundas associações fundamentais entre preços de ativos e variáveis condicionantes. Quando o objetivo é entender os mecanismos econômicos, o Machine Learning ainda pode ser útil. Isto é, requer que o pesquisador adicione estrutura. Por meio do exame da literatura, esta dissertação adicionou uma restrição de não arbitragem aos modelos de Machine Learning.

\subsection{Literatura}

Essa dissertação estendeu a literatura empírica sobre previsão de retorno de ações, índices, taxa de câmbio e juros, que vem em duas vertentes básicas. A primeira vertente modela as diferenças nos retornos esperados entre as ações em função das características do nível das ações e foi exemplificada por Fama e French (2008) e Jenter e Lewellen (2015). A abordagem típica nesta literatura realizou regressões transversais dos retornos futuros de ações com algumas características de ações defasadas, via fatores não negociáveis. A segunda vertente prevê a série temporal de retornos e foi pesquisada por Koijen e Nieuwerburgh (2011) e Rapach e Zhou (2013). Essa literatura tipicamente conduziu regressões de séries temporais com amplo retorno agregado de portfólio em um pequeno número de variáveis preditoras macroeconômicas. Esses métodos tradicionais têm limitações potencialmente graves, que as ferramentas estatísticas mais avançadas de Machine Learning podem ajudar a superar. O mais importante é que as regressões e os tipos de portfólio não são adequados para lidar com o grande número de variáveis preditoras que a literatura acumulou ao longo das últimas décadas.

Os métodos de Machine Learning apareceram constantemente na literatura de 
precificações de ativos. Recentemente, novos métodos foram desenvolvidos para estudar a seção transversal de retornos na estrutura linear respondendo a uma grande quantidade de informações condicionantes. Rapach e Zhou (2013) aplicaram o LASSO para prever retornos globais do mercado de ações usando retornos defasados de todos os países. Lettau e Pelger (2018) estenderam a análise de componentes principais para explicar a não arbitragem. Eles mostraram que um termo de penalidade de não arbitragem permite superar o problema da baixa relação sinal/ruído nos dados financeiros e encontrar as informações relevantes para o FDS. Esta dissertação foi estruturada sobre uma intuição semelhante e mostramos que esse resultado se estende aos preditores específicos dos ativos. Kozak, Nagel e Santosh (2018) aplicaram um processo de otimização da variância média com uma penalidade sobre a liquidez dos fatores de desconto estocásticos. Gu, Kelly e Xiu (2018) aplicaram PCA aos retornos esperados das ações para obter um FDS linear. Chen, Pelger e Zhu (2019) combinou dados de alta frequência com o PCA para capturar não parametricamente a variação no tempo do fator de risco. Pelger e Xiong (2018) mostraram que os estados macroeconômicos são relevantes para capturar a variação do tempo em fatores baseados na PCA. Freyberger, Neuhierl e Weber (2017) usaram os métodos de seleção LASSO para aproximar o FDS como uma função não linear das características, mas excluíram os efeitos de interação.

Modelos de precificação não lineares que utilizam da estrutura de Machine Learning estão presentes de forma robusta na literatura de finanças. Tal literatura utiliza do ferramental de redes neurais, redes neurais profundas, Boosted Regression Trees, Random Forests, feed forward (FFN), rede gerativa adversária (GAN) e redes recorrentes (LSTM) para obter o fator de desconto estocástico. Os modelos podem ser vistos como concorrentes dos modelos lineares propostos nesta dissertação. Em relação aos trabalhos que compararam métodos de Machine Learning lineares e não lineares, em seu trabalho pioneiro, Gu, Kelly e Xiu (2018) realizaram uma comparação de métodos de Machine Learning para prever o painel de retornos individuais de ações nos EUA. Suas estimativas dos prêmios de risco esperados das ações foram mapeadas para um modelo de precificação de ativos de seção transversal. Messmer e Audrino (2017) e Feng, Wang e Zhang (2018) seguiram 
uma abordagem semelhante a de Gu, Kelly e Xiu (2018) para prever retornos de ações com redes neurais. Bianchi et al. (2019) forneceram uma comparação entre os métodos de Machine Learning para prever retornos de títulos dado trabalho de Gu, Kelly e Xiu (2018). Feng, Wang e Zhang (2018) impuseram uma restrição de não arbitragem usando um conjunto de fatores de preços lineares pré-especificados e estimativas de cargas de risco com uma rede neural. Ismailov e Rossi (2018) usou árvores de regressão aprimoradas para formar portfólios condicionais eficientes de variação média com base no portfólio de mercado e no ativo livre de risco. Nossa abordagem também produziu o portfólio eficiente de variância média condicional, mas baseado em todas as ações. Gu, Kelly e Xiu (2019) estenderam o modelo de fator condicional linear de Gu, Kelly e Xiu (2018) para um modelo de fator não linear usando uma rede neural. O foco de nossa dissertação foi explorar simultaneamente uma ampla variedade de métodos de Machine Learning lineares para estudar o comportamento dos retornos esperados de estoque, com ênfase particular na análise comparativa entre os métodos.

O resto da dissertação está organizado da seguinte forma. A Seção 2 apresenta a metodologia e a estrutura dos modelos desenvolvidos a seção 3 desenvolve a parte empírica da pesquisa. A seção 4 fornece resultados em relação a modelos para estrutura a termo do prêmio do risco esperado. Os resultados empíricos em relação às estratégias de alocação de ativos são coletados na seção 5. A Seção 6 conclui a dissertação. O apêndice A apresenta o conjunto dos dados analisados, o apêndice B completa a explanação sobre os modelos e apresenta seus algoritmos de forma resumida. 


\section{Metodologia}

Esta seção descreve a coleção de métodos de Machine Learning que usamos em nossa análise. Em cada subseção, introduzimos um novo método e o descrevemos em termos de seus dois elementos fundamentais. Primeiro, o modelo estatístico que descreve a forma funcional geral de um método para previsões de prêmio de risco, e o segundo, uma função objetiva para estimar os parâmetros do modelo. Todas as nossas estimativas compartilharam o objetivo básico de minimizar o erro quadrático médio das previsões (RMSE). O conjunto de permutações dos modelos se expandiu rapidamente quando se considera as transformações lineares de preditores e combinação de diferentes métodos. Essa proliferação foi agravada em nosso conjunto de preditores de alta dimensão, que nos levou ao seguinte número final: 212 modelos ao todo para cada ativo analisado. No apêndice B são apresentados de forma resumida os algoritmos computacionais para identificar eficientemente a especificação ótima entre as permutações abrangidas por um determinado método. À medida que apresentamos cada método, nosso objetivo foi fornecer uma descrição suficientemente profunda do modelo estatístico, para trazer o leitor ao ambiente de pesquisa explorado.

Em sua forma mais geral, descrevemos o excesso de retorno de um ativo como a expectativa do excesso de retorno esperada em $t$ mais um erro de previsão aditivo:

$$
r_{i, t+1}=E_{t}\left[r_{i, t+1}\right]+\mu_{i, t+1}
$$

Onde os ativos são indexados por $i$, os períodos no tempo por $t$ e onde $T$ é a primeira observação utilizada. Nosso objetivo foi isolar uma representação de $E_{t}\left[r_{i, t+1}\right]$ como uma função de variáveis preditoras que maximizam o poder explicativo fora da amostra para o $r_{i}$ realizado em $t+1$. Onde para facilitar a explicação utilizamos:

$$
E_{t}\left[r_{i, t+1}\right]=C_{i, t \mid t}^{*}\left(z_{i, t \mid t, t-1, t-2, \ldots, T}\right)
$$


Denotamos o conjunto de preditores como o vetor $z_{i, t \mid t, t-1, t-2, \ldots, T}$ e assumimos que o retorno esperado condicional $C_{i, t \mid t}^{*}$ é uma função flexível desses preditores. A função $C_{i, t \mid t}^{*}$ depende de $i$ e de $t$. Isto é, não mantém a mesma forma ao longo do tempo e em diferentes ativos, o modelo aproveita as informações de todo os dados para o desenvolvimento da previsão para o ativo $i$ no período $t+1$. Para facilitar a notação consideramos o conjunto completo de preditores da pesquisa como $\Omega$, i.e, $z_{i, t \mid t, t-1, t-2, \ldots, T} \in \Omega_{t}$.

\subsection{Precificação de ativos com não arbitragem}

A suposição fundamental de não arbitragem é equivalente à existência de um fator de desconto estocástico comum ou especifico, de modo que, para qualquer retorno em excesso da taxa livre de risco $E_{t}\left[r_{i, t+1}^{e}\right]=E_{t}\left[r_{i, t+1}\right]-r_{t}^{f}$. Definimos FDS como: $F_{t+1}=w_{t}^{T} E_{t}\left[r_{i, t+1}^{e}\right]$, onde $w_{t}^{T}$ são os pesos do portfólio eficiente de explicação da variância condicional. Assim, pudemos escrever $w_{t}$ como:

$$
w_{t}=E_{t}\left[r_{i, t+1}^{e} r_{i, t+1}^{e}\right]^{-1} E_{t}\left[r_{i, t+1}^{e}\right]
$$

Desta forma a equação de precificação de ativos encontrada foi:

$$
E_{t}\left[r_{i, t+1}^{e}\right]=\frac{\operatorname{Cov}_{t}\left(r_{i, t+1}^{e}, F_{t+1}\right)}{\operatorname{Var}_{t}\left(F_{t+1}\right)} E_{t}\left[F_{t+1}\right]
$$

Portanto, o processo de não arbitragem implicou em um modelo de um fator, descrito a seguir:

$$
r_{i, t+1}^{e}=\beta_{i, t} F_{t+1}+\epsilon_{i, t+1}
$$

Onde $F_{t+1}$ é o conjunto de fatores explicativos de $r_{i, t+1}^{e}$, com $E_{t}\left[\epsilon_{i, t+1}\right]=0$ e $\operatorname{Cov}_{t}\left(F_{t+1}, \epsilon_{i, t+1}\right)=0$. A formulação do modelo de fator implica a formulação estocástica do fator de desconto acima. Além disso, se o risco idiossincrático $\epsilon_{i, t+1}$ for diversificável e 
o fator FDS for sistemático, o conhecimento dos carregamentos de risco são suficientes para construir o fator de desconto estocástico:

$$
\left(\beta_{i, t}^{T} \beta_{i, t}\right)^{-1} \beta_{i, t}^{T} r_{i, t+1}^{e}=F_{t+1}+\left(\beta_{i, t}^{T} \beta_{i, t}\right)^{-1} \beta_{i, t}^{T} \epsilon_{i, t+1}=F_{t+1}+o_{p}(1)=E_{t}\left[F_{t+1}\right]
$$

O problema fundamental foi encontrar os pesos do portfólio do FDS $w_{t}$ e as cargas de risco $\beta_{i, t}$. Ambas são funções gerais e variáveis no tempo das informações definidas no período $t$. O conhecimento de $w_{t}$ e $\beta_{i, t}$ resolveu três problemas: (1) Explicamos a variação transversal dos retornos individuais das ações. (2) Construímos o portfólio de tangência eficiente de média-variância. (3) Decompomos o retorno das ações em seu componente sistemático previsível e seu componente imprevisível não sistemático. Para encontrar a matriz de carregamento e os pesos de $w_{t}$ utilizamos das metodologias apresentadas neste capítulo. Encontrar os pesos FDS foi equivalente a resolver um método de problema de momento. Uma vez obtidos os pesos dos fatores FDS, as cargas se tornaram proporcionais ao momento condicional $E_{t}\left[F_{t+1}, r_{i, t+1}^{e}\right]$. No modelo de um fator sem arbitragem, as cargas são proporcionais à $\operatorname{Cov}_{t}\left(r_{i, t+1}^{e}, F_{t+1}\right.$ e $E_{t}\left[F_{t+1}, r_{i, t+1}^{e}\right]$, onde o último tem a vantagem de evitarmos estimar o primeiro momento condicional. Nossos resultados empíricos mostraram que podemos estimar melhor o co-movimento condicional dos retornos das ações com os fatores FDS, que é um segundo momento, do que o primeiro momento condicional.

\subsection{Ajuste via validação e divisão da amostra}

Os procedimentos de regularização discutidos abaixo foram as principais defesas do Machine Learning contra o overfitting, e basearam-se na escolha de hiperparâmetros. Isso foi essencial para o desempenho dos métodos de Machine Learning, pois eles controlam a complexidade do modelo. Os hiperparâmetros incluíram, por exemplo, os parâmetros de penalização no LASSO, adaLASSO e na ELASTICNET. Na maioria dos estudos, há pouca orientação teórica sobre como "ajustar" os hiperparâmetros para otimizar o desempenho fora da amostra. Seguimos a abordagem mais comum na literatura e selecionamos parâmetros 
de ajuste de forma adaptável, a partir da utilização de critérios de informação e da minimização de erro quadrático médio.

Dividimos nossa amostra em três períodos disjuntos que mantêm a ordem temporal dos dados. A primeira subamostra, ou "treinamento", foi usada para estimar os modelos sujeitos a um conjunto específico de valores de parâmetros de ajuste. A segunda amostra, ou "validação", foi usada para ajustar os hiperparâmetros e selecionar os melhores modelos para previsão fora da amostra. Construímos previsões para pontos na amostra de validação com base no modelo estimado da amostra de treinamento. A seguir, calculamos a função objetivo com base em erros de previsão da amostra de validação e encontramos hiperparâmetros que otimizam o objetivo da validação. A ideia da validação foi simular um teste fora da amostra do modelo. O ajuste do hiperparâmetro foi equivalente a procurar um grau de complexidade do modelo que tende a produzir um desempenho confiável fora da amostra. Os ajustes da amostra de validação obviamente não ficaram fora da amostra porque foram usados para o ajuste, o que, por sua vez, foi uma entrada para a estimativa. Assim, a terceira subamostra, ou "teste", que não foi usada para estimativas nem ajustes, ficou realmente fora de amostra e, portanto, foi usada para avaliar o desempenho preditivo de um método. Detalhes adicionais sobre nosso esquema de divisão de amostras são fornecidos no capítulo 3.

\subsection{Penalização Linear}

Os métodos de penalização linear atuaram na seleção de subconjuntos produzindo um modelo que possivelmente realizou previsões melhores que o modelo contendo todo conjunto informacional. Esta seção é uma descrição rápida destes métodos. Para uma descrição detalhada veja por exemplo Statistical Learning with Sparsity: The Lasso and Generalizations Hastie, Tibshirani e Wainwright (2015). Tais métodos frequentemente sofrem com grande variabilidade devido ao procedimento de inclusão ou retirada de variáveis do modelo. Uma alternativa existente na literatura foram os métodos de shrinkage, que não apresentam muita variabilidade, foram uma alternativa existente na literatura, como aponta Hastie, Tibshirani e Friedman (2001). Um modelo shrinkage amplamente conhecido é a 
regressão Ridge, onde o conjunto de coeficientes são escolhidos ao impor uma penalização de soma dos quadrados dos mesmos.

$$
\beta^{\text {Ridge }}=A R G M I N_{\beta_{0}, \beta_{1}, \ldots, \beta_{k}} \sum_{i=1}^{n}\left(r_{i, t}-\beta_{0}-\sum_{j=1}{ }_{k} \beta_{j} I_{j, t}\right)^{2}+\lambda \sum_{j=1}^{k} \beta_{j}^{2}
$$

Onde o parâmetro $\lambda>0$ controla a quão severa é a penalização. Quanto maior for $\lambda>0$, maior será a penalização. Quando $\lambda=0$, o vetor $\beta^{\text {ridge }}$ será igual ao vetor de coeficientes obtidos por mínimos quadrados ordinários (MQO). A variável $I_{j, t}$ fez parte do conjunto informacional completo da pesquisa $\left(\Omega\right.$, i.e, $I_{j, t} \in \Omega$ ). Tibshirani (1996) propôs o primeiro modelo de penalização estudado: o LASSO (Least Absolute Shrinkage and Selection Operator), no contexto de regressão linear. O LASSO impõe uma penalização ao conjunto de normas dos coeficientes. Devido à natureza dessa penalização, o LASSO tende a zerar alguns coeficientes, tornando-se útil para selecionar covariáveis e para reduzir a dimensionalidade do espaço paramétrico, onde um conjunto de coeficientes são escolhidos ao impor uma penalização da soma dos quadrados dos mesmos.

$$
\beta^{L A S S O}=A R G M I N_{\beta_{0}, \beta_{1}, \ldots, \beta_{k}} \sum_{i=1}^{n}\left(r_{i, t}-\beta_{0}-\sum_{j=1}{ }_{k} \beta_{j} I_{j, t}\right)^{2}+\lambda \sum_{j=1}^{k}\left|\beta_{j}\right|
$$

O método LASSO realiza a escolha das variáveis e a estimação dos coeficientes simultaneamente. Ao observar que pode haver situações nas quais o LASSO não é consistente na seleção de variáveis, Zou (2006) propôs o LASSO adaptativo (adaLASSO), onde são empregados diferentes pesos para diferentes coeficientes:

$$
\beta^{\text {adaLASSO }}=A R G M I N_{\beta_{0}, \beta_{1}, \ldots, \beta_{k}} \sum_{i=1}^{n}\left(r_{i, t}-\beta_{0}-\sum_{j=1}{ }_{k} \beta_{j} I_{j, t}\right)^{2}+\lambda \sum_{j=1}^{k} w_{j}\left|\beta_{j}\right|
$$

Os pesos individuais $w_{j}$ servem para ajudar na seleção das variáveis relevantes. Uma variável relevante $I_{j, t}$ tende a possuir um coeficiente $\beta^{\text {ridge }}$ grande, o que faz diminuir o peso $w_{j}$ atribuído ao coeficiente daquela variável, caso contrário, se a variável $I_{j, t}$ for irrelevante, o coeficiente $\beta^{\text {Ridge }}$ tende a ser pequeno e implicará em um peso $w_{j}$ grande. Desse modo, 
penalizam-se mais os coeficientes das variáveis que aparentam ser pouco importantes. Outro método que também deve ser apresentado é o Elastic Net, que pretende obter o melhor entre os dois métodos de regressão, Ridge e LASSO, porém com novas propriedades que estes métodos carecem. A ideia é bastante simples, consistindo em minimizar a soma de quadrados do resíduo restrito a uma combinação linear das restrições do método Ridge e do LASSO. Onde a penalização da soma de quadrados é dada por:

$$
\begin{gathered}
\lambda_{1}\|\beta\|^{2}+\lambda_{2}\|\beta\|_{1} \\
L\left(\beta, \lambda_{1}, \lambda_{2}\right)=\left\|r_{i, t}-I_{t} \beta\right\|^{2}+\lambda_{1}\|\beta\|^{2}+\lambda_{2}\left\|\beta_{1}\right\| \\
\beta^{\text {ElasticNet }}=A R G M I N_{\beta} L\left(\beta, \lambda_{1}, \lambda_{2}\right)
\end{gathered}
$$

O Elastic Net envolve dois hiperparâmetros não negativos, $\lambda_{1}$ e $\lambda_{2}$. Otimizamos adaptativamente os parâmetros de ajuste, $\lambda_{1}$ e $\lambda_{2}$, usando critério de informação Akaike (AIC), critério de informação Bayesiano BIC e a amostra de validação da pesquisa balizando pela minimização do erro quadrático médio das previsões dentro da amostra selecionada.

\subsection{Vetor Autoregressivo (VAR)}

Durante décadas, vetores autoregressivos (VAR) e vetores autoregressivos com variáveis exógenas estruturais aos modelos (SVAR) têm servido como ferramentas essenciais na previsão de séries temporais multivariadas por exemplo nos trabalhos de Granger (1969), Sims (1980), Tiao e Box (1981), Bernanke e Mihov (1997) e Galí, López-Salido e Vallés (2007). No entanto, na ausência de regularização, o VAR e o SVAR são excessivamente parametrizados, muitas vezes forçando os profissionais a especificar arbitrariamente um subconjunto reduzido de séries a serem modeladas. Os últimos anos têm testemunhado tremendos desenvolvimentos em direção à incorporação de métodos de regularização na previsão de séries temporais multivariadas de alta dimensão, com um interesse particular no LASSO (Tibshirani (1996)), destacado na subseção anterior. Também podemos citar 
algumas de suas variantes estruturadas: o grupo LASSO de Wang e Leng (2008) e LASSO de grupo esparso de Simon et al. (2013)).

Assim, para o desenvolvimento de modelos esparsos e que permitissem avançarmos sobre a alta dimensão, foi necessário adaptar os algoritmos de solução de regressão penalizada mencionados na subseção anterior para uma configuração de série temporal multivariada, permitindo a previsão simultânea de muitas séries temporais potencialmente inter-relacionadas. Desta forma, foi possível a estimação simultânea de séries temporais de alta dimensão aplicando penalidades às estruturas de autoregressão vetorial padrão (VAR). Dado que $r_{i, t}^{e}$ denota um vetor de series temporais com dimensão $K$, o modelo $\operatorname{VAR}(\mathrm{P})$ pode ser expresso como:

$$
r_{i, t}^{e}=\beta_{0}+\sum_{L=1}^{P} \beta^{(L)} \Omega_{t-L}+u_{t}
$$

Onde $\Omega$, como anteriormente apresentado, denota o conjunto completo informacional de séries temporais incluindo $r_{i, t}^{e}$, i.e, $r_{i, t}^{e} \in \Omega_{t}$. Temos que $\beta_{o}$ denota um vetor de interceptos $K X 1$, cada $\beta^{L}$ representa uma matriz de coeficientes endógenos $K X K$, e $u_{t} \sim\left(0, \Sigma_{u}\right)$. Em uma configuração como a apresentada anteriormente, sendo o comprimento da série, $T$, o modelo VAR pode ser ajustado por mínimos quadrados multivariados, com $\beta_{0}$ e $=\left[\beta^{(1)}, \beta^{(2)}, \ldots, \beta^{(P)}\right]$ estimados como:

$$
A R G M I N_{\beta_{0}, \beta} \sum_{t=1}^{T}\left\|r_{i, t}^{e}-\beta_{0}+\sum_{L=1}^{P} \beta^{(L)} \Omega_{t-L}+u_{t}\right\|_{f}^{2}
$$

Em que $\|A\|=\sqrt{\Sigma_{i}, A_{i}^{2}}$ denota a norma de Frobenius de uma matriz $A$. A partir da estrutura apresentada, conseguimos realizar as extensões para a inclusão dos termos de esparcidade que possibilitaram a estimação de modelos de VAR de alta dimensão. Considerando o objetivo da pesquisa de realização de previsões em relação a variável $r_{i, t}^{e}$, temos que a utilização de um modelo de vetores autoregressivos (VAR) foi utilizada de forma exaustiva em suas mais diversas extensões que, modelam ou penalizam o formato no qual utilizamos as informações contidas em $\Omega_{t-1}$. 


\subsubsection{Vetores Autoregressivos Esparsos (VAR-S)}

Nessa dissertação utilizamos o VAR-SL, modelos de vetores autoregressivos esparsos via LASSO, como o agrupamento mais geral, e pode ser visto como particionando cada variável em seu próprio grupo ou aplicando uma penalidade de LASSO a toda a matriz do coeficiente VAR, não incorporando qualquer estrutura adicional. Como referência para tais modelos utilizamos Davis, Zang e Zheng (2016). A estimação do modelo foi realizada no formato a seguir:

$$
A R G M I N_{\beta_{0}, \beta} \sum_{t=1}^{T}\left\|r_{i, t}^{e}-\beta_{0}+\sum_{L=1}^{P} \beta^{(L)} \Omega_{t-L}+u_{t}\right\|_{f}^{2}+\lambda\|[\beta]\|
$$

O VAR-SL envolve um hiperparâmetro não negativo, $\lambda$. Otimizamos adaptativamente os parâmetros de ajuste, $\lambda$, usando critérios de informação AIC, BIC e a amostra de validação da pesquisa balizando pela minimização do erro quadrático médio das previsões dentro da amostra selecionada. Em relação aos modelos de penalização adaLASSO e Elastic Net para o VAR, utilizamos do mesmo processo exposto anteriormente para o LASSO.

Como modelo complementar ao VAR-SL e um formato adicional de extensão aos modelos VAR, estruturamos o VAR-SHL. Dado que o parâmetro $\beta^{L}$ controla a dependência dinâmica do $i$-ésimo componente de $r_{i, t}^{e}$ sobre o $j$-ésimo componente de $\Omega_{t-l}$, adicionar uma penalização estruturada sobre este parâmetro pôde trazer resultados positivos considerando o processo de redução de dimensionalidade. Para permitir uma maior flexibilidade, em vez de impor uma única ordem de defasagem universal (como tendem a ser as abordagens baseadas na minimização do critério de informação), permitimos que ela variasse entre os modelos marginais, mas dentro de uma série onde todos os componentes têm a mesma defasagem máxima, aplicando uma maior regularização para defasagens de ordem mais altas. Assim, pudemos apresentar o modelo da seguinte forma:

$$
A R G M I N_{\beta_{0}, \beta} \sum_{t=1}^{T}\left\|r_{i, t}^{e}-\beta_{0}+\sum_{L=1}^{P} \beta^{(L)} \Omega_{t-L}+u_{t}\right\|_{f}^{2}+\sum_{L=1}^{P} L^{\gamma}\left\|\beta^{(L)}\right\|
$$

Podemos observar que um parâmetro de penalidade adicional foi adicionado $\gamma \in$ 
$(0,1)$, possibilitando uma maior flexibilidade ao modelo quando comparado a modelo VAR-SL quando comparamos a estrutura de defasagens. Em ambos modelos apresentados anteriormente, o critério para seleção dos parâmetros $\lambda$ e $\gamma$ foi a utilização dos critérios de informação AIC, BIC e a amostra de validação da pesquisa balizando pela minimização do erro quadrático médio das previsões dentro da amostra selecionada. Nossa abordagem usou o resultado do período anterior como uma inicialização, i.e, "inicialização um passo a trás", que diminui substancialmente o tempo de computação do modelo.

\subsubsection{VAR Bayesiano Esparso (BVAR-S)}

Utilizando a especificação de VAR apresentada na subseção presente, com os mesmos pressupostos adotados, apenas adicionando que $u_{t}$ é um ruído branco gaussiano. Utilizamos o modelo VAR Bayesiano (BVAR), abordagem que auxilia a superar o problema de alta dimensão através da imposição de priores sobre os parâmetros. Ao definir as distribuições priores, seguimos a prática padrão e usamos o procedimento desenvolvido em Litterman (1996) com modificações propostas por Kadiyala e Karlsson (1997) e Sims e Zha (1998). Litterman (1996) sugeriu o uso de uma priori frequentemente referida como priori de Minnesota. O princípio básico por trás disso foi que todas as equações foram "centradas"em torno do passeio aleatório, isto é, a média anterior pode ser associada à seguinte representação para $\Omega_{t}$ :

$$
\Omega_{i, t}=\Omega_{i, t-1}+v_{i, t}
$$

Isso equivale a encolher os elementos diagonais de $\beta^{(L)}$ em direção a um e os coeficientes em $\left[\beta^{(1)}, \beta^{(2)}, \ldots, \beta^{(P)}\right]$ para zero. Além disso, a especificação anterior incorporou a crença de que as defasagens mais recentes devem fornecer informações mais confiáveis do que as mais distantes e que as defasagens próprias devem explicar mais da variação de uma dada variável do que as defasagens de outras variáveis na equação.

$$
E\left[\left(\beta_{i, j}^{(k)}\right)\right]=\left\{\begin{array}{c}
\delta_{i}, j=i, k=1 \\
0, j \neq i, k \neq 1
\end{array}\right.
$$




$$
V\left[\left(\beta_{i, j}^{(k)}\right)\right]=\left\{\begin{array}{c}
\lambda^{2} / k^{2}, j=i \\
\vartheta\left(\lambda^{2} \sigma_{i}^{2} / k^{2} \sigma_{j}^{2}\right), j \neq i
\end{array}\right.
$$

Os coeficientes $\left[\beta^{(1)}, \beta^{(2)}, \ldots, \beta^{(P)}\right]$ foram assumidos como sendo priores independentes e normalmente distribuídas. Quanto à matriz de covariância dos resíduos, assumiu-se que é diagonal, fixa e conhecida: $\Sigma=\operatorname{diag}\left(\sigma_{1}^{2}, \ldots, \sigma_{k}^{2}\right)$. Assim, a priori no intercepto é difusa. O hiperparâmetro $\lambda$ controla a rigidez geral da distribuição da priori em torno do passeio aleatório ou do ruído branco e rege a importância relativa das crenças anteriores em relação às informações contidas nos dados. Para $\lambda=0$, a posterior é igual a priori e os dados não influenciam as estimativas. A rigidez global determinada por $\lambda$ foi escolhida em relação ao tamanho do sistema. À medida que o número de variáveis aumenta, os parâmetros devem ser reduzidos para evitar ajustes excessivos. Este ponto foi mostrado formalmente por Mol, Giannone e Reichlin (2008). O fator $1 / k^{2}$ é a taxa na qual a variação anterior diminui com o aumento do tempo de defasagem e $\sigma_{i}^{2} / \sigma_{j}^{2}$ considera a diferente escala e variabilidade dos dados. O coeficiente $\vartheta \in(0,1)$ determina a extensão em que as defasagens de outras variáveis são "menos importantes"do que as próprias defasagens. Consequentemente, a suposição de Litterman da matriz de covariância fixa e diagonal é um pouco problemática. Para superar este problema, seguimos Kadiyala e Karlsson (1997) e Robertson e Tallman (1999) e impusemos uma Wishart normal invertida como priori, o qual retém os princípios da priori de Minnesota. Isso foi possível sob a condição de que $\vartheta=1$. Assim, a priori de normal invertida de Wishart tem o formato:

$$
\begin{gathered}
V E C(\beta) \mid \Sigma \sim N\left(V E C\left(\beta_{0}\right), \Sigma \otimes \Omega_{0}\right) \\
E(\Sigma) \sim W\left(S_{0}, \alpha_{0}\right)
\end{gathered}
$$

Onde os parâmetros da priori $\beta_{0}, \Omega_{0}, S_{0}$ e $\alpha_{0}$ são escolhidos de modo que expectativas e variações anteriores de $\Phi$ coincidam com aquelas implícitas pela equação (2.18) e a expectativa de $\Sigma$ é igual à matriz de covariância residual fixa da priori de Minnesota, como citado por Kadiyala e Karlsson (1997). Neste modelo, o critério para seleção do parâmetro $\lambda$ foi o de minimizar a raiz do erro quadrático médio (RMSE). A literatura sugere que a 
melhoria na previsão pode ser obtida pela imposição de prévias adicionais que limitam a soma dos coeficientes (Sims (1992), Sims e Zha (1998) e Robertson e Tallman (1999)). Isto é o mesmo que impor uma "diferenciação inexata", e é uma simples modificação do Minnesota envolvendo combinações lineares dos coeficientes VAR (Doan, Litterman e Sims (1984)). O hiperparâmetro $\tau$ é adicionado para controlar o grau de encolhimento: quando $\tau$ vai para zero, nos aproximamos do caso das diferenças exatas; e quando $\tau$ vai para 1 , nos aproximamos do caso de MQO. Assim, foi descrito o modelo BVAR esparso utilizado na dissertação.

\subsubsection{Métodos de Redução de Dimensionalidade Para o Conjunto Informacio- nal $\Omega$}

A seguir apresentamos um conjunto de ferramentas para redução de dimensionalidade aplicado ao conjunto de informações completo, $\Omega$. Posterior à aplicação destes métodos, encontramos como resultados os fatores de desconto estocásticos (FDS), $F_{t}$, que foram aplicados na metodologia VAR como descrito a seguir:

$$
\begin{gathered}
r_{i, t}^{e}=\beta_{0}+\sum_{L=1}^{P} \beta^{(L)} F_{t-L}+u_{t} \\
\operatorname{ARGMIN}_{\beta_{0}, \beta} \sum_{t=1}^{T}\left\|r_{i, t}^{e}-\beta_{0}+\sum_{L=1}^{P} \beta^{(L)} F_{t-L}+u_{t}\right\|_{f}^{2}
\end{gathered}
$$

Desta forma, o primeiro método a ser abordado para estimação dos fatores de desconto estocástico, $\left(F_{t}\right)$, é a análise de componentes principais (PCA). Temos que o PCA é um procedimento matemático que utiliza uma transformação ortogonal para converter um conjunto de variáveis possivelmente relacionadas em conjunto de valores de variáveis linearmente não correlacionadas chamadas de componentes principais. O número de componentes principais é menor ou igual ao número de variáveis originais. A transformação ortogonal é definida de forma que o primeiro componente principal tem a maior variância possível, e cada componente seguinte, por sua vez, tem a máxima variância sob a restrição de ser ortogonal aos componentes anteriores. Os componentes principais 
são garantidamente independentes apenas se os dados forem normalmente distribuídos conjuntamente. O PCA é sensível à escala relativa das variáveis originais, motivos que nos levaram a utilizar em nossos modelos dados normalizados. O estimador de componentes principais faz parte de um conjunto de métodos de média não paramétricos, que podem ser representados com a devida simplicidade pelo modelo descrito a seguir:

$$
F_{t}^{*}\left(N^{-1} W\right)=N^{-1} W^{*} \Omega_{t}
$$

O estimador de componentes principais de $F_{t}^{*}$ é o estimador ponderado da média da equação anterior, com $W=\Lambda^{*}$, onde $\Lambda^{*}$ é a matriz de autovetores da matriz de variância da amostra de $X_{t}, \Sigma_{\Omega}^{*}=T^{-1} \sum_{t=1}^{T}\left(\Omega_{t}-\Lambda F_{t}\right)^{t}\left(\Omega_{t}-\Lambda F_{t}\right)$, associada com os $r$ maiores autovalores de $\Sigma_{\Omega}^{*}$. O estimador de componentes principais pode ser derivado como a solução para o problema dos mínimos quadrados:

$$
\begin{gathered}
M I N_{F_{t}, \ldots, F_{T}, \Lambda} V_{r}(\Lambda, F) \\
V_{r}(\Lambda, F)=\frac{1}{N T} \sum_{t=1}^{T}\left(\Omega_{t}-\Lambda F_{t}\right)^{t}\left(\Omega_{t}-\Lambda F_{t}\right)
\end{gathered}
$$

Sujeito a normalização $N^{-1} \Lambda^{t} \Lambda=I$. Para resolver a equação anterior, primeiro tivemos que minimizar $F_{t}$ dado $\Lambda$ para obter:

$$
\left.F_{t}^{*}\left(\Lambda\left(\Lambda^{t} \Lambda\right)_{-1}\right)\right)=\left(\Lambda^{t} \Lambda\right)_{-1} \Lambda^{t} \Omega_{t}
$$

Então concentrando na função objetivo encontramos:

$$
\left.M I N_{\Lambda} T^{-1} \sum_{t=1}^{T}\left[I-\Lambda\left(\Lambda^{t} \Lambda\right)^{-1} \Lambda\right)\right] \Omega_{t}
$$

Consequentemente a solução para o problema final é o conjunto $\Lambda^{*}$ igual a escala dos autovetores de $\Sigma_{\Omega \Omega}^{*}$ correspondente aos $r$ maiores autovalores. Devido a $\Lambda^{* t} \Lambda^{*}=N I$, que segue do estimador de mínimos quadrados, em que $F_{t}$ são os $r$ componentes principais de $\Omega_{t}$. Um fator importante a ser elencado para o desenvolvimento da primeira etapa foi a 
seleção do número de componentes principais a serem utilizados no modelo. De acordo com a literatura contemporânea existente, utilizamos o critério de seleção baseado em critérios de informação. Bai e Ng (2002) desenvolveram uma família de estimadores para $r$ motivados na utilização de critérios de informação. Os critérios de informação negociam o benefício de incluir um fator adicional contra o custo de maior variabilidade de amostragem decorrente da estimativa de outro parâmetro. Isso é feito minimizando uma verossimilhança penalizada ou uma soma dos quadrados, onde o fator de penalidade aumenta linearmente ao número de fatores (ou parâmetros). No caso dos modelos de fatores dinâmicos, Bai e Ng (2002) propuseram minimizar a soma penalizada dos quadrados:

$$
I C(r)=\ln \left(V_{r}\left(\Lambda^{*}, F^{*}\right)\right)+r * g(N, T)
$$

Onde $V_{r}\left(\Lambda^{*}, F^{*}\right)$ é a função objetivo de mínimos quadrados, avaliada nos estimadores de componentes principais, e $g(N, T)$ é o fator de penalidade. A seguir apresentamos os três critérios de informação utilizados na pesquisa.

$$
\begin{gathered}
I C_{p 1}(r)=\ln \left(V\left(r, F^{* k}\right)\right)+r\left(\frac{N+T}{N T}\right) \ln \left(\frac{N T}{N+T}\right) \\
I C_{p 2}(r)=\ln \left(V\left(r, F^{* k}\right)\right)+r\left(\frac{N+T}{N T}\right) \ln \left(J_{N T}^{2}\right) \\
I C_{p 3}(r)=\ln \left(V\left(r, F^{* k}\right)\right)+r\left(\frac{\ln \left(J_{N T}^{2}\right)}{J_{N T}^{2}}\right)
\end{gathered}
$$

Onde temos que $J_{T, N}^{2}=M I N(T, N)$. Assim, de acordo com os critérios apresentados anteriormente, podemos selecionar o "melhor" $r$ para dar sequência ao nosso modelo. A aplicação dos $r$ componentes principais encontrados através do PCA em modelos VAR é amplamente utilizado na literatura macroeconômica, sendo desenvolvido na brilhante pesquisa de Bernanke, Boivin e Eliasz (2005), como o FAVAR (Vetores autoregressivos fatoriais). A aplicação desse modelo de extração de fatores de desconto estocásticos também é utilizada de forma extensiva no ambiente de finanças, como pode ser visto em Gu, Kelly e 
Xiu (2018). Este modelo foi denotado em nossa dissertação como FAVAR, onde encontramos o seguinte conjunto de FDS $F_{t}$.

Em relação a tal modelo, realizamos um conjunto de extensões, onde podemos dividir essas extensões em dois grupos. O primeiro foi formado pelo conjunto de extensões que utilizando-se de métodos de penalização para realizar uma pré-seleção no conjunto informativo completo $(\Omega)$, dando origem a um novo conjunto de dados contido em $\Omega$. Esse novo conjunto de dados então foi inserido na metodologia de análise de componentes principais (PCA) fornecendo novos conjuntos de fatores de desconto estocásticos $F_{t}$. Os métodos de pré-seleção utilizados na dissertação foram: Ridge com critério arbitrário de balizamento, LASSO, adaLASSO e Elastic Net. Gerando os seguintes conjuntos informativos: $\Omega^{\text {Ridge }}, \Omega^{\text {LASSO }}, \Omega^{\text {adaLASSO }}$ e $\Omega^{\text {ElasticNet }}$ e consequentemente os seguintes fatores de desconto estocásticos $F_{t}^{\text {Ridge }}, F_{t}^{\text {LASSO }}, F_{t}^{\text {adaLASSO }}$ e $F_{t}^{\text {ElasticNet }}$. Tais conjuntos de FDS foram aplicados aos modelos VAR, e encontramos como resultado os seguintes modelos esparsos: Ridge-FAVAR, LASSO-FAVAR, adaLASSO-FAVAR e ElasticNet-FAVAR. Ressaltamos que tais modelos são extensões propostas pela dissertação à literatura existente.

O segundo conjunto de extensões ocorreu da inclusão do método de penalização Elastic Net na própria estrutura de estimação do PCA, dando origem a um modelo conhecido como analise de componentes principais esparsos (SPCA). A SPCA baseiase no fato de que o PCA pode ser escrito como um problema de otimização do tipo de regressão, com uma penalidade quadrática. No Elastic Net, os coeficientes esparsos são uma consequência direta da penalidade $\lambda_{1}$ e não dependem da função de perda de erro quadrada. Desta forma, escolhemos com flexibilidade uma aproximação esparsa do componente principal. Como item destaque devemos mencionar que os componentes principais ordinários não são correlacionados e suas cargas são ortogonais. Contudo, a SPCA não impõe explicitamente a condição de componentes não correlacionados. No entanto, utilizamos uma projeção de regressão para remover a dependência linear entre os componentes correlacionados.

Para estimação do modelo proposto utilizamos o algoritmo proposto por Zou et al. (2005). Evidências empíricas sugerem que o resultado do algoritmo não muda tanto 
quando $\lambda$ é alterado. Para dados $N>P$, a opção padrão de $\lambda$ pode ser zero. Praticamente $\lambda$ é escolhido para ser um pequeno número positivo superando potenciais problemas de colinearidade em $\Omega$. Em princípio, podemos tentar várias combinações de $\lambda_{1}$ para descobrir uma boa escolha dos parâmetros de ajuste, uma vez que o algoritmo converge bastante rápido. Existe um atalho fornecido pela aproximação esparsa direta. O algoritmo LARSEN fornece, eficientemente, uma sequência inteira de aproximações esparsas para cada componente principal e dos valores correspondentes de $\lambda_{1}$. Portanto, podemos escolher um $\lambda_{1}$ que ofereça um bom compromisso entre a variância e a dispersão. Ao enfrentar o trade-off de variação e dispersão, deixamos a variação ter uma prioridade mais alta.

Um dos critérios de grande importância para o desenvolvimento do SPCA foi a determinação do número de variáveis que incorporam cada componente principal. O critério de escolha utilizado na pesquisa e de acordo com bibliografia existente foi o de Kristensen e Salanié (2017), que desenvolveu um critério de informação para seleção do número de variáveis que estava presente na composição de cada componente, como apresentado a seguir:

$$
\Psi_{t}=A R G M I N_{\Psi_{t}} \log \left(n * T^{-1} \sum_{i=1}^{n} \sum_{t=1}^{T}\left(\Omega_{i, t}-\lambda_{i}^{t} F_{\Psi_{t}}\right)^{2}\right)+m\left(\frac{n * T}{n * T}\right)
$$

Onde $\lambda_{i}^{t}$ e $F_{\Psi_{t}}$ são as estimativas de SPCA para um dado $\Psi_{t}$, e $m$ é o número de não-zeros em $\lambda_{i}^{t}$. Assim podemos julgar a capacidade de escolher corretamente o número de fatores, a precisão dos fatores estimados e a capacidade de estimar corretamente as cargas fatoriais como sendo esparsas. Como uma limitação desta pesquisa, consideramos o mesmo número de variáveis não-zeros para todos os componentes principais selecionados. Após encontrar os componentes principais, utilizamos do critério de Bai e Ng (2002) apresentado anteriormente para a determinação do número ótimo de componentes principais a serem utilizados. Posterior aos passos enumerados, aplicamos os componentes principais esparsos estimados no modelo VAR para previsão de $r_{i, t}^{e}$, apresentado na equação (2.13), dando origem ao modelo adicionado na dissertação como S-FAVAR (Vetores autoregressivos fatoriais esparsos). Ainda duas extensões foram propostas para tal modelo, sendo a primeira relacionada a utilização do método para seleção do hiperparâmetro $\lambda_{1}$ através da 
minimização da raiz do erro quadrático médio (RMSE) e originando os modelos MS-FAVAR. A segunda extensão utiliza dos hiperparâmetros $\lambda_{1}$, calculados na etapa de pré-seleção de variáveis de $\Omega$, para estimação do SPCA. Tal modelo foi nomeado como OS-FAVAR, que inclui a caraterística de estimação do hiperparâmetro $\lambda_{1}$ via critério de informação AIC e BIC.

Outra metodologia proposta foram os mínimos quadrados parciais (PLS), que realizam a redução da dimensão explorando diretamente a covariação de preditores, com o objetivo de previsão. Na regressão PLS, para cada preditor $\Omega_{j}$, é estimado seu coeficiente de previsão de retorno uni-variado via MQO. Esse coeficiente, denotado $\beta_{j}$, reflete a sensibilidade parcial dos retornos para o preditor $\Omega_{j}$. Em seguida, é calculada a média de todos os preditores em um único componente agregado com pesos proporcionais à $\beta_{j}$, colocando os pesos mais altos nos preditores uni-variados mais fortes e os menores pesos nos mais fracos. Dessa forma, o PLS realiza sua redução de dimensão com o objetivo final de previsão em mente. Para formar mais de um componente preditivo, o alvo e todos os preditores são ortogonalizados em relação aos componentes construídos anteriormente, e o procedimento acima é repetido no conjunto de dados ortogonalizado. Isso é repetido até que o número desejado de componentes PLS seja atingido. O objetivo da PLS busca $h$ combinações lineares de $\Omega$ que tenham um máximo associação preditiva com a meta de previsão $r_{i, t}^{e}$. Os pesos usados para construir o $j$-ésimo componente do PLS são determinados seguindo:

$$
\begin{gathered}
w_{t}=A R G M A X_{w} \operatorname{COV}^{2}\left(r_{i, t}^{e}, \Omega w\right), \text { s.t } \\
w^{t} w=1 ; \operatorname{COV}\left(\Omega w, \Omega w_{l}\right)=0, l=1,2, \ldots, j-1 .
\end{gathered}
$$

Onde $w_{t}$ são os pesos alocados aos preditores $\Omega$, no instante do tempo $t$. Desta forma, o PLS está disposto a sacrificar a precisão com que $\Omega W$ se aproxima de $\Omega$ para encontrar componentes com previsibilidade de $r_{i, t}^{e}$ mais potentes. A solução para o modelo PLS ocorre via regressão MQO de $r_{i, t}^{e}$ em $\Omega W$. Para o modelo, $h$ é um hiperparâmetro que pode ser determinado de forma adaptativa a partir da amostra de validação. 


\subsection{Estimação da Matriz de Covariâncias}

Em muitas aplicações em finanças, a ordem da correlação serial é desconhecida, o que pode gerar problemas em relação a estimação e sobre a capacidade de previsão. Uma solução para este problema incorre na utilização dos estimadores da matriz de covariância de longo prazo, na presença de heterocedasticidade condicional e autocorrelação que são denominados estimadores HAC. Iniciando a apresentação desse conjunto de estimadores considere: $\Phi(\tau)=E\left[u_{t} u_{t-\tau}^{t}\right]$, sendo $u_{t}=\left(x_{j}-\bar{x}\right)$. Onde seu formato amostral é dado por:

$$
\Phi_{T}(\tau)=\frac{1}{T} \sum_{t=\tau+1}^{T} u_{t} u_{t-\tau}^{t}
$$

Onde $\Phi_{T}(\tau)=\Phi_{T}(-\tau)$ para $\tau=0$. Quando lidamos com um grande lag $t, u_{1}, \ldots, u_{T}$, $\Phi_{T}(\tau)$ não pode ser estimado com fidedignidade utilizando o estimador amostral. Nas próximas subseções descrevemos um conjunto de ferramentas para melhora do processo de estimação da matriz de covariância, quando lidamos com um $T$ (número de observações) e $K$ (número de variáveis) grande, sendo que em alguns casos $K>T$.

\subsubsection{Matriz de Covariâncias de Longo Prazo (LRCM)}

Uma solução proposta na literatura para lidarmos com um $T$ grande é utilizar uma função de Kernel. Assim, para a estimação da matriz de covariância $\Sigma$ de Kernel HAC encontramos:

$$
\Sigma_{T}=\sum_{\tau=-T+1}^{T-1} k\left(\frac{\tau}{S_{t}}\right) \Phi_{T}(\tau)
$$

Onde $k($.$) é uma função de valor real Kernel, e S_{t}$ é um parâmetro de largura de banda. Andrews (1991) defende um estimador que usa a função de Kernel Quadratic Spectral (QS) que não coloca pesos zero em nenhum $\Phi_{T}(\tau)$ para $|\tau| \leq T-1$. A função de Kernel Quadratic Spectral (QS), pode ser apresentada como:

$$
k(x)=\frac{25}{12 \pi^{2} x^{2}}\left(\frac{\operatorname{Sin}(6 \pi x / 5}{6 \pi x / 5}\right)-\operatorname{Cos}\left(\frac{6 \pi x}{5}\right)
$$


Um importante problema encontrado foi como escolher o parâmetro de largura de banda $S_{t}$. A matriz de covariâncias de Andrews (1991) fornece fórmulas para a escolha ideal do parâmetro de largura de banda, $S_{t}^{*}$, para uma variedade de núcleos. O $S_{t}^{*}$ é ideal no sentido de minimizar o RMSE para uma dada matriz semidefinida positiva $G$, no caso da Kernel Quadratic Spectral.

$$
\begin{gathered}
S_{t}^{*}=1.3221(\alpha(2) T)^{\frac{1}{5}} \\
\alpha(q)=\frac{2\left(V E C f^{q}\right)^{t} G V E C f^{q}}{\operatorname{tr} G\left(I+K_{p p}\right) f^{0} \otimes f^{0}} \\
f^{q}=\frac{1}{2 \pi} \sum_{j=-\infty}^{\infty}|j|^{q} \Phi_{T}(\tau)
\end{gathered}
$$

onde $G$ é uma matriz de pesos $p^{2} X p^{2}, K_{p p}$ é a matriz de comutação $p^{2} X p^{2}$ que realiza a transformação de $\operatorname{VEC}(A)$ em $V E C\left(A^{t}\right), f^{0}$ é a densidade espectral na frequência zero e a matriz de covariância de longo prazo $\Sigma_{T}$ é igual a $2 \pi f^{0}$. Tais fórmulas incluem os parâmetros desconhecidos que desejamos estimar.

Andrews propôs estimadores para largura de banda nos quais esses parâmetros desconhecidos são estimados a partir de um modelo parametrizado. Seu método envolve dois passos. O primeiro passo é parametrizar o modelo para estimar os movimentos de $u_{t}$. Por exemplo, podemos usar um modelo $\operatorname{AR}(1)$ para cada elemento de $u_{t}$ ou um modelo VAR(1) para $u_{t}$. O segundo passo é calcular os parâmetros para o parâmetro ideal de largura de banda a partir da estimação do movimento. Por exemplo, calculamos os parâmetros desconhecidos assumindo que o modelo estimado de $\mathrm{AR}(1)$ é verdadeiro. Em suas simulações de Monte Carlo, Andrews (1991) usou uma parametrização AR(1) para cada termo da perturbação, mostrando que o Kernel QS é o Kernel ideal, no sentido de minimizar o RMSE assintótico entre os estimadores de Kernel, que são garantidos como semidefinidos positivos. Suas simulações em Monte Carlo mostraram que o Kernel QS e o Parzen funcionam melhor que o Kernel Bartlett na maioria dos modelos que ele considerou. Ele também descobriu que mesmo os estimadores baseados no kernel QS e Parzen não são satisfatórios, no sentido de que os erros padrão calculados a partir desses estimadores não 
são precisos em pequenas amostras, quando a quantidade de autocorrelação é grande, o que não é o caso de nossa dissertação.

Uma abordagem alternativa utilizada na pesquisa advém da pesquisa de Kiefer e Vogelsang (2005), que desenvolveram uma série de hipóteses em que a largura de banda envolvida no estimador HAC, para o tamanho da amostra $T$, denotado como $b=T-1$, é mantida fixa na amostra. Possuindo melhores propriedades em amostras finitas.

\subsubsection{Modelo fatorial de volatilidade estocástica}

Considerando a variável $\Omega_{t}$, com dimensões $T X K$, como modelada na seção 2.4 , recuperamos a seguinte formulação: os efeitos específicos dos termos de erro $U_{t}$, condicionados à sua matriz de variâncias $\Phi_{t}$ diagonal, foram considerados serialmente independentes e realizações de um processo latente:

$$
U_{t} \mid \Phi_{t} \sim N_{q}\left(0 ; \Phi_{t}\right), t=1, \ldots T
$$

Com estas condições, a estrutura de covariâncias da séries presentes na base de dados completa $\Omega_{t}$ quando condicionada a $\beta_{0}, \Omega_{t-1}, \Phi_{t}$. E a matriz de variâncias diagonal $H_{t}$ é:

$$
\Sigma_{T}=X H_{t} X^{t}+\Phi_{t}
$$

De acordo com Trucíos, Hotta e Pereira (2019), os modelos de volatilidade estocástica utilizados nesta dissertação modelam o logaritmo neperiano das variâncias dos fatores comuns $F_{t}$ e efeitos específicos $U_{t}$, que são os termos da diagonal das matrizes $H_{t}$ e $\Phi_{t}$, como processos (vetoriais) autoregressivos estacionários de primeira ordem onde seguimos a nomenclatura de Trucíos, Hotta e Valls (2019): VE-VAR(1).

Denotando $\kappa_{j, t}^{f}=\log h_{j, t}$, para $j=1, \ldots, k$, e, $\kappa_{j, t}^{f}=\left(\kappa_{j, t}^{1}, \ldots, \kappa_{j, t}^{f}\right)$, na notação vetorial, tivemos que o processo $k$-variado das log-volatilidades dos fatores comuns $F_{t}$ é 
modelado como:

$$
\kappa_{t}^{f}=\mu^{f}+\Psi^{f}\left(\kappa_{t-1}^{f}-\mu^{f}\right)+\varpi_{t}^{f}
$$

Com $\varpi_{t}^{f} \sim N_{K}\left(0 ; \Sigma_{\varpi}^{f}\right), t=1,2, \ldots, T$ independentes, $\kappa_{t}^{f}$ tem média $\mu^{f}=\mu_{1}^{f}, \ldots, \mu_{k}^{f}$, persistência $\Psi^{f}=D I A G\left(\psi_{1}^{f}, \ldots, \psi_{k}^{f}\right)$ e matriz de variância das inovações $\Sigma_{\varpi}^{f}$. Podemos notar que a distribuição de $\kappa_{t}^{f} \mid\left(\kappa_{t-1}^{f}, \mu^{f}, \psi^{f}, \Sigma_{\varpi}^{f}\right)$ é normal com média $\mu^{f}+\Psi^{f}\left(\kappa_{t-1}^{f}-\mu^{f}\right)$ e matriz de covariâncias $\Sigma_{T}^{\varpi}$. Para as perturbações específicas, denote $\kappa_{t}^{u}=\log \psi_{j, t}$ na forma vetorial, $\kappa_{t}^{u}=\left(\kappa_{1, t}^{u}, \ldots, \kappa_{k, t}^{u}\right)$. O processo de log-volatilidades $k$-variado dos efeitos específicos foi escrito utilizando parâmetros da média $\mu^{u}=\left(\mu_{1}^{u}, . ., \mu_{k}^{u}\right)$, persistência $\Psi^{u}=$ $D I A G\left(\psi_{1}^{u}, \ldots, \psi_{k}^{u}\right)$ e matriz de variância das inovações $\Sigma_{\varpi}^{u}$, que neste processo é diagonal. Essa forma equivale a considerar $K$ processos univariados onde temos que:

$$
\kappa_{t}^{u}=\mu^{u}+\psi^{u}\left(\kappa_{t-1}^{u}-\mu^{u}\right)+\varphi_{t}^{u}
$$

Os resultados encontrados acima foram similares aos casos anteriormente explorados, em relação a distribuição condicional e independência. Na especificação do modelo fatorial de volatilidade estocástica utilizado na pesquisa, a distribuição da priori para o conjunto de parâmetros apresentados, foi tomada como o produto de priores independentes. De acordo com a literatura da área, o modelo apresentado tem sido estimado na literatura por inferência Bayesiana, por meio de simulação MCMC de Kastner, Frühwirth-Schnatter e Lopes (2017). De forma a não tornar exaustiva a explicação sobre o método de estimação utilizado, concentramos a explicação no apêndice B.

\subsection{Avaliação do desempenho preditivo}

Para avaliar o desempenho preditivo das previsões individuais de excesso de retorno e de retornos dos ativos, calculamos o $R^{2}$ fora da amostra como:

$$
R_{o o s}^{2}=1-\frac{\sum_{(i, t) \in T^{f}}\left(r_{i, t+1}-r_{i, \hat{t}+1}\right)}{\sum_{(i, t) \in T^{f}} r_{i, t+1}^{2}}
$$


Em que $T^{f}$ indica que os ajustes foram avaliados apenas na subamostra de teste, cujos dados não entraram na estimativa ou ajuste do modelo. $\mathrm{O} R^{\wedge} 2_{\text {oos }}$ agrupou erros de previsão dos retornos ao longo do tempo em uma grande avaliação, em nível de painel de cada modelo estimado na dissertação. Um aspecto sutil, mas importante, da nossa métrica $R^{2}$ foi que o denominador é a soma dos retornos quadráticos excedentes. Em muitas aplicações de previsão fora da amostra, as previsões são comparadas com retornos médios históricos. Embora essa abordagem seja sensata para o índice agregado ou para as carteiras Long/short, é falha quando se trata de analisar retornos de ações individuais. Prever excesso de retornos futuro de ações com médias históricas, geralmente, apresenta um desempenho ingênuo de zero por uma grande margem. Ou seja, o retorno médio histórico das ações é tão ruidoso que reduz artificialmente um "bom"desempenho de previsão. Evitamos essa armadilha comparando nosso $R^{2}$ com um valor previsto de zero. Para dar uma indicação da importância dessa escolha, quando comparamos as previsões do modelo com os retornos médios históricos das ações, o $R^{2}$ mensal fora da amostra de todos os métodos aumentou aproximadamente dez pontos percentuais.

Para fazer comparações dos métodos aos pares, usamos o teste de DIEBOLD e MARIANO (1995) para diferenças na previsão preditiva fora da amostra entre dois modelos. Embora a dependência nos retornos seja suficientemente fraca, é improvável que as condições de dependência fraca do erro do teste de Diebold-Mariano se apliquem a nossa análise de nível do retorno devido à dependência potencialmente forte na seção transversal (amplamente estudada na literatura). Para testar o desempenho da previsão do método (1) versus o método (2), definimos a estatística do teste $D M_{12}=\frac{\overline{d_{12}}}{\varepsilon d_{12}}$, onde:

$$
d_{12, t+1}=\frac{1}{n_{f, t+1}} \sum_{i=1}^{n_{f}}\left(\left(e_{i, \hat{t}+1}^{(1)}\right)^{2}-\left(e_{i, \hat{t}+1}{ }^{(2)}\right)^{2}\right)
$$

Onde $e_{i, \hat{t}+1}{ }^{(1)}$ e $e_{i, \hat{t}+1}{ }^{(2)}$ denotem o erro de previsão para o ativo $i$, no período de tempo $t$, usando os métodos avaliados, e $n_{f, t+1}$ é o número de observações na amostra de teste. Então $\overline{d_{12}}$ e $\varepsilon d_{12}$ são a média e o erro padrão de Newey-West de $d_{12, t+1}$ na amostra de teste. Essa estatística modificada do teste de Diebold-Mariano, que agora foi baseado em uma única série temporal $d_{12, t+1}$ de diferenças de erro com pouca autocorrelação, se 
mostrou satisfatória às condições de regularidade necessárias para a normalidade assintótica e, por sua vez, forneceu p-valores apropriados para nossos testes de comparação entre os modelos.

\subsection{Alocação de Carteiras}

A literatura de alocação de ativos foi abordada pela primeira vez por Markowitz (1952), que criou o modelo conhecido como Média-Variância (MV). Sua abordagem considera que os investidores, no processo de escolha da carteira ótima, se preocupam com apenas dois fatores: o risco e o retorno da carteira de ativos. O modelo propõe encontrar a carteira ótima, por meio da maximização dos retornos esperados e sujeito a um determinado nível de risco. Apesar de sua relevância, o modelo apresentou fragilidades, como a obtenção de carteiras concentradas em um número restrito de ativos, resultados pouco intuitivos, que desconsideram a opinião do tomador de decisão sobre o desempenho dos ativos no futuro, e alta sensibilidade aos dados de entrada.

Como uma alternativa para o modelo MV, Black e Litterman (1992) propuseram uma nova abordagem que utiliza métodos Bayesianos para combinar o equilíbrio do mercado no longo prazo, derivado do CAPM (Capital Asset Pricing Model), com as visões dos investidores sobre os retornos futuros. Similarmente ao modelo de média-variância, a abordagem de Black- Litterman (BL) também otimiza os retornos sujeitos a uma matriz de risco, entretanto apresenta duas diferenças substanciais. A primeira é a proposta de se partir de uma carteira no equilíbrio de longo prazo para encontrar a distribuição a priori dos retornos. A segunda é a possibilidade de se incorporar ao modelo visões sobre o comportamento dos ativos, obtendo a distribuição a posteriori. Neste contexto, o principal objetivo do modelo BL foi introduzir um método de alocação de carteira que fornecesse resultados intuitivos e sem as inconsistências observadas na abordagem de Markowitz. O equilíbrio de longo prazo está sujeito a modificações a todo instante, tendo em vista que os investidores possuem suas próprias visões de curto prazo. Essas visões de curto prazo foram incorporadas no modelo de BL, de forma que as informações do equilíbrio de longo prazo gerassem um conjunto de retornos esperados, a partir do qual são fornecidos os 
pesos da carteira ótima.

O desenvolvimento do modelo BL pode ser dividido em quatro etapas. Primeiramente, são encontradas as distribuições a priori dos retornos dos ativos, a partir do equilíbrio de mercado. Em seguida, são determinadas as visões dos investidores em relação a todos ou à parte dos ativos analisados. O terceiro passo é a incorporação das visões na distribuição a priori para se o obter a distribuição posterior dos retornos. Por fim, usando o mesmo processo de minimização do modelo Média-Variância, encontra-se a carteira ótima de investimento. Em nossa dissertação desenvolvemos uma extensão do modelo BL para utilizarmos todo conjunto de previsões desenvolvidas na pesquisa. Desta forma, a seguir, apresentamos como modificamos o modelo tradicional, para o desenvolvimento de um modelo de não arbitragem. A introdução da não arbitragem ao modelo nos permitiu melhorar o sinal de prêmio de risco e possibilitou explicar os retornos individuais das ações com maior precisão. A condição de não arbitragem baseou-se na explicação dos prêmios de risco sobre o primeiro momento. Podemos decompor o retorno das ações em uma parte de prêmio de risco previsível e um componente de martingale imprevisível. A maior parte da variação é motivada pelo componente imprevisível que não possui um prêmio de risco. Ao considerar retornos médios desagregados, o componente imprevisível foi diversificado ao longo do tempo e o sinal de risco previsível foi reforçado. Para tal efeito utilizamos do teorema de Bayes, via priori e posterior, para incluirmos as informações sobre uma parte de prêmio de risco previsível e um componente de martingale imprevisível.

O modelo original assumiu, em um primeiro momento, que os retornos dos ativos seguem uma distribuição normal com médias $\mu$ e matriz de covariância $\Sigma$ :

$$
R \sim N(\mu, \Sigma)
$$

O investidor não conhece os valores das médias dos retornos, de forma que pode considerá- los como variáveis aleatórias. Dessa forma, foi necessário determinar um método para estimar essas médias, o qual foi apresentado no modelo BL. Nesse contexto, o ponto de partida do modelo BL é considerar uma carteira de mercado como a situação de 
equilíbrio de longo prazo. Utilizando a lógica semelhante à do modelo de Markowitz, pode-se encontrar os retornos esperados de longo prazo a partir de um processo chamado de otimização reversa. Intuitivamente, o processo de otimização reversa deriva do fato de que, uma vez que o investidor conhece a carteira de equilíbrio de mercado, os retornos esperados podem ser calculados, dados que eles estão implícitos nos pesos dos ativos nessa carteira.

Em nossa dissertação podemos encontrar uma estimativa para as variáveis aleatórias $\mu$, que possuem distribuição normal com esperança a prior igual a $r_{i, t}^{M}$. Resumidamente, vamos encontrar:

$$
\begin{gathered}
\mu=r_{i, t}^{\hat{M}}+\varrho \\
\mu \sim N\left(r_{i, t}^{\hat{M}}, \Sigma_{r_{i, t}^{M}}\right)
\end{gathered}
$$

Onde temos que $r_{i, t}^{\hat{M}}$ é a melhor previsão mensal desagregada, de acordo com método detalhado na seção anterior. Como método de desagregação, utilizamos o modelos de retornos compostos, i.e, $\left.r_{i, t}^{\hat{M}}=\left(1+\hat{R_{i, t}^{M}}\right)^{(1 / 21)}\right)-1$. A matriz $\Sigma_{r_{i, t}^{\hat{M}}}$, que representa a variância do fator aleatório $\varrho$, é obtida como uma proporção da variância $\Sigma$. Com isso, temos:

$$
\Sigma_{r_{i, t}^{\hat{M}}}=\tau \Sigma
$$

A determinação do coeficiente $\tau$ é um assunto amplamente discutido na literatura, contudo, ainda não possui um formato consolidado. Intuitivamente, ele significa a confiança do investidor em relação à distribuição a priori obtida pelo CAPM. Em nossa extensão, tal variável de incerteza se encaixa perfeitamente na incerteza em relação à distribuição a priori obtida pela melhor previsão mensal desagregada, de acordo com método $R M S E_{v}$, i.e. A raiz do erro quadrático médio do modelo de previsão $v$ dentro da amostra de teste, em nossa extensão temos que: $\tau=1 / R M S E_{v}$. Tal escolha ocorre como forma natural dado que $R M S E$ representa o tamanho de erro do modelo preditivo escolhido, onde o inverso pode ser visto como a confiança em relação ao modelo preditivo. Essa abordagem já foi 
utilizada na literatura, contudo, utilizar o RMSE específico do próprio modelo preditivo escolhido foi uma extensão da pesquisa.

A visão do analista, por definição, é um posicionamento do analista em relação ao desempenho futuro de determinado ativo. No Modelo de Black-Litterman, considera-se a visão do analista em relação aos retornos dos ativos analisados. A visão pode ser definida como relativa, quando se compara o desempenho esperado de um ativo em relação a outro ativo, ou absoluta, quando se compara o desempenho esperado de determinado ativo da carteira com algum ativo referência ou com toda a carteira. Um fator intuitivo da visão do investidor é a sua incerteza. Infere-se que, ainda que o analista tenha conhecimento do mercado, nunca haverá total certeza de que sua visão está correta. O grau de incerteza da visão também foi incorporado ao modelo, conforme será mostrado adiante. Formalmente, $i$ visões no modelo de Black-Litterman são representadas por um vetor $I, i$-dimensional dado por:

$$
\begin{gathered}
I=P\left(\hat{r_{i, t}}\right)+z \\
z \sim N\left(0, \Sigma_{z}\right)
\end{gathered}
$$

Onde $P$ é uma matriz i X N. Temos que $\hat{r_{i, t}}$ é um vetor de $N X 1$ de retornos esperados, determinado pelo melhor modelo de previsão diário escolhido pelo critério $R_{o o s}^{2}$ dentro da amostra de teste. A matriz $\Sigma_{z}$ é uma matriz $i X i$, expressa a confiabilidade da previsão $\hat{r_{i, t}}$. Destaca-se que, conforme será verificado adiante na fórmula de BlackLitterman, a magnitude de $\Sigma_{z}$ afeta diretamente os resultados obtidos com a aplicação do modelo. Isso ocorre porque a metodologia intuitiva de Black-Litterman permite que uma maior incerteza em relação a $\hat{r_{i, t}}$, forneça resultados mais próximo do equilíbrio de mercado, ou seja, da distribuição a priori. Por outro lado, uma vez que o analista define sua opinião como altamente confiável, sua matriz de visões modificará de maneira relevante os resultados do modelo a posteriori em comparação à distribuição a priori. Para escolhermos a confiança em relação a previsão $\left(\hat{r_{i, t}}\right)$ utilizamos o mesmo critério adotado para a priori 
detalhado anteriormente.

Uma vez determinada a distribuição a priori dos retornos dos ativos e os parâmetros referentes à opinião do investidor, o modelo BL propõe uma forma de incorporar as matrizes de visões ao equilíbrio inicialmente obtido. A abordagem está relacionada à ótica bayesiana de probabilidades condicionais. O resultado dessa incorporação é a Fórmula de Black-Litterman, que fornece uma nova distribuição dos retornos dos ativos, chamada de distribuição a Posteriori, a ser utilizada no processo de escolha da carteira ótima de ativos. Dessa forma, em relação a $\mu$ e $R$, temos a esperança e a variância estimadas dos retornos:

$$
\begin{gathered}
\mu_{B L}=E[R]=\left[(\tau \Sigma)^{-1}+P^{t} \Sigma_{z}^{-1} P\right]^{-1}\left[(\tau \Sigma)^{-1} r_{i, t}^{\hat{M}}+P^{t} \Sigma_{z}^{-1} P\right] \\
\Sigma_{B L}=\left[(\tau \Sigma)^{-1}+P^{t} \Sigma_{z}^{-1} P\right]^{-1}
\end{gathered}
$$

Uma vez que se obteve a distribuição a posteriori dos retornos dos ativos, adotamos a mesma técnica de otimização do modelo Média-Variância para encontrarmos a alocação ótima, representada por $w_{B L}$.

$$
M I N_{w_{B L}} w_{B L}^{t} \Sigma_{B L} w_{B L}-\lambda w_{B L}^{t} \mu_{B L}
$$

Resolvendo o problema, pudemos adicionar um conjunto de restrições, por exemplo: $\sum_{i=1}^{N} w_{B L}=1$, onde chegamos aos pesos:

$$
w_{B L}^{*}=\left(\lambda w_{B L}^{t}\right)^{-1} \mu_{B L}
$$

Substituindo os resultados anteriormente encontrados chegamos ao seguinte resultado:

$$
w_{B L}^{*}=\left(\lambda w_{B L}^{t}\right)^{-1}\left[(\tau \Sigma)^{-1}+P^{t} \Sigma_{z}^{-1} P\right]^{-1}\left[(\tau \Sigma)^{-1} r_{i, t}^{\hat{M}}+P^{t} \Sigma_{z}^{-1} P\right]
$$


No capítulo 5, aplicamos o modelo BL apresentado nesta seção, explorando melhor os resultados a serem utilizados como cada critério de entrada.

\subsection{Interpolação de dados e preenchimento de curvas}

Nesta seção discutimos uma representação em estado de espaços que pode ser usada com três propósitos distintos. O primeiro é na interpolação de séries temporais, o segundo é como base na reconstrução histórica (back-cast) de séries econômicas incompletas e o terceiro é na extrapolação de abrangência de estruturas de previsão. A estimação dos modelos associados à representação estado de espaços se dá a partir do uso do filtro de Kalman. Uma descrição teórica e aplicada mais detalhada dessas técnicas pode ser encontrada em Bollerslev, Chou e Kroner (1992) ou em Hamilton e Susmel (1994).

Considere um vetor de retornos $r_{i, t}^{o}$ de $N X 1$, observáveis no período $t$, e um vetor $r_{i, t} R X 1$ de variáveis latentes (não observáveis) no período $t-1$. Uma representação de espaço de estados é uma forma de resumir as relações entre esses dois conjuntos de variáveis, onde a natureza dinâmica do sistema é levada em consideração. Na maioria das aplicações, a representação de espaço de estados é linear, o que leva naturalmente à log verossimilhança condicional do sistema sob inovações Gaussianas. A representação em espaço de estados foi considerada aqui como equação de estado e equação de medida, respectivamente:

$$
\begin{gathered}
r_{i, t}=r_{i, t-1}+\nu_{t} \\
r_{i, t}^{o}=r_{i, t}+\eta_{t}
\end{gathered}
$$

A equação de estado (2.57) descreve a dinâmica do vetor de estado $r_{i, t}$, o qual contém as variáveis latentes que foram estimadas. A equação de observação (2.58) relaciona o vetor contendo as observáveis $r_{i, t}^{o}$. Os erros $\nu_{t}$ e $\eta_{t}$ são, por hipótese, ortogonais em todos os lags e leads. Além disso, estes termos de erro têm a distribuição normal multivariada, o que torna (2.58) e (2.59) um sistema linear gaussiano condicional, no qual a estimação e 
previsão podem se basear. Com este procedimento tentou-se obter os valores da variável de estados não observável $r_{i, t}$. Pode-se prevê-la baseado no conjunto completo de dados, o que é chamado de estimativa suavizada de $r_{i, t}$, ou, pode-se prevê-la usando apenas dados disponíveis até o período $t-1$, o que é chamado de estimativa filtrada. Dado o objetivo da pesquisa, utilizamos a estimativa suavizada, representada a seguir:

$$
r_{t \mid T}=E\left(r_{t} \mid z_{1}, \ldots, z_{t-1}\right)
$$

Como resultado desta aplicação, podemos atuar interpolando nossos dados quando lidamos com o problema de "lacunas temporais", respeitando a volatilidade da série sem impor uma estrutura adicional que dificulte o processo de modelagem. Também utilizamos tal modelo para a construção das estruturas a termo do excesso de retorno, realizando o preenchimento da estrutura a termo com um maior número de vértices. Para a estimação deste modelo, utilizamos uma ferramenta tradicional conhecida como filtro de Kalman et al. (1960).

\subsection{Relevância das variáveis e relacionamento marginal}

Nosso objetivo na interpretação de modelos de Machine Learning foi robusto e extremamente útil para formulações futuras. Com objetivo de identificar variáveis que tenham uma influência preditiva significativa nos retornos esperados de cada ativo, enquanto controlamos simultaneamente os muitos outros preditores do sistema. Analisando qual a relação preditiva existente entre cada variável do modelo.

Consideramos duas noções diferentes de importância. A primeira foi a redução no $R_{2}$ preditivo dos dados para definir todos os valores do preditor $\Omega_{j}$ para zero, mantendo as demais estimativas do modelo fixas, conforme utilizada no contexto de redução de dimensão por He, Kelly e Manela (2017). Como parte de nossa análise, traçamos também a relação marginal entre retornos esperados e cada característica. Apesar das limitações óbvias, esses gráficos são uma ferramenta eficaz para visualizar o impacto de primeira ordem das covariáveis em um modelo de Machine Learning. 


\section{Um Estudo Empírico para Ativos Brasilei-}

\section{ros}

Neste capítulo descrevemos a aplicação empírica da pesquisa: base de dados, modelos estimados e a comparação das previsões encontradas nos modelos propostos nas diferentes frequências.

\subsection{Base de dados}

O conjunto informativo foi retirado das seguintes fontes: IPEA-DATA, FRED, Economatica, Banco Central do Brasil, Thomson Reuters e FGV Dados. Os ativos que foram analisados dentro da pesquisa foram: Índice IBOVESPA (IBOVESPA), Taxa de Câmbio Real/Dólar (R\$/US\$), Certificado de Deposito Interbancário (CDI), ABEV3.SA, CMIG4.SA, ITUB4.SA, PETR4.SA e VALE3.SA. Os ativos foram escolhidos de acordo com o nível de liquidez acumulada do período de 1995 até 2015 pela metodologia de Acharya e Pedersen (2005). A restrição do número de ativos analisados ocorre devido a uma limitação de capacidade operacional (computacional). Tal limitação advém do elevado número de modelos propostos (53), do tamanho da base de dados utilizada, número de previsões desenvolvidas (482) para cada um dos modelos e pela proposta de pesquisa de desenvolvimento de um FDS especifico para cada ativo. O total de previsões geradas no modelo foi de 25.646. O total de séries temporais utilizadas nos modelos de previsão foi de 630 séries temporais de dados divididas da seguinte forma:

Tabela 1 - Total de séries temporais.

\begin{tabular}{lccccccc}
\hline Intervalo de Tempo & Geral & ABEV3 & CMIG4 & ITUB4 & PETR4 & VALE3 & Total \\
\hline Número de variáveis Diárias & 54 & 30 & 29 & 22 & 34 & 31 & $\mathbf{2 0 0}$ \\
Número de variáveis Mensais & 95 & 19 & 22 & 17 & 28 & 30 & $\mathbf{2 1 1}$ \\
Número de variáveis Trimestrais & 28 & 25 & 27 & 24 & 25 & 27 & $\mathbf{1 5 6}$ \\
Número de variáveis Anuais & 15 & 8 & 8 & 10 & 13 & 9 & $\mathbf{6 3}$ \\
Total & $\mathbf{1 9 2}$ & $\mathbf{8 2}$ & $\mathbf{8 6}$ & $\mathbf{7 3}$ & $\mathbf{1 0 0}$ & $\mathbf{9 7}$ & $\mathbf{6 3 0}$ \\
\hline
\end{tabular}

Fonte: Elaborada pelos autores. 
Para mais detalhes com relação as séries utilizadas, o anexo A mostra todo o conjunto de séries atualizadas nos intervalos diários, mensais, trimestrais e anuais. O número de observações presentes no conjunto total de dados para series diárias, mensais, trimestrais e anuais foram 1891, 191, 86 e 23, respectivamente, sendo que tais números foram selecionados para maximizar na visão dos pesquisadores a qualidade do conjunto de dados inseridos no modelo. O total de entradas (sinais) para cada um dos modelos são de 433.336. Em relação aos dados, um dos empecilhos encontrados para lidar com um conjunto informativo de tal magnitude foi a presença de dados com observações faltantes ao longo do tempo. Para resolução deste problema, o primeiro passo foi a determinação de qual o intervalo temporal seria analisado considerando o número de observações a serem incluídas. Desta forma, para observações diárias, foi utilizado como base os dias nos quais o mercado de câmbio foi negociado, tabela de dias uteis divulgada pela B3, com objetivo de evitar o problema de acumulação de informação entre os diferentes mercados (mercado de cambio possui um maior número de dias de negociação do que o mercado acionário). Para período mensal, trimestral e anual não foram feitas modificações em relação ao calendário padrão. Para o processo de preenchimento dos dados faltantes foi utilizado o mecanismo de espaços de estados do modelo de nível local estimado via filtro de Kalman, sendo utilizada a estimativa suavizada.

O segundo passo da preparação dos dados ocorreu através da realização para cada série de tempo do teste de raiz unitária DF-GLS (Elliott, Rothenberg e Stock (1996)), onde avaliamos se as séries temporais possuam raiz unitária ou são estacionárias no formato com intercepto e/ou tendência. Um fato que merece destaque é que todas as séries foram analisadas em sua forma gráfica e seu correlograma, na tentativa de evitar o problema de baixo poder presentes nos testes de raiz unitária. Assim, as séries que apresentaram raiz unitária passaram pelo processo de indução de estacionariedade, como descrito a seguir:

$$
\Omega_{j, t}=\ln \left(\Omega_{j, t}\right)-\ln \left(\Omega_{j, t-1}\right)
$$

As variáveis que no teste se apresentaram como estacionárias foram mantidas em seu formato original posterior ao processo de interpolação. O terceiro passo para 
tratamento dos dados ocorreu através de um processo de normalização descrito a seguir:

$$
N\left(\Omega_{j, t}\right)=\frac{\Omega_{j, t}-E_{T}\left(\Omega_{j}\right)}{\sqrt{\operatorname{var}_{T}\left(\Omega_{j}\right)}}
$$

O objetivo desta transformação foi evitar o problema gerado por se trabalhar com séries que possuem diferentes formatos e magnitudes, fato que pode vir a gerar grandes falhas em modelos abordados na pesquisa, como exemplo, PCA e SPCA. Após o tratamento dos dados, caminhamos para a etapa de estimação dos modelos mencionados no capítulo 2.

\subsection{Estruturas dos Modelos Preditivos}

Considerando o conjunto de dados desenvolvido através das etapas mencionadas na seção anterior, um passo de grande importância foi a seleção dos intervalos de estimação (treinamento), previsão controlada fora da amostra (validação) e previsão final do modelo fora da amostra (avaliação). A divisão dos conjuntos amostrais para as quatro frequências de tempo analisadas (dia, mês, trimestre e ano) pode ser vista na figura a seguir:

Figura 1 - Divisão do espaço de tempo da pesquisa

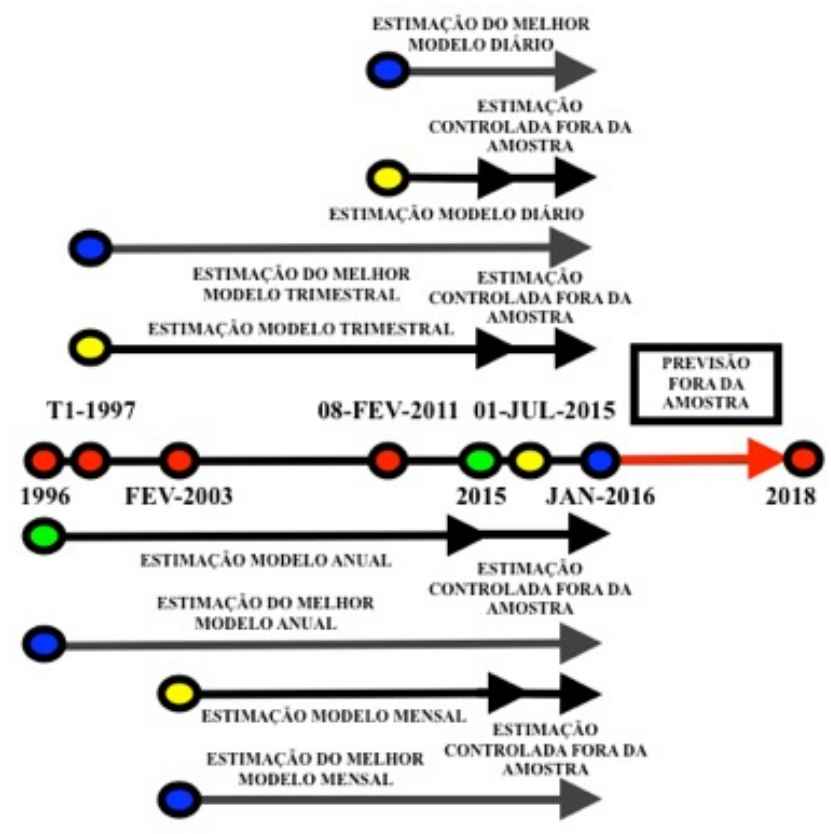

Fonte: Elaborada pelos autores. 
O processo de seleção do período de amostra, utilizado durante a etapa de estimação, foi realizado de forma a garantir uma amostra suficiente e robusta que possibilitasse a estimação dos modelos previstos. Um empecilho encontrado durante o processo se encontra quando a frequência dos dados é reduzida e determinados testes, por exemplo teste de DIEBOLD e MARIANO (1995), acabam por ter seu poder reduzido. Na tentativa de contornar esse problema, separamos uma parte da amostra para um período de previsão fora da amostra controlada (validação), para analisar qual dos modelos estimados possui melhor ajuste. Após a analise dos modelos na amostra de validação, aquele que apresentou maior $R_{\text {oos }}^{2}$ foi utilizado como modelo escolhido para previsão fora da amostra. A seguir apresentamos os modelos estimados na pesquisa para as quatro frequências de dados selecionadas: 
Tabela 2 - Apresentação dos modelos estimados.

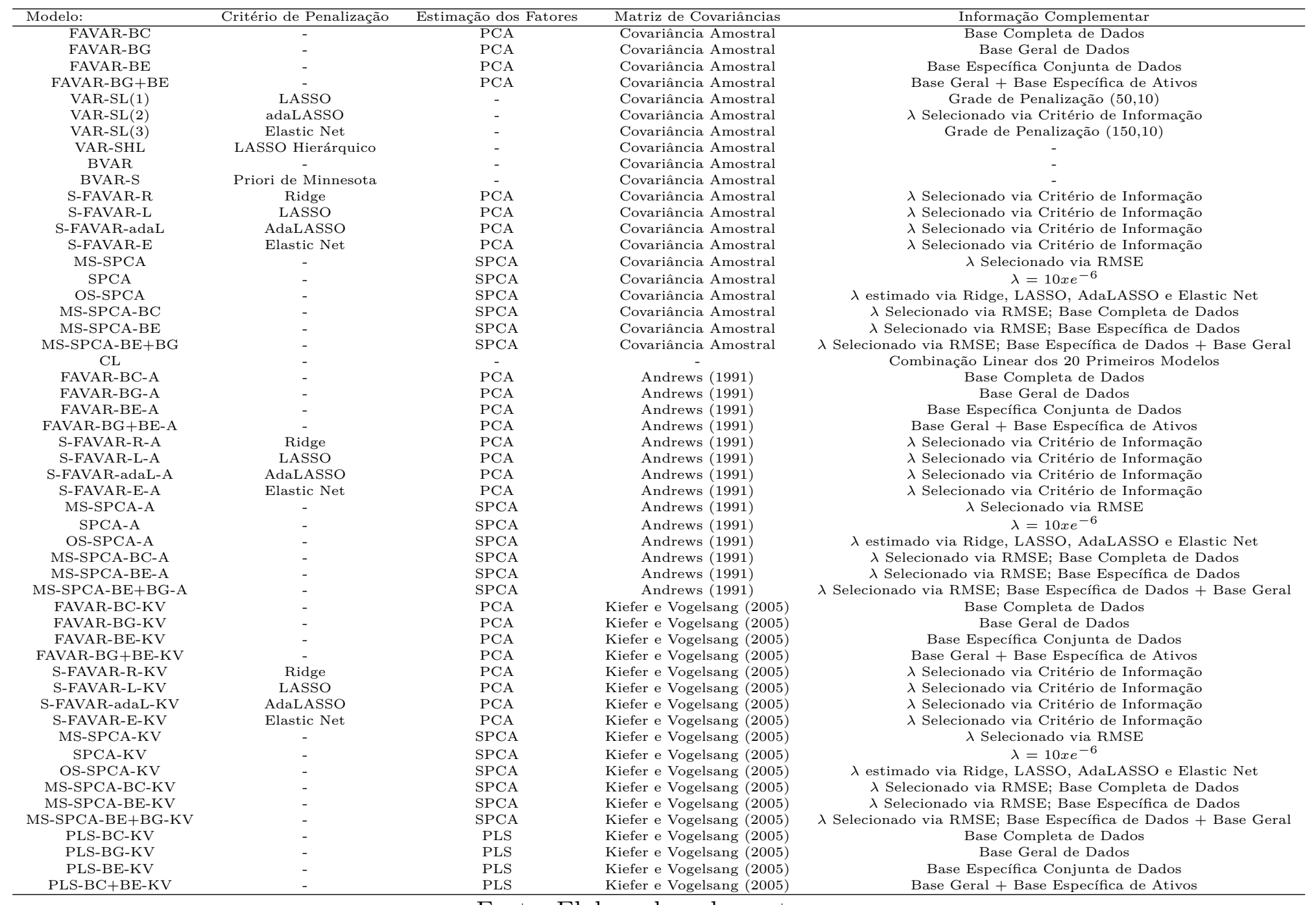


Desta forma, na tabela 2, chegamos a um total de 53 modelos de Machine Learning Lineares esparsos estimados na pesquisa para cada umas das quatro frequência de dados (212 modelos ao total nas diferentes frequências). Ressaltamos que os modelos desenvolvidos são esparsos e possuem a condição de não arbitragem apresentada no capítulo 2. Em relação a tabela apresentada anteriormente, temos que a grade de penalização representa o tamanho da penalização imposto via o hiperparâmetro $\lambda$, onde utilizamos três formatos distintos: critérios arbitrários de penalização do $\lambda_{1}$ e $\lambda_{2}$ foram $(50,10)$, critérios arbitrários de penalização do $\lambda_{1}$ e $\lambda_{2}$ foram $(150,10)$ com a minimização do RMSE. Em relação aos formatos de base de dados utilizados na pesquisa, encontramos quatro especificações: Base completa - utilizamos todos os dados presentes na base de dados; Base Geral - utilizamos apenas os dados macroeconômicos e microeconômicos não incluindo variáveis referentes aos ativos analisados; Base Específica de Ativos - formada apenas pelos dados específicos do ativo analisado $\left(r_{i}\right)$; Base Específica Conjunta - formada pela união dos dados gerais mais os dados específicos do ativo analisado. Em relação aos métodos de validação dos hiperparâmetros $\lambda$ e $\lambda_{1}$, utilizamos tanto critérios de informação (AIC e BIC) quanto critério de minimização do RMSE do modelo na etapa de validação. De forma simples a condição de momento de não arbitragem imposta aos modelos de predição implica que:

$$
r_{i, t+1}^{e^{\hat{n}}}=r_{i, \hat{t}+1}-r_{C \hat{D I}, t+1}
$$

Sendo assim, a previsão para o retorno em excesso do ativo $i$ dos modelos deve ser igual a previsão do retorno do ativo $i$ menos a previsão para o retorno do ativo livre de risco (CDI). No capítulo 2 realizamos uma explicação completa das propriedades de não arbitragem aplicada aos modelos estimados na pesquisa. O conjunto de dados existente para estimação diária foi formado por $N=200$ séries temporais e $T=1891$ (08-02-2011 até 30-12-2017) observações. Para o período de estimação do modelo diário foi selecionado uma amostra de tamanho $T_{e}=1091$ (08-02-2011 até 30-12-2013) de treinamento, e amostra de validação $T_{v}=481$ (02-01-2014 até 30-12-2015). Em relação ao conjunto de dados existente para estimação mensal foi formado por $N=211$ séries temporais e $T=191$ (02-2003 até 12-2017) observações. Para o período de estimação do modelo mensal foi 
selecionado uma amostra de tamanho $T_{e}=131$ (02-2003 até 12-2013), e amostra de validação $T_{v}=24$ (01-2014 até 12-2015). O ambiente de análise para o conjunto de dados existente para estimação trimestral foi formado por $N=159$ séries temporais e $T=86$ (T1-1997 até T4-2017) observações. Para o período de estimação do modelo trimestral foi selecionado uma amostra de tamanho $T_{e}=68$ (T1-1997 até T4-2013), e amostra de validação $T_{v}=8$ (T1-2014 até T4-2015). Para a última frequência o conjunto de dados existente para estimação anual foi formado por $N=65$ séries temporais e $T=23$ (1996 até 2017) observações. Para o período de estimação do modelo anual foi selecionado uma amostra de tamanho $T_{e}=18$ (1996 até 2013), e amostra de validação $T_{v}=2$ (2014 até 2015).

Na tabela 3 a seguir podemos encontrar os principais resultados para cada um dos modelos de predição diária:

Tabela 3 - Resultados para cada um dos modelos de predição diária.

\begin{tabular}{|c|c|c|c|c|c|}
\hline Modelo: & $\begin{array}{l}\text { Número de Fatores } \\
\text { Bai e Ng (2002) }\end{array}$ & $\begin{array}{c}\text { Número de variáveis não zero } \\
\text { Kristensen }(2017)\end{array}$ & \% da Variação Explicada & $\begin{array}{l}R^{2} \text { Ajustado } \\
\text { Médio }\end{array}$ & $R_{\text {oos }}^{2}$ em $T_{f}$ \\
\hline FAVAR-BC & 22 & - & 0.80 & 0.63 & 0.19 \\
\hline FAVAR-BG & 7 & - & 0.83 & 0.64 & 0.22 \\
\hline FAVAR-BE & 18 & - & 0.91 & 0.66 & 0.18 \\
\hline FAVAR-BG+BE & $7+18$ & - & $0.83 ; 0.91$ & 0.49 & 0.17 \\
\hline VAR-SL (1) & - & - & - & 0.58 & 0.15 \\
\hline VAR-SL $(2)$ & - & - & - & 0.65 & 0.09 \\
\hline VAR-SL $(3)$ & - & - & - & 0.66 & 0.10 \\
\hline VAR-SHL & - & - & - & 0.61 & 0.07 \\
\hline BVAR & - & - & - & 0.05 & 0.03 \\
\hline BVAR-S & - & - & - & 0.56 & 0.08 \\
\hline S-FAVAR-R & 8 & - & 0.92 & 0.61 & 0.21 \\
\hline S-FAVAR-L & 10 & - & 0.71 & 0.60 & 0.27 \\
\hline S-FAVAR-adaL & 12 & - & 0.89 & 0.60 & 0.19 \\
\hline S-FAVAR-E & 9 & - & 0.84 & 0.62 & 0.24 \\
\hline MS-SPCA & 18 & 39 & 0.95 & 0.63 & 0.29 \\
\hline SPCA & 18 & 71 & 0.93 & 0.63 & 0.20 \\
\hline OS-SPCA & 18 & 100 & 0.89 & 0.63 & 0.28 \\
\hline MS-SPCA-BC & 22 & 131 & 0.81 & 0.63 & 0.14 \\
\hline MS-SPCA-BE & 18 & 20 & $0.89 ; 0.90$ & 0.63 & 0.09 \\
\hline $\mathrm{CL}(20)$ & - & - & - & 0.43 & 0.05 \\
\hline FAVAR-BC-A & 4 & - & 0.91 & 0.67 & 0.19 \\
\hline FAVAR-BG-A & 3 & - & 0.90 & 0.59 & 0.22 \\
\hline FAVAR-BE-A & 5 & - & 0.94 & 0.69 & 0.21 \\
\hline FAVAR-BG+BE-A & $3+5$ & - & $0.90 ; 0.92$ & 0.46 & 0.22 \\
\hline S-FAVAR-R-A & 2 & - & 0.96 & 0.60 & 0.21 \\
\hline S-FAVAR-L-A & 1 & - & 0.99 & 0.63 & 0.20 \\
\hline S-FAVAR-adaL-A & 3 & - & 0.93 & 0.65 & 0.22 \\
\hline S-FAVAR-E-A & 2 & - & 0.93 & 0.39 & 0.24 \\
\hline MS-SPCA-A & 5 & 45 & 0.95 & 0.51 & 0.29 \\
\hline SPCA-A & 5 & 81 & 0.90 & 0.69 & 0.13 \\
\hline OS-SPCA-A & 5 & 100 & 0.90 & 0.63 & 0.28 \\
\hline MS-SPCA-BC-A & 4 & 100 & 0.93 & 0.65 & 0.25 \\
\hline MS-SPCA-BE-A & 5 & 18 & $0.90 ; 0.92$ & 0.64 & 0.14 \\
\hline FAVAR-BC-KV & 2 & - & 0.98 & 0.63 & 0.19 \\
\hline FAVAR-BG-KV & 1 & - & 0.97 & 0.64 & 0.22 \\
\hline FAVAR-BE-KV & 2 & - & 0.99 & 0.65 & 0.29 \\
\hline FAVAR-BG+BE-KV & $1+2$ & - & $0.99 ; 0.97$ & 0.49 & 0.17 \\
\hline S-FAVAR-R-KV & 2 & - & 0.99 & 0.61 & 0.16 \\
\hline S-FAVAR-L-KV & 1 & - & 0.99 & 0.60 & 0.14 \\
\hline S-FAVAR-adaL-KV & 1 & - & 0.99 & 0.60 & 0.19 \\
\hline S-FAVAR-E-KV & 2 & - & 0.99 & 0.62 & 0.22 \\
\hline MS-SPCA-KV & 1 & 49 & 0.99 & 0.63 & 0.31 \\
\hline SPCA-KV & 1 & 72 & 0.98 & 0.63 & 0.25 \\
\hline OS-SPCA-KV & 1 & 123 & 0.98 & 0.63 & 0.28 \\
\hline MS-SPCA-BC-KV & 2 & 14 & 0.99 & 0.63 & 0.16 \\
\hline PLS-BC-KV & 2 & 25 & 0.99 & 0.71 & 0.07 \\
\hline PLS-BG-KV & 1 & 35 & 0.99 & 0.82 & 0.11 \\
\hline PLS-BE-KV & 2 & 98 & 0.99 & 0.61 & 0.24 \\
\hline PLS-BG+BE-KV & $1+2$ & 18 & $0.99 ; 0.99$ & 0.54 & 0.15 \\
\hline
\end{tabular}

Fonte: Elaborada pelos autores. 
Na tabela anterior podemos notar claramente que as modificações propostas na matriz de covariâncias geraram uma redução clara no número de componentes principais ótimos, utilizando o critério de Bai e Ng (2002). Esse efeito foi maior ainda quando utilizamos a matriz de covariâncias de longo prazo de Kiefer e Vogelsang (2005). É importante ressaltar que, mesmo com um menor número de componentes principais os modelos apresentaram um maior percentual da variação explicada. Tais resultados vão de encontro a condição de não arbitragem imposta aos modelos. Quando analisamos as matrizes de longo prazo, descartamos grande parte dos ruídos de curto prazo (Martingale imprevisível), o que favorece a uma maior capacidade explicativa para o modelo. Em relação ao critério de Kristensen e Salanié (2017) para determinação de variáveis não zero no SPCA, podemos notar que não existe um caminho certo de redução ou aumento no número de variáveis não zero quando adicionamos as matrizes de longo prazo. Considerando que o objetivo de nossa dissertação se concentrou na análise do $R_{\text {oos }}^{2}$ (amarelo) e consequentemente, $R^{2}$ (azul), o gráfico a seguir concentramos as duas informações referentes aos 53 modelos diários desenvolvidos.

Figura 2 - Avaliação da Capacidade Preditiva dos Modelos Diários.

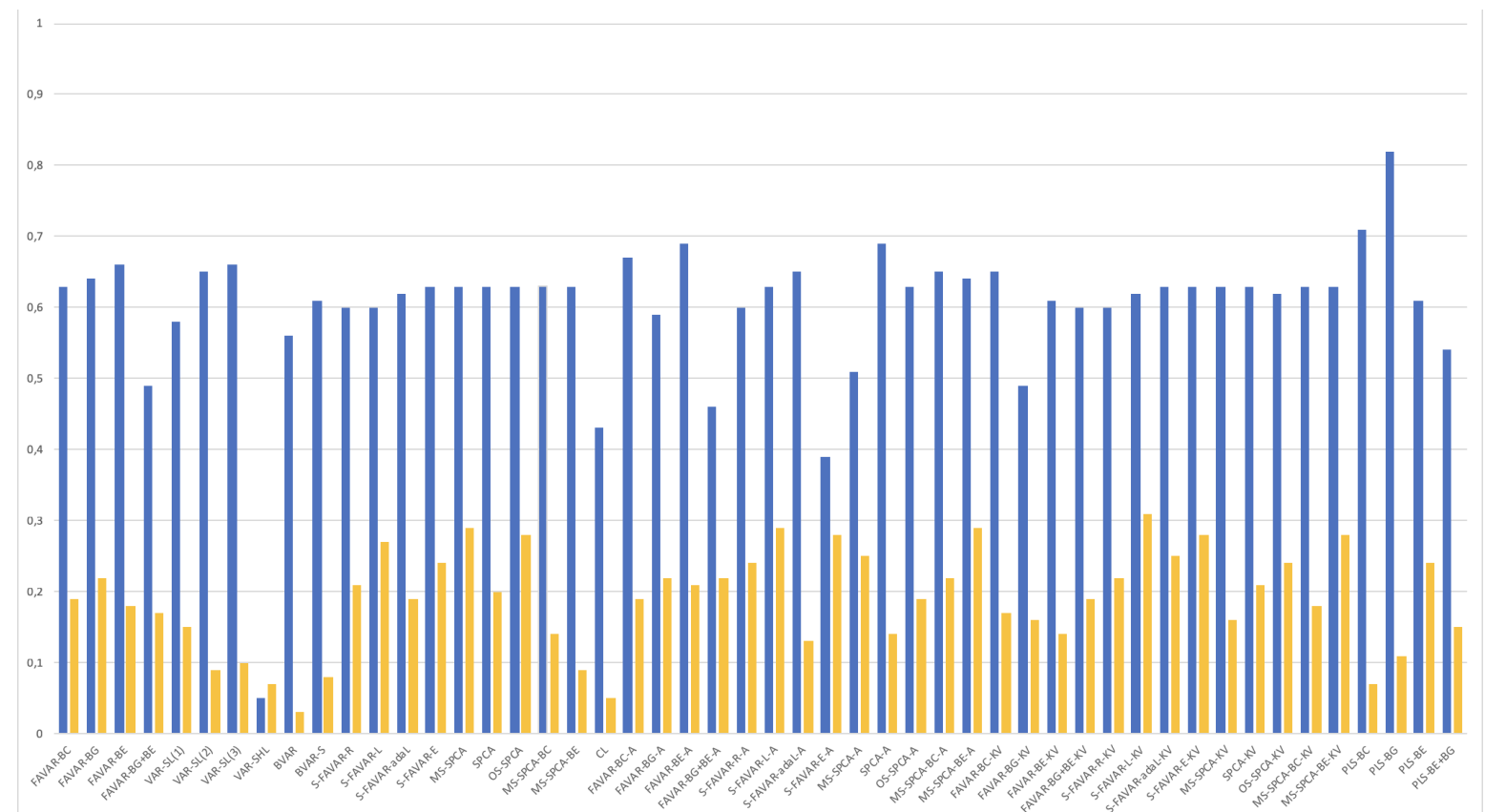

Legenda: $R_{\text {oos }}^{2}$ em Amarelo e $R^{2}$ Azul

Fonte: Elaborada pelos autores. 
Observando a figura 2, podemos notar como esperado uma queda elevada da variável $R^{2}$ em relação a variável $R_{\text {oos }}^{2}$. Tal redução ocorre devido ao fato de que $R^{2}$ é percentual explicada dentro da amostra e $R_{o o s}^{2}$ é uma modificação feita por Diebold e Mariano (1995) para o percentual explicado fora da amostra. Logo, $R_{\text {oos }}^{2}$ resume a capacidade preditiva dos modelos. Comparativamente, se realizarmos o cálculo da média entre o grupo de modelos apresentados, vamos encontrar que os modelos estimados com a matriz de covariâncias amostrais possuem um $R_{\text {oos }}^{2}$ de aproximadamente $17 \%$, enquanto as matrizes de covariâncias de longo prazo de Andrews (1991) e Kiefer e Vogelsang (2005), respectivamente, apresentam um $R_{\text {oos }}^{2}$ de $22 \%$ e $20 \%$. Realizando o agrupamento dos modelos em relação a métodos de penalização no VAR, métodos de pré-seleção anteriormente ao PCA, métodos de SPCA, FAVAR, métodos Bayesianos e métodos de PLS, vamos encontrar respectivamente os seguintes percentuais para $R_{\text {oos }}^{2}: 10,3 \%, 22,8 \%, 20 \%, 19 \%, 5,5 \%$ e 18,6\%. Deste modo, para os modelos preditivos diários, notamos que a matriz de covariâncias de Andrews (1991) e métodos de pré-seleção anteriormente ao PCA produzem um maior $R_{\text {oos }}^{2}$. Como destaque, o maior valor de $R_{\text {oos }}^{2}$ encontrado foi de $31 \%$ no modelo S-FAVAR-L-KV. Os percentuais encontrados superam com ampla distancia os resultados presentes na literatura para modelos de predição diários, onde muitos encontraram percentuais de $R_{\text {oos }}^{2}$ negativos. Contudo, vale mencionar que os valores apresentados são uma média de previsão para todos ativos estudados, como valores máximos e mínimos encontramos $69 \%$ e -0.78\% em toda amostra.

Para tornar mais clara a comparação entre os modelos, selecionamos os dez modelos que possuem maior $R_{\text {oos }}^{2}$ para realização do teste de Diebold e Mariano (1995). Os resultados podem ser encontrados na tabela 4.

As conclusões em relação à tabela 4 ocorrem em nível de comparação par, a par de cada um dos dez melhores modelos em relação ao $R_{\text {oos }}^{2}$. A interpretação da tabela não apresenta grandes dificuldades. Ressaltamos que os detalhes estão presentes na nota da tabela. 
Tabela 4 - Teste de Diebold e Mariano.

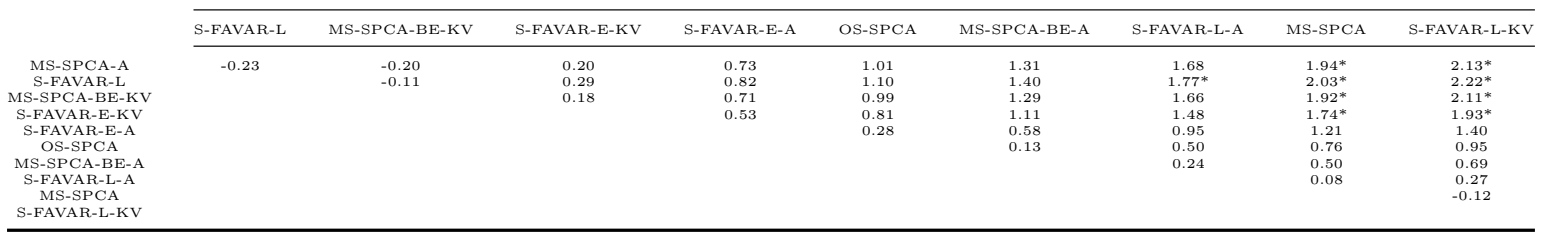

Fonte: Elaborada pelos autores.

A tabela reporta estatísticas de teste Diebold-Mariano em pares comparando o desempenho de previsão dos retornos dos ativos fora da amostra entre dez modelos. Números positivos indicam que o modelo de coluna supera o modelo de linha. Um asterisco indica significância no nível de $5 \%$ para comparações.

Agora investigamos a importância relativa de covariáveis individuais para o desempenho preditivo, usando as medidas de importância marginal descritas no capítulo 2 . Para começar, calculamos a redução no $R_{o s}^{2}$ da configuração de todos os valores de um determinado preditor para zero em cada amostra de treinamento e calculamos a média deles em uma única medida de importância para cada preditor, i.e, além de calculamos o efeito marginal de cada variável na capacidade preditiva. A Figura 3 relata o grau de importância das 5 principais características do retorno de cada ativo utilizando a base completa diária. O grau de importância das variáveis dentro de um modelo é normalizado para somar um, fornecendo a interpretação da importância relativa para esse modelo em particular. Ressaltamos que a figura a seguir apresenta as variáveis de maior magnitude para melhora na capacidade preditiva para os modelos lineares de Machine Learning em nível macroeconômico, microeconômico e específico, seguindo um padrão para todas as variáveis analisadas ao longo do tempo. Desta forma, não observamos uma mudança em relação aos preditores com o passar o tempo. 
Figura 3 - Análise Diária de Efeitos Marginais Por Ativo.

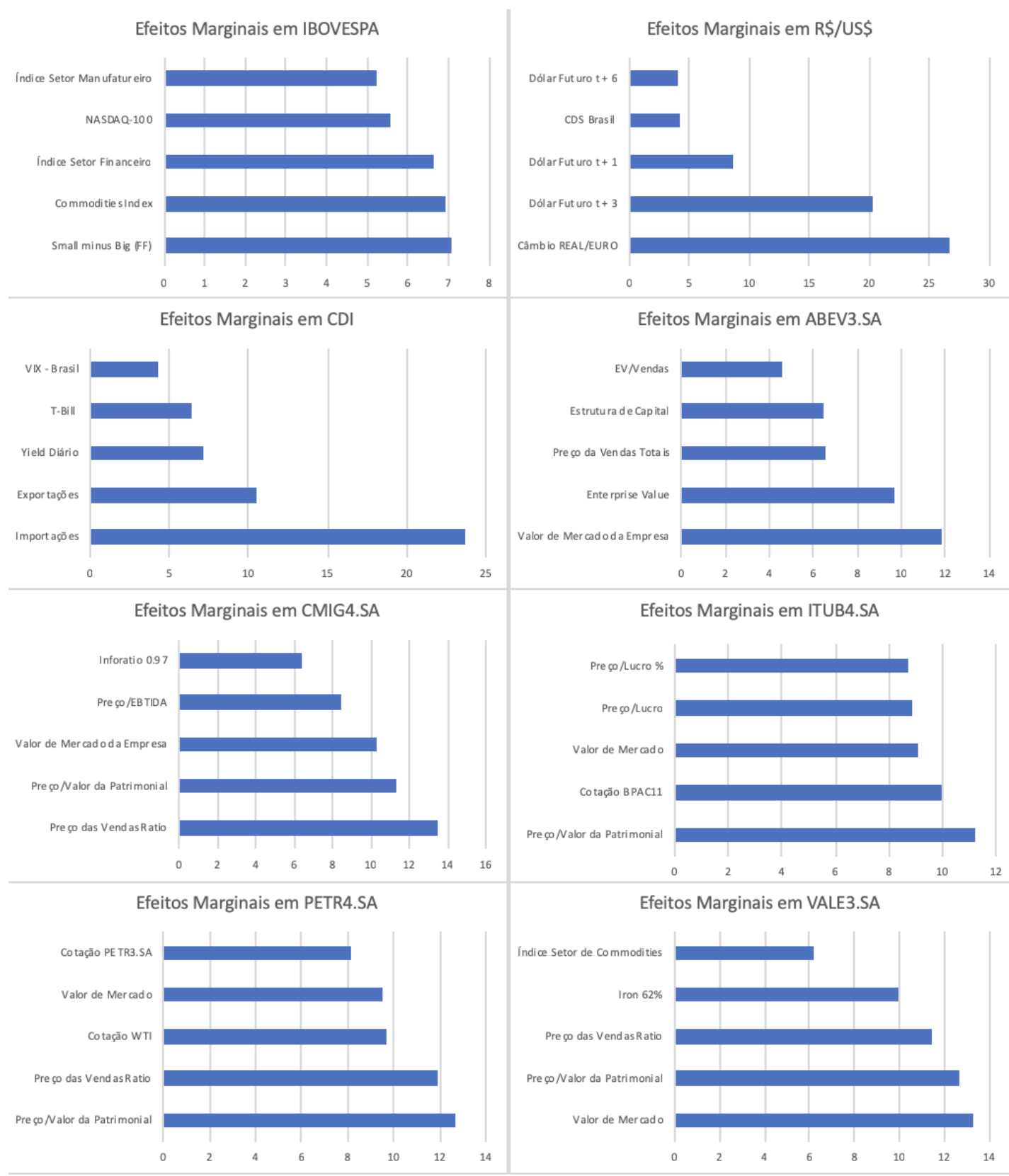

Fonte: Elaborada pelos autores.

O resultado apresentado na Figura 3 vai ao encontro ao esperado pelos modelos de precificação de ativos anteriormente citados na pesquisa, visão dos autores e também dos principais analistas de mercado. Um ponto de grande interesse ocorre do fato de que os ativos individuais analisados não possuem grande impacto de variáveis macroeconômicas e microeconômicas, retirando o efeito de commodities específicos. Em relação ao Índice IBOVESPA observamos um maior efeito marginal vindo dos principais componentes do índice, setores exportadores de commodities e financeiro. Em relação ao CDI, notamos um 
interessante resultado referente a importações e exportações que foge dos demais resultados da literatura. Entretanto, quando observamos o caso brasileiro podemos rapidamente ligar a balança comercial e seu efeito na desvalorização da moeda Real, gerando uma pressão inflacionária, e para seu combate, uma elevação nas taxas de juros (CDI). Em relação a taxa de câmbio Real/Dólar (R\$/US\$), o resultado se assemelha à literatura, ressaltando a interligação entre moedas fortes (Euro), risco Brasil (CDS) e expectativas cambiais futuras. Os resultados encontrados vão ao encontro aos objetivos da pesquisa. Em relação aos ativos específicos, é necessário ressaltar a importância de variáveis como ratio preço sobre o valor patrimonial, valor total das vendas e preço sobre lucros. Conforme esperado, o resultado marginal na capacidade preditiva de cada variável confirma a estrutura proposta de arbitragem informacional. Tal metodologia apesar do alto custo computacional gera uma elevada melhora na capacidade preditiva dos modelos.

A seguir, apresentamos os resultados mensais referentes ao total de 53 modelos estimados. Para o desenvolvimento de um critério comparativo entre os modelos em diferentes frequências, comparamos os resultados médios do conjunto de modelos estimados com a matriz de covariâncias amostrais que possuem um $R_{\text {oos }}^{2}$ de aproximadamente $43 \%$, enquanto as matrizes de covariâncias de longo prazo de Andrews (1991) e Kiefer e Vogelsang (2005), respectivamente, apresentam um $R_{\text {oos }}^{2}$ de $54 \%$ e $51 \%$. Realizando o agrupamento dos modelos em relação a métodos de penalização no VAR, métodos de pré-seleção anteriormente ao PCA, métodos de SPCA, FAVAR, métodos Bayesianos e métodos de PLS, encontramos respectivamente, os seguintes percentuais para $R_{\text {oos }}^{2}: 41,5 \%, 48,9 \%$, $39,1 \%, 43,6 \%, 9,2 \%$ e 40,6\%. Portanto, para os modelos preditivos mensais, notamos que a matriz de covariâncias de Andrews (1991) e métodos de pré-seleção anteriormente ao PCA produzem um maior $R_{\text {oos }}^{2}$, resultado semelhante ao encontrado para os modelos diários. Com objetivo de tornar mais clara a análise, apresentamos apenas os quatro modelos com maior $R_{\text {oos }}^{2}$, seguindo o objetivo da pesquisa. Na tabela podemos observar os principais resultados:

Analisando os resultados encontrados na tabela 5 e os anteriormente apresentados, podemos notar que a capacidade preditiva dos modelos obteve uma melhora significativa 
Tabela 5 - Resultados dos modelos mensais.

\begin{tabular}{|c|c|c|c|c|c|}
\hline Modelo: & $\begin{array}{l}\text { Número de Fatores } \\
\text { Bai e Ng (2002) }\end{array}$ & $\begin{array}{c}\text { Número de variáveis não zero } \\
\text { Kristensen }(2017)\end{array}$ & \% da Variação Explicada & $\begin{array}{l}R^{2} \text { Ajustado } \\
\text { Médio }\end{array}$ & $R_{o o s}^{2}$ em $T_{f}$ \\
\hline S-FAVAR-L & 2 & - & 0.95 & 0.85 & 0.73 \\
\hline VAR-SL(1) & - & - & - & 0.74 & 0.67 \\
\hline MS-SPCA-BE-A & 5 & 29 & 0.94 & 0.69 & 0.62 \\
\hline MS-SPCA-KV & 4 & 82 & 0,90 & 0.65 & 0.61 \\
\hline
\end{tabular}

Fonte: Elaborada pelos autores.

em relação ao $R_{\text {oos }}^{2}$. Tal resultado atua de acordo com a condição de não arbitragem que em modelos mensais obtém melhor ajuste em relação aos modelos diários. Essa característica é facilmente explicada pela dissipação dos efeitos de ruido (Martingale não previsível), presente nas variações diárias. Em relação ao teste de Diebold e Mariano, devido ao ambiente de previsões reduzidos e ao elevado número de modelos estimados optamos por não realizar o teste. Os resultados ressaltam a importância da estrutura utilizada de FDS, quando comparamos a capacidade preditiva encontrada notamos um resultado superior ao presente na literatura. Uma análise a ser destacada na pesquisa se refere aos efeitos marginais de cada variável sobre a capacidade preditiva dos modelos mensais. A Figura 4 relata o grau de importância das 5 principais características do retorno de cada ativo, utilizando a base completa mensal.

Em relação à figura 4, podemos notar que a estrutura em relação aos efeitos marginais não sofreram grandes modificações quando comparadas à frequência diária para análise dos ativos individuais, onde ressaltamos maior efeito marginal de variáveis de resultado e caráter de precificação utilizadas pelo mercado financeiro. No que se refere à variável Índice IBOVESPA, notamos um grande efeito de variáveis de Índices externos como: S\&P500, NASDAQ-100 e Índice Industrial Dow Jones. Esse fator é extremamente esperado dado o grau de conectividade e dependência dos mercados. Ainda em relação ao IBOVESPA, uma associação importante e amplamente explorada no mercado e na literatura é o efeito marginal da taxa de câmbio Real/Dólar e em relação às expectativas dos agentes de mercado. Quanto a taxa de câmbio Real/Dólar, mencionamos o efeito das taxas de câmbio reais e bilaterais em relação aos principais parceiros comerciais e em relação a uma medida de preços IGP-DI. Em relação ao CDI, continuamos dando destaque as exportações, índice de confiança do setor industrial, taxas referenciais e como surpresa 
Figura 4 - Análise Mensal de Efeitos Marginais Por Ativo.

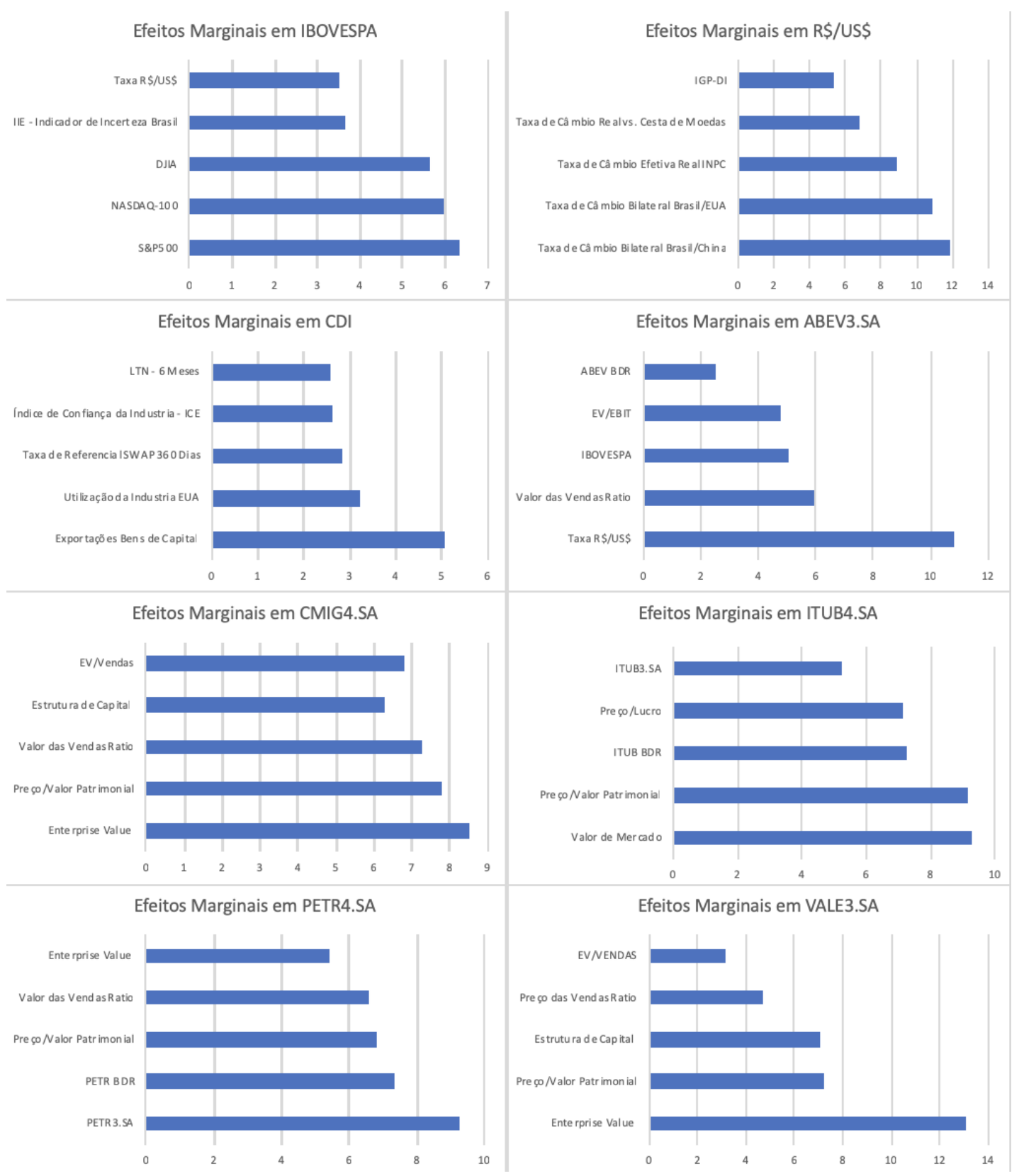

Fonte: Elaborada pelos autores.

ao índice de utilização da indústria no EUA. Quanto ao último item, um relacionamento secundário pode ser desenvolvido em relação a indicação de capacidade ociosa e realizações de políticas monetárias no EUA.

A seguir, apresentamos os resultados trimestrais referentes ao total de 53 modelos estimados. Para desenvolvimento de um critério comparativo entre os modelos em diferentes frequências, comparamos os resultados médios do conjunto de modelos estimados com a matriz de covariâncias amostrais que possui um $R_{\text {oos }}^{2}$ de aproximadamente $42 \%$, enquanto 
as matrizes de covariâncias de longo prazo de Andrews (1991) e Kiefer e Vogelsang (2005), respectivamente, apresentam um $R_{\text {oos }}^{2}$ de $43 \%$ e $60 \%$. Realizando o agrupamento dos modelos em relação a métodos de penalização no VAR, métodos de pré-seleção anteriormente ao PCA, métodos de SPCA, FAVAR, métodos Bayesianos e métodos de PLS, encontramos respectivamente os seguintes percentuais para $R_{\text {oos }}^{2}: 46,1 \%, 29,9 \%$, $37,3 \%, 51,2 \%, 14,2 \%$ e $38,15 \%$. Assim, para os modelos preditivos mensais, notamos que a matriz de covariâncias de Kiefer e Vogelsang (2005) e métodos de pré-seleção anteriormente ao PCA produzem um maior $R_{o o s}^{2}$, resultado diferente ao encontrado para os modelos mensais e diários. Com objetivo de tornar mais clara a análise, iremos apresentar apenas os quatro modelos com maior $R_{\text {oos }}^{2}$. Na tabela 6 podemos observar os principais resultados:

Tabela 6 - Resultados dos modelos trimestrais.

\begin{tabular}{|c|c|c|c|c|c|}
\hline Modelo: & $\begin{array}{l}\text { Número de Fatores } \\
\text { Bai e Ng (2002) }\end{array}$ & $\begin{array}{c}\text { Número de variáveis não zero } \\
\text { Kristensen }(2017)\end{array}$ & \% da Variação Explicada & $\begin{array}{l}R^{2} \text { Ajustado } \\
\text { Médio }\end{array}$ & $R_{o o s}^{2}$ em $T_{f}$ \\
\hline S-FAVAR-L-A & 2 & - & 0.97 & 0.71 & 0.67 \\
\hline MS-SPCA-A & 5 & 25 & 0.99 & 0.65 & 0.54 \\
\hline MS-SPCA-BC-KV & 1 & 6 & 0.96 & 0.64 & 0.54 \\
\hline S-FAVAR-R-A & 2 & - & 0.98 & 0.60 & 0.47 \\
\hline VAR-SL (1) & - & - & - & 0.53 & 0.43 \\
\hline
\end{tabular}

Fonte: Elaborada pelos autores.

As diferenças em relação aos modelos diários e mensais é um fator que corrobora com o objetivo da pesquisa de desenvolvimento de um modelo diferente para cada um dos ativos e das frequências estimadas. A capacidade preditiva dos modelos se mostrou superior aos resultados encontrados mensais. Tal capacidade pode ser explicada pelas variáveis incluídas nos modelos. Para os dados trimestrais, consideramos uma maior abrangência da base de dados, devido a uma base mais completa e com melhor mensuração de informações. Outro ponto no qual merece destaque advém de uma menor presença de ruído nas variáveis e maior interligação com variáveis de fundamento. Para os dados trimestrais, foram adicionadas variáveis de demonstração de resultados dos ativos analisados. Uma análise a ser destacada na pesquisa se refere aos efeitos marginais de cada variável sobre à capacidade preditiva dos modelos mensais. A Figura 5 relata o grau de importância das 5 principais características do retorno de cada ativo utilizando a base completa trimestral.

Em relação à figura 5, observamos que a estrutura em relação aos efeitos marginais sofreram modificações quando comparadas à frequência diária e mensal para análise dos 
Figura 5 - Análise Trimestral de Efeitos Marginais Por Ativo.

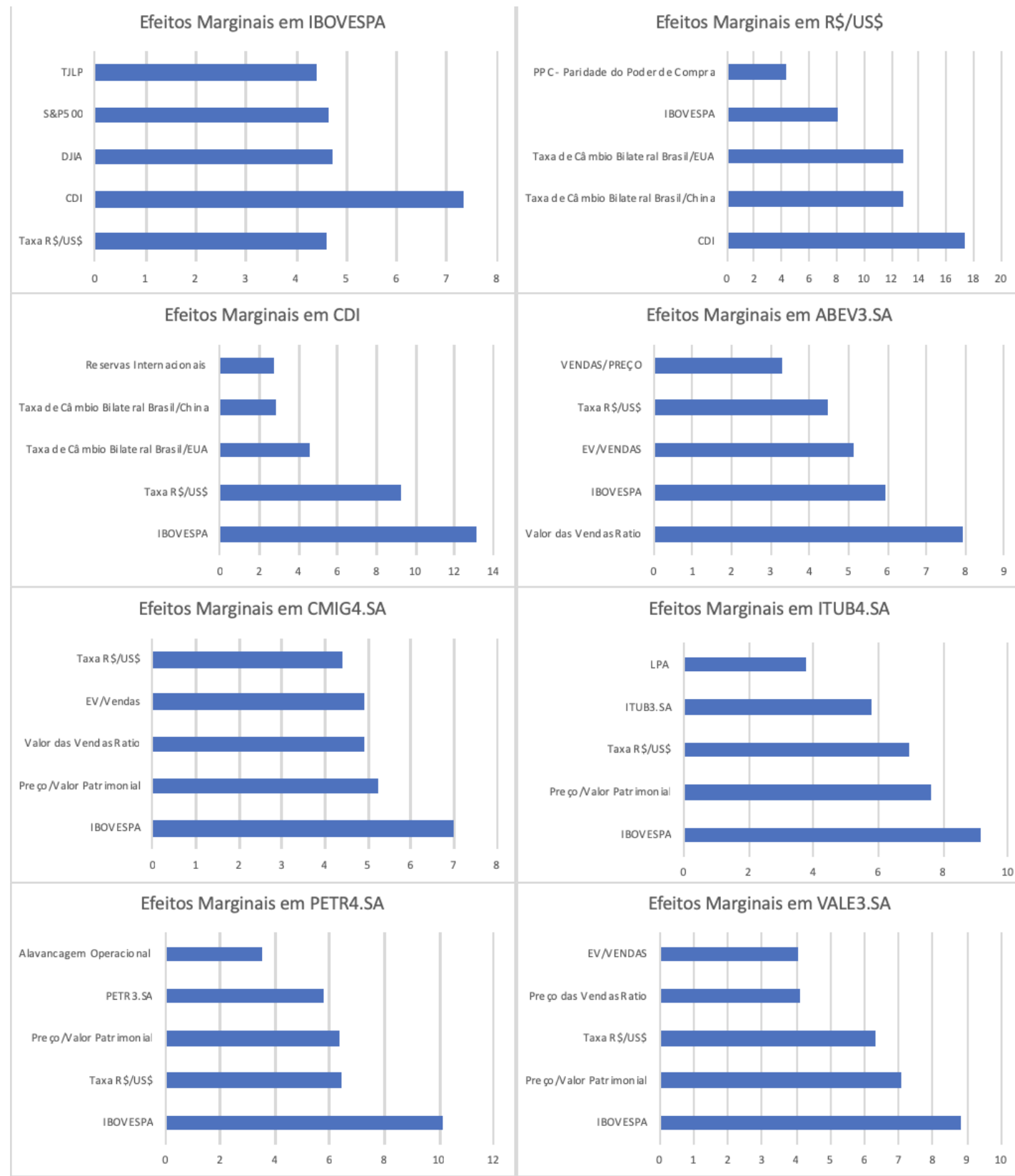

Fonte: Elaborada pelos autores.

ativos individuais, onde ressaltamos maior efeito marginal de variáveis de resultado e caráter de precificação utilizadas pelo mercado financeiro. Em relação à variável Índice IBOVESPA, notamos um grande efeito de variáveis de Índices externos como: S\&P500 e Índice Industrial Dow Jones, sendo tal fator extremamente esperado dado o grau de conectividade e dependência dos mercados. Ainda quanto ao IBOVESPA, uma associação importante e amplamente explorada no mercado e na literatura é o efeito marginal da taxa de câmbio Real/Dólar, CDI e taxa de juros de longo prazo (TJLP). Em relação a 
taxa de câmbio Real/Dólar mencionamos o efeito das taxas de câmbio reais e bilaterais em relação aos principais parceiros comerciais e em relação a uma medida de paridade do poder de compra. Contudo o maior efeito marginal é realizado pelo IBOVESPA e CDI. Em relação ao CDI, conferimos destaque as taxas de câmbio reais e bilaterais em relação aos principais parceiros comerciais, IBOVESPA, taxa de câmbio Real/Dólar e as reservas internacionais. Em relação as ações, notamos que as variáveis Índice IBOVESPA e taxa de câmbio Real/Dólar contém grande efeito marginal, tal efeito não foi observado anteriormente quando analisamos o conjunto de dados diário e mensal, mas já era esperado nas demais frequências.

Como última frequência estudada na dissertação, apresentamos os resultados dos 53 modelos desenvolvidos para a frequência anual. Utilizando do mesmo critério comparativo entre os modelos em diferentes frequências, comparamos os resultados médios do conjunto de modelos estimados com a matriz de covariâncias amostrais que possui um $R_{\text {oos }}^{2}$ de aproximadamente $13 \%$, enquanto as matrizes de covariâncias de longo prazo de Andrews (1991) e Kiefer e Vogelsang (2005), respectivamente, apresentam um $R_{\text {oos }}^{2}$ de $19 \%$ e $14 \%$. Realizando o agrupamento dos modelos em relação a métodos de penalização no VAR, métodos de pré-seleção anteriormente ao PCA, métodos de SPCA, FAVAR, métodos Bayesianos e métodos de PLS, encontramos, respectivamente, os seguintes percentuais para $R_{\text {oos }}^{2}: 13,5 \%, 11,2 \%, 13,1 \%, 15,3 \%, 13,2 \%$ e $9,76 \%$. Desta forma, para os modelos preditivos mensais, notamos que a matriz de covariâncias de Andrews (1991) e métodos de pré-seleção anteriormente ao PCA produzem um maior $R_{\text {oos }}^{2}$, resultado similar ao encontrado para os modelos mensais e diários. Com objetivo de tornar mais clara a análise, apresentamos apenas os quatro modelos com maior $R_{o o s}^{2}$. Na tabela 7 podemos observar os principais resultados: 
Tabela 7 - Resultados dos modelos anuais.

\begin{tabular}{|c|c|c|c|c|c|}
\hline Modelo: & $\begin{array}{l}\text { Número de Fatores } \\
\text { Bai e } \mathrm{Ng}(2002)\end{array}$ & $\begin{array}{l}\text { Número de variáveis não zero } \\
\text { Kristensen }(2017)\end{array}$ & \% da Variação Explicada & $\begin{array}{l}R^{2} \text { Ajustado } \\
\text { Médio }\end{array}$ & $R_{o o s}^{2}$ em $T_{f}$ \\
\hline VAR-SHL & - & - & - & 0.36 & 0.19 \\
\hline FAVAR-BC-A & 3 & - & 0.81 & 0.31 & 0.18 \\
\hline MS-SPCA-A & 5 & 14 & 0.93 & 0.21 & 0.17 \\
\hline
\end{tabular}

Fonte: Elaborada pelos autores.

Como podemos notar, os resultados encontrados pelos modelos anuais possuem baixo poder preditivo, como observamos um $R_{\text {oos }}^{2}$ baixo em relação aos modelos anteriores. Tal valor ainda foi inflado devido a um ambiente previsível pequeno $T_{f}=2$. Contudo, ainda podemos notar ainda que os modelos seguiram padrões até então encontrados em relação ao conjunto de preditores e matrizes de covariâncias. Em relação aos efeitos marginais, tal análise não se mostrou válida devido ao pequeno tamanho de amostra de previsão e ao pequeno efeito marginal de cada variável dentro do modelo, onde muitas vezes o maior efeito marginal é gerado pela própria variável defasada.

Por conseguinte, enceramos a apresentação dos modelos estimados, resultados e efeitos marginais. No total apresentamos resultados de 212 modelos e 630 séries de tempo. Desse capítulo podemos levar alguns resultados:

(I). Os métodos de estimação das matrizes de covariâncias de longo prazo de Andrews (1991) e Kiefer e Vogelsang (2005) apresentam resultados superiores a matriz de covariâncias amostral, considerando a capacidade preditiva como também em relação ao critério informacional mínimo. Em três frequências a matriz de covariâncias de Andrews (1991) apresentou resultados superiores as demais, e apenas na frequência trimestral a matriz de Kiefer e Vogelsang (2005) se mostrou superior na capacidade preditiva. Tal resultado foi uma das principais contribuições da dissertação para literatura de previsões e modelos de Machine Learning Lineares.

(II). A transformação na matriz de covariâncias em conjunto com a condição de não arbitragem para previsão proposta na pesquisa atuou na redução do ruído informacional (Martingale imprevisível), presente nas séries de retornos de ativos. Tal extensão à literatura de finanças empírica significa uma adequação dos modelos de previsão a um fato crucial na teoria de finanças teórica. 
(III). Os modelos propostos como extensões possuem resultados muitas vezes superiores aos modelos já estudados na literatura, mas tais resultados não se mostraram consistentes ao longo do tempo para um determinado modelo em específico. Se aumentarmos a comparação dos modelos para uma análise por classe de modelos, como divididos a seguir (métodos de penalização no VAR, métodos de pré-seleção anteriormente ao PCA, métodos de SPCA, FAVAR, métodos Bayesianos e métodos de PLS), encontramos que, nas quatro frequências na média dos modelos, os melhores resultados foram observados em modelos com métodos de pré-seleção anteriormente ao PCA. Tais métodos aplicados a finanças podem ser vistos como uma extensão de propriedade da pesquisa.

(IV). A capacidade preditiva dos modelos desenvolvidos na pesquisa, quando comparada às demais pesquisas contemporâneas existentes, apresentaram resultados similares ou superiores. No entanto, ressaltamos que está é a única pesquisa de aplicação de precificação de ativos via métodos lineares e paramétricos de Machine Learning focada em previsão para o mercado brasileiro.

(V). O diferencial da pesquisa em desenvolver um fator de desconto estocástico específico para cada ativo analisado, além de gerar resultados superiores aos modelos que consideraram um único fator de desconto estocástico para todos ativos, ainda atuou no caminho para o desenvolvimento de uma taxa interna de retorno dinâmica para cada ativo analisado. Tal modificação foi considerada pelos autores o principal componente da pesquisa, pois o acréscimo de capacidade preditiva avaliando pelo $R_{\text {oos }}^{2}$ chega a ser superior a $50 \%$.

Nas próximas duas seções realizamos aplicações das previsões estimadas nesse capítulo com objetivo de mostrar a capacidade preditiva e capacidade de desenvolvimento de estratégias com resultados persistentes ao longo do tempo. No capítulo 4 desenvolvemos uma metodologia inovadora na literatura de estruturas a termo para o retorno em excesso esperado para um conjunto de ativos e para o ativo livre de risco (CDI). No capitulo 5 utilizamos do arcabouço teórico apresentado no capítulo 2 sobre alocação de carteiras (modificamos o modelo de Black-Litterman na seção 2.7) para utilização de nossas previsões como prioris e posteriores e comparamos a um conjunto de benchmark presentes no ambiente 
financeiro. 


\section{Aplicação:Desenvolvimento da Estrutura a}

\section{Termo do Retorno Esperado}

A estrutura a termo do retorno esperado representa graficamente a taxa de retorno de determinado ativo em diferentes períodos a frente, i.e, a previsão do retorno acumulado para o ativo em diferentes horizontes. Para o processo de desenvolvimento da estrutura a termo do retorno esperado, a metodologia embarcada possuiu como objetivo a simplicidade de métodos, visando uma maior abrangência em sua aplicação. Assim, inicialmente após a seleção dos modelos a serem utilizados através da metodologia $R_{o o s}^{2}$ dentro da amostra de validação, como destacado em cada uma das frequências na seção anterior, realizamos a estimação de 212 modelos, englobando o total da amostra disponível para etapa de estimação do modelo e incluindo dados até 31 de dezembro de 2015 com o objetivo de previsão até 31 de dezembro de 2017. Para facilitar a apresentação dos melhores modelos dentro da amostra de validação, propomos na tabela 8 um resumo dos modelos selecionados:

Tabela 8 - Resumo dos modelos selecionados.

\begin{tabular}{ccccc}
\hline Modelo: & Modelo Diário & Modelo Mensal & Modelo Trimestral & Modelo Anual \\
\hline Índice IBOVESPA & S-FAVAR-E & FAVAR-BG & FAVAR-BG-A & MS-SPCA-BE-A \\
Taxa de Câmbio Real/Dólar & S-FAVAR-E & FAVAR-BG-A & MS-SPCA-BE & MS-SPCA-KV \\
CDI & S-FAVAR-R-A & FAVAR-BG & MS-SPCA-A & CL \\
ABEV3.SA & MS-SPCA-BE & FAVAR-BC-KV & S-FAVAR-adaL-A & FAVAR-BC-KV \\
CMIG4.SA & S-FAVAR-R & S-FAVAR-L & S-FAVAR-E-A & MS-SPCA-BE-KV \\
ITUB4.SA & S-FAVAR-L & S-FAVAR-adaL-KV & OS-SPCA-KV & FAVAR-BG+BE-KV \\
PETR4.SA & FAVAR-BG & S-FAVAR-E & OS-SPCA-A & MS-SPCA-BC-A \\
VALE3.SA & FAVAR-BG & S-FAVAR-adaL-A & S-FAVAR-E-A & OS-SPCA-A \\
\hline
\end{tabular}

Fonte: Elaborada pelos autores.

Analisando os melhores modelos encontrados utilizando o critério de $R_{\text {oos }}^{2}$ dentro da amostra de validação, podemos notar que não existe um melhor modelo a frente dos demais. Porém, é possível considerarmos que modelos com a correção da matriz de covariâncias possuem uma melhor capacidade preditiva dada a amostra de validação. Com objetivo de apresentar de maneira simples e rápida a divisão da amostra realizada, e o horizonte de previsão selecionado para cada uma das frequências, apresentamos a próxima tabela: 
Tabela 9 - Horizonte de previsão.

\begin{tabular}{cccc}
\hline & Amostra de Estimação $T_{e}$ & Amostra de Validação $T_{v}$ & Amostra de Teste $T_{f}$ \\
\hline Modelo Diário & 864 & 248 & 15 \\
Modelo Mensal & 132 & 24 & 12 \\
Modelo Trimestral & 68 & 8 & 8 \\
Modelo Anual & 18 & 2 & 0 \\
\hline
\end{tabular}

Fonte: Elaborada pelos autores.

Seguindo para o objetivo da aplicação, consideramos as 15 primeiras previsões dos modelos diários, 12 primeiras previsões para dos modelos mensais e as 4 últimas previsões dos modelos trimestrais para o desenvolvimento da estrutura a termo dos retornos dos ativos propostos. A escolha de tamanho da amostra de teste, $T_{f}$, para cada frequência, decorre da observação dos resultados encontrados na seção de estimação dentro da amostra de validação $\left(T_{v}\right)$, onde analisamos para cada frequência de previsão qual obteve o menor RMSE de previsão, i.e, e analisamos também qual o horizonte de previsão $h$ que leva os modelos a apresentarem o menor RMSE. Tal método é utilizado devido a falta de alternativas para seleção de melhor horizonte de previsão $h$. Para cada frequência no tempo utilizamos o critério apresentado para encontrar o melhor $h$ em conjunto com os melhores modelos. Logo, para cada frequência de previsão encontramos o melhor modelo $j$ para $h$ passos a frente. Ressaltamos que o método adotado possui elevado custo computacional. Com carácter excepcional, notamos que a estimação da frequência temporal mensal foi superior a frequência trimestral para previsão do primeiro ano dentro da amostra de validação, assim, vamos apenas utilizar as previsões trimestrais de $t+5$ até $t+8$. Em relação aos modelos anuais, notamos que a capacidade preditiva dos modelos é deveras reduzida, de forma que não utilizamos seu conjunto informacional para o desenvolvimento das estruturas a termo.

Utilizando a estrutura de dados imposta anteriormente, temos um ambiente de previsão de 01 de janeiro de 2016 até 31 de dezembro de 2017, sendo esse nosso período previsto da estrutura a termo. Objetivando uma maior inclusão de informação dentro das estruturas a termo previstas, realizamos o processo de extrapolação de vértices da curva a termo, baseado em modelos de nível locais, como apresentado no capítulo 2, de 
forma a obter um total de 481 passos as frentes condicionadas em $t=31-12-2015$ para nossas estruturas a termo. É importante ressaltar que tal método não modifica a estrutura da curva, apenas tem o objetivo de facilitar a interpretação e fornece um melhor critério de análise para cada vértice presente na curva. Para facilitar a compreensão do modelo adotado, exemplificamos a aplicação para o Índice IBOVESPA: utilizando o modelo S-FAVAR-E para realizar a previsão diária dado os 15 passos a frente $(t+1)$ até $t+15)$. Para as previsões mensais utilizamos o modelo FAVAR-BG para os vértices: $t+21, t+42$, $t+63, t+84, t+105, t+126, t+147, t+168, t+189, t+210, t+232$ e $t+252$, para as previsões trimestrais utilizamos o modelo FAVAR-BG-A para os vértices $t+315, t+387$, $t+441$ e $t+482$. Os demais vértices existentes na estrutura a termo são preenchidos via modelo de nível local, estimado via filtro de Kalman. A seguir podemos observar os resultados encontrados para cada uma das estruturas a termo do retorno esperado para os ativos selecionado:

Figura 6 - Estrutura a termo do retorno esperado: Índice IBOVESPA.

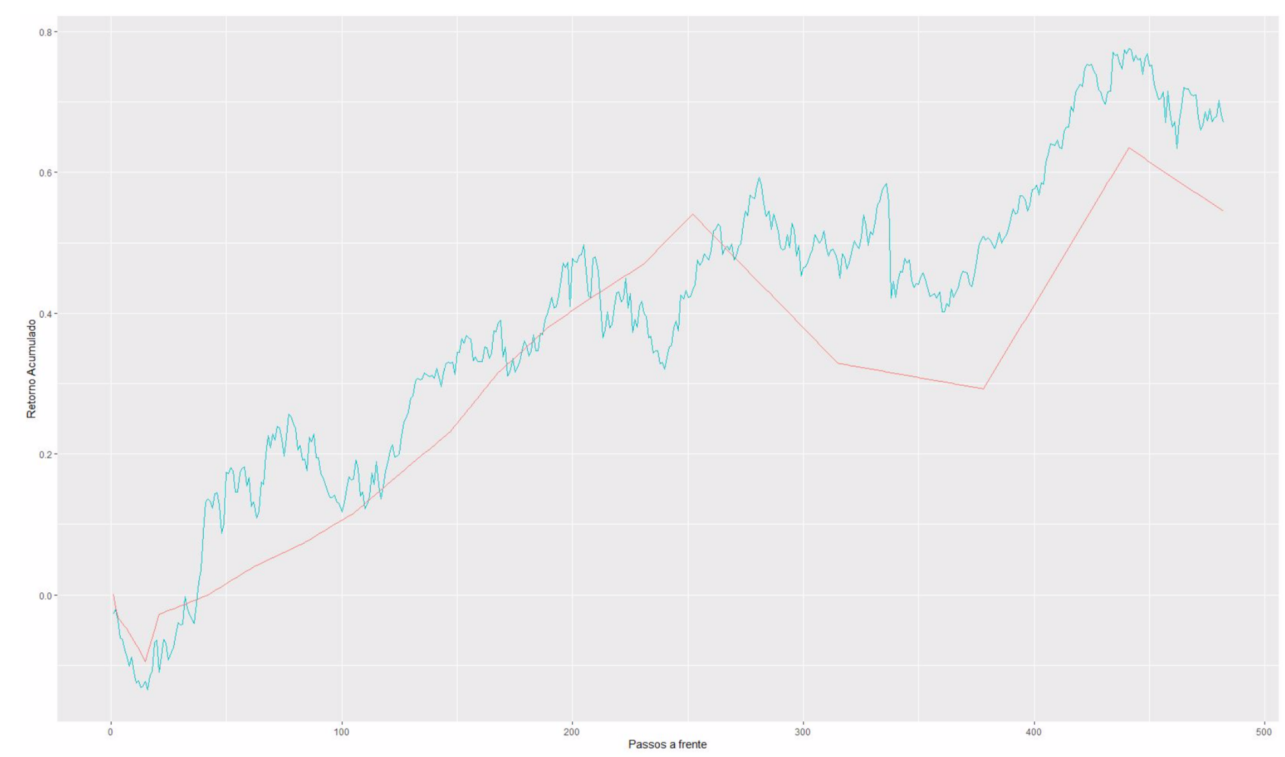

Fonte: Elaborada pelos autores e Economatica.

A linha azul apresenta o acumulado realizado pelo Índice IBOVESPA no período analisado e a linha em vermelho é a estrutura a termo do retorno esperado estimada na dissertação para o Índice IBOVESPA. 
Figura 7 - Estrutura a termo do retorno esperado: Taxa de Câmbio Real/Dólar.

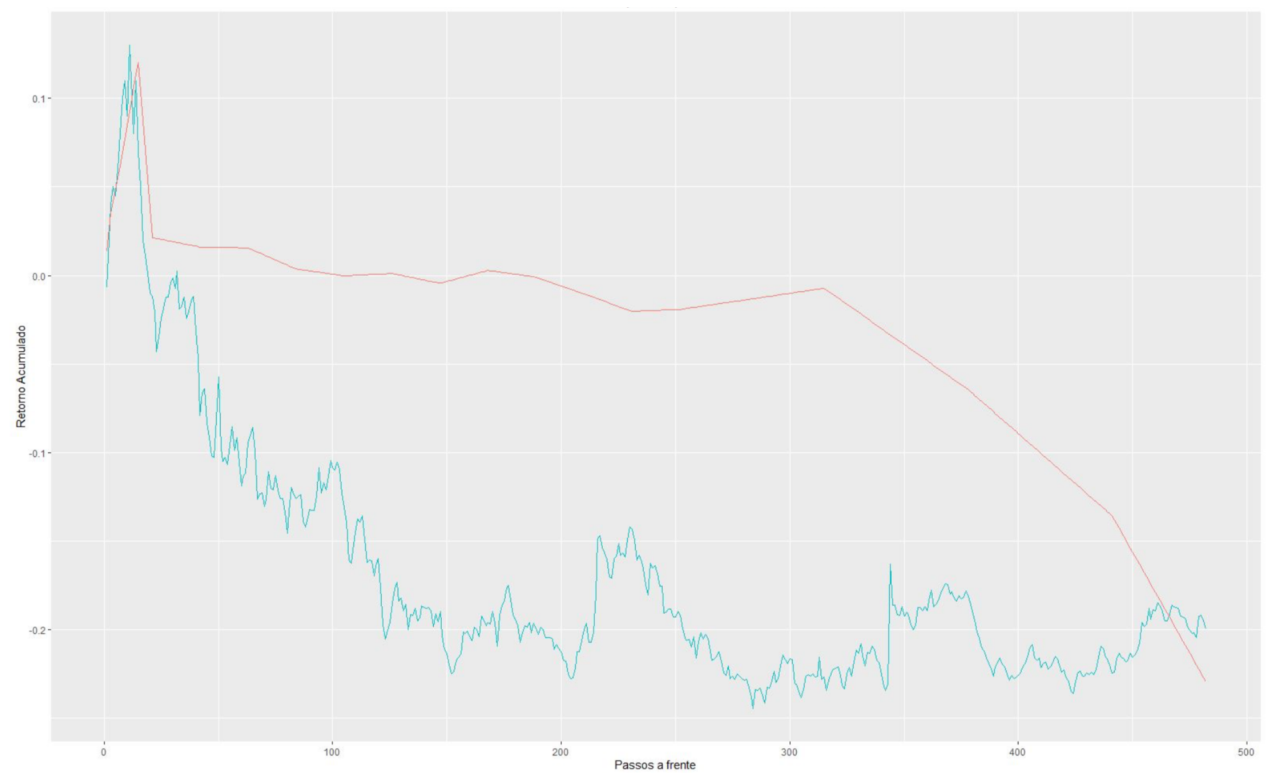

Fonte: Elaborada pelos autores e Economatica.

A linha azul apresenta o acumulado realizado pela Taxa de Câmbio Real/Dólar no período analisado e a linha em vermelho é a estrutura a termo do retorno esperado estimada na dissertação para a Taxa de Câmbio Real/Dólar.

Figura 8 - Estrutura a termo do retorno esperado: Taxa CDI.

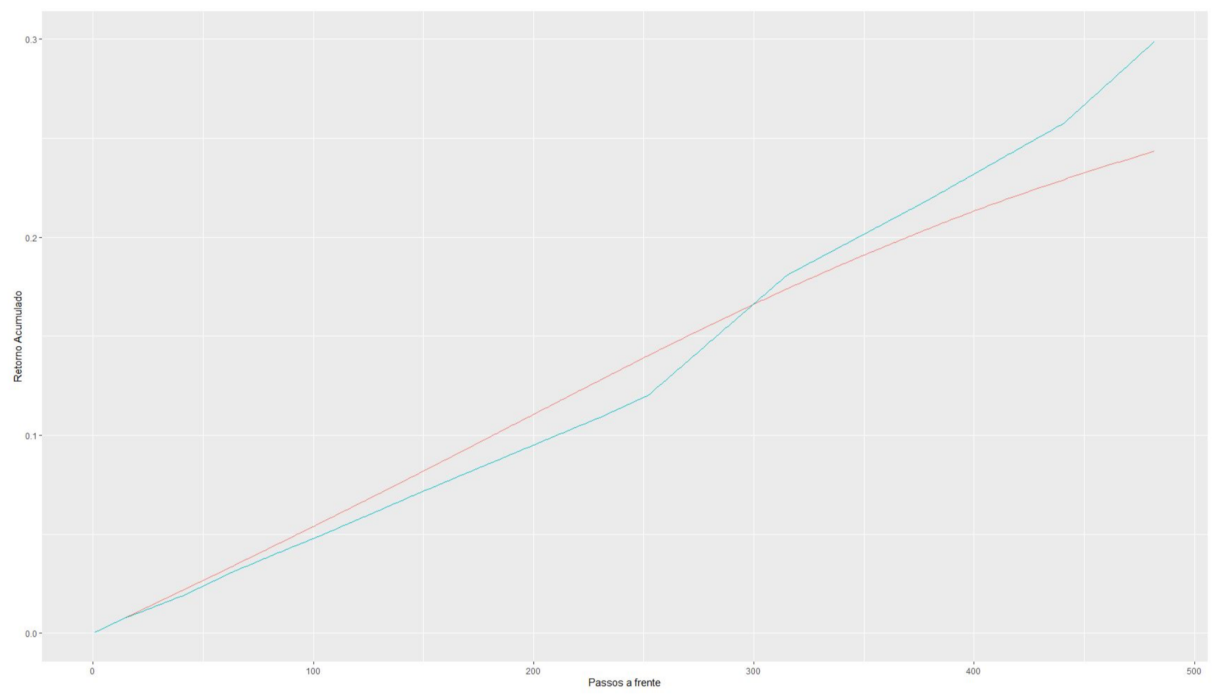

Fonte: Elaborada pelos autores e Economatica.

A linha azul apresenta o acumulado realizado pela Taxa CDI no período analisado e a linha em vermelho é a estrutura a termo do retorno esperado estimada na dissertação para a Taxa CDI. 
Figura 9 - Estrutura a termo do retorno esperado: ABEV3.SA.

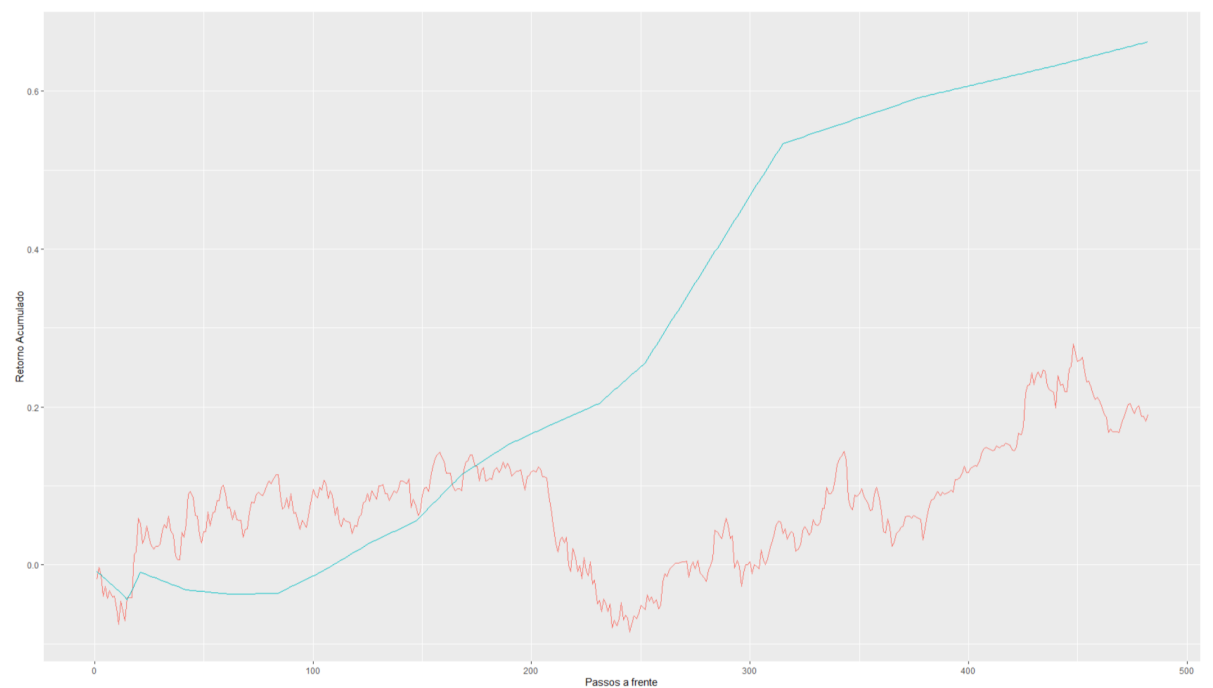

Fonte: Elaborada pelos autores e Economatica.

A linha azul apresenta o acumulado realizado pela ação ABEV3 no período analisado e a linha em vermelho é a estrutura a termo do retorno esperado estimada na dissertação para a ação ABEV3.

Figura 10 - Estrutura a termo do retorno esperado: CMIG4.SA.

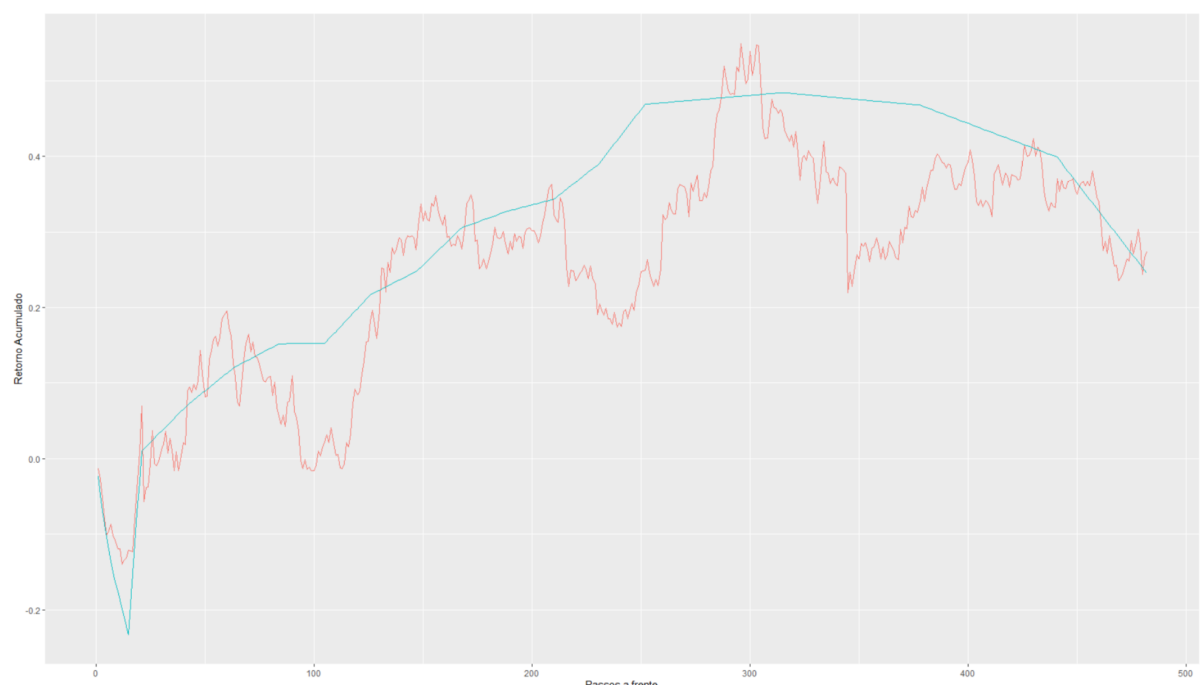

Fonte: Elaborada pelos autores e Economatica.

A linha azul apresenta o acumulado realizado pela ação CMIG4 no período analisado e a linha em vermelho é a estrutura a termo do retorno esperado estimada na dissertação para a ação CMIG4. 
Figura 11 - Estrutura a termo do retorno esperado: ITUB4.SA.

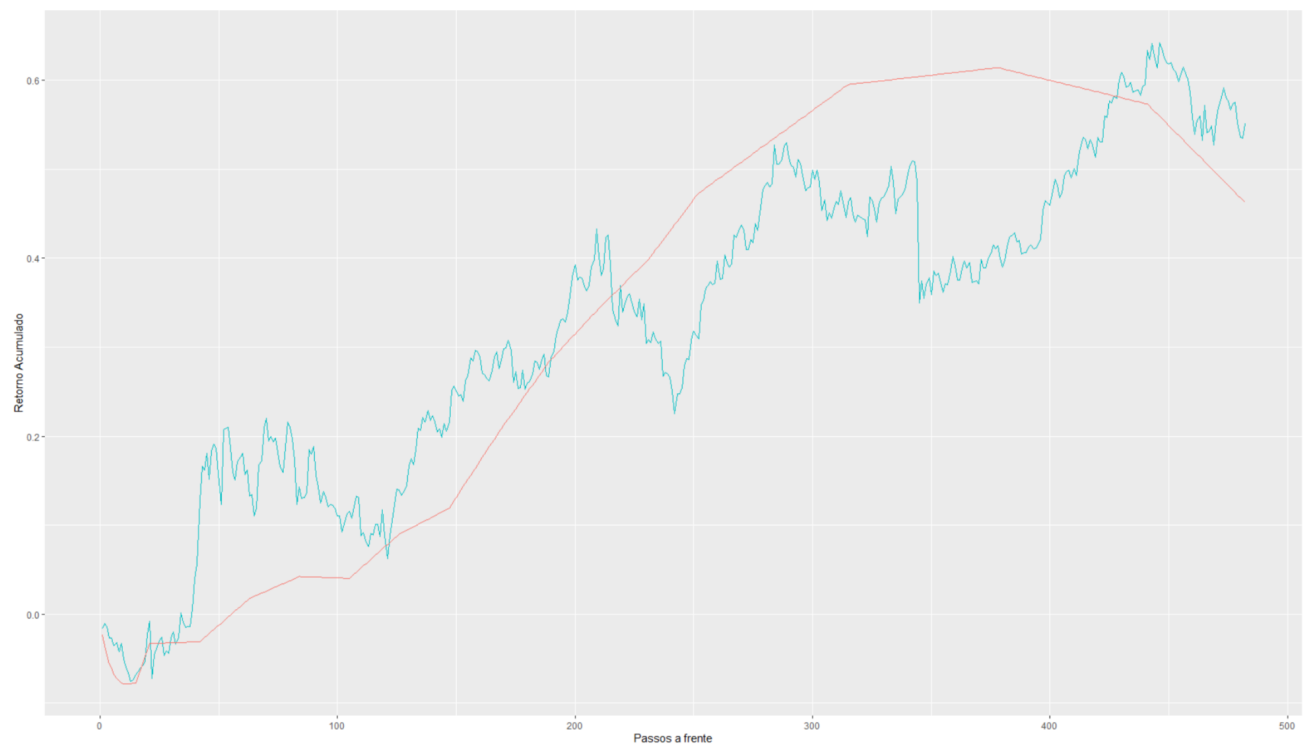

Fonte: Elaborada pelos autores e Economatica.

A linha azul apresenta o acumulado realizado pela ação ITUB4 no período analisado e a linha em vermelho é a estrutura a termo do retorno esperado estimada na dissertação para a ação ITUB4.

Figura 12 - Estrutura a termo do retorno esperado: PETR4.SA.

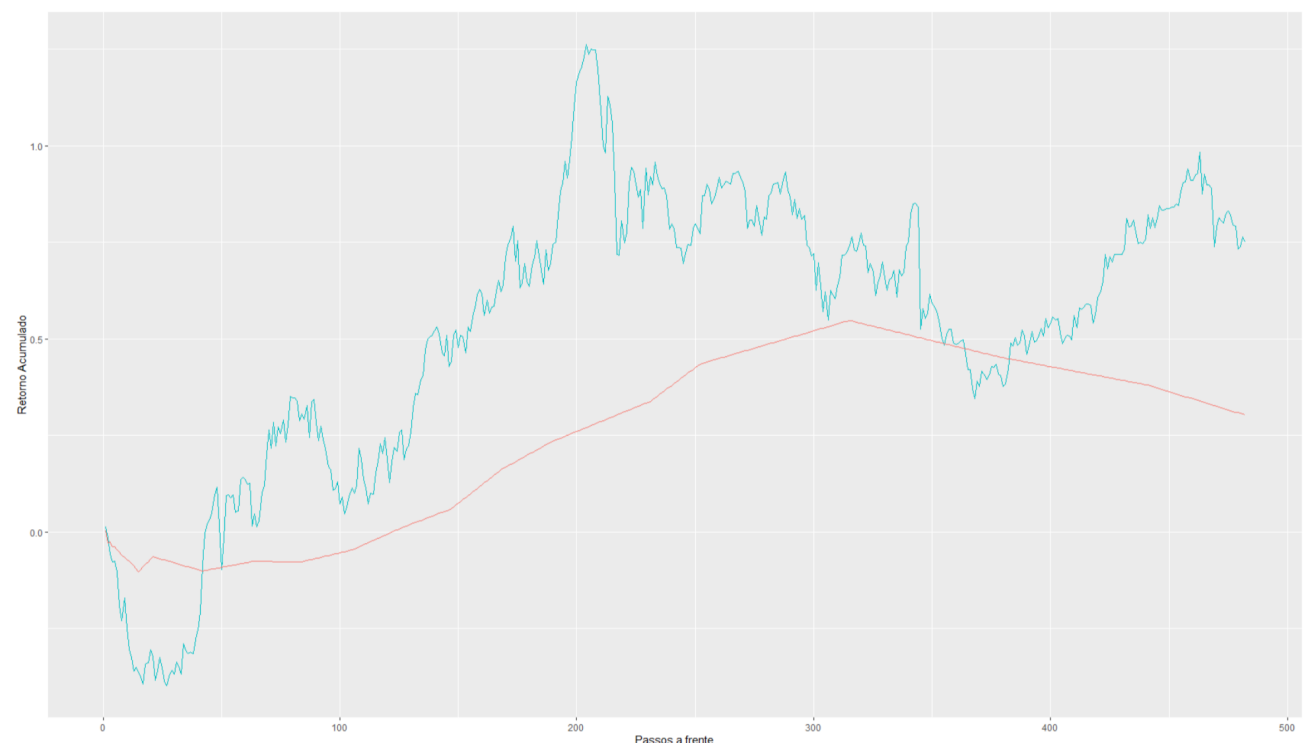

Fonte: Elaborada pelos autores e Economatica.

A linha azul apresenta o acumulado realizado pela ação PETR4 no período analisado e a linha em vermelho é a estrutura a termo do retorno esperado estimada na dissertação para a ação PETR4. 
Figura 13 - Estrutura a termo do retorno esperado: VALE3.SA.

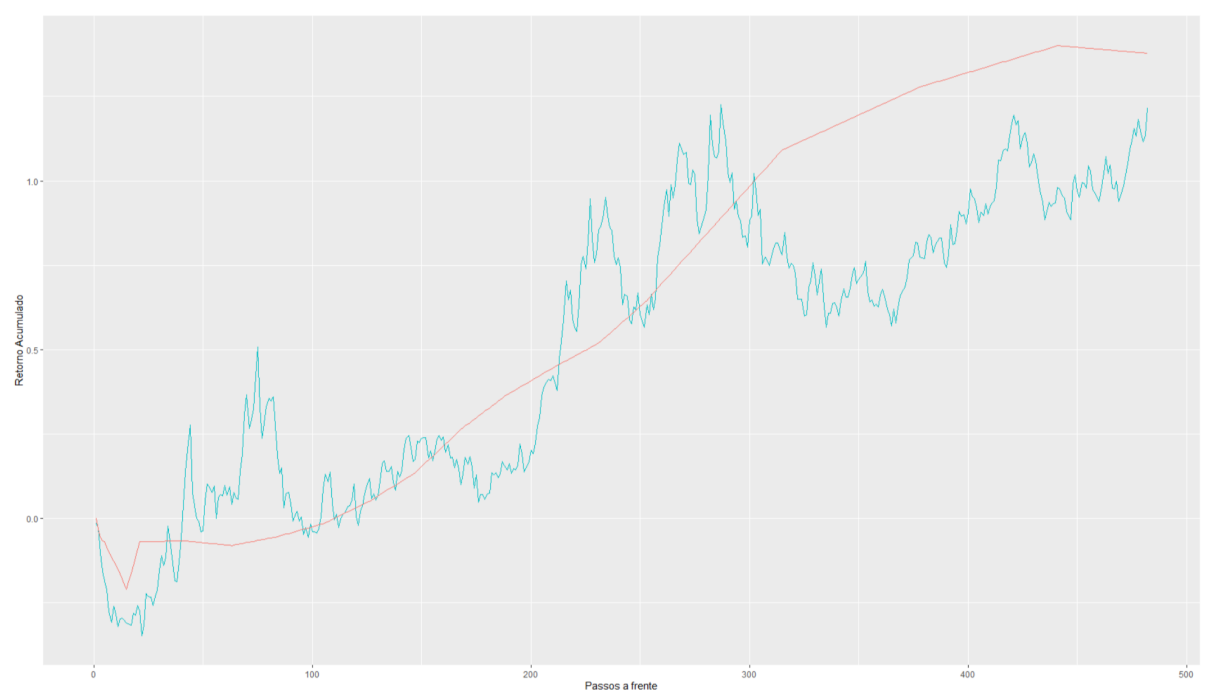

Fonte: Elaborada pelos autores e Economatica.

A linha azul apresenta o acumulado realizado pela ação VALE3 no período analisado e a linha em vermelho é a estrutura a termo do retorno esperado estimada na dissertação para a ação VALE3.

Observando os resultados encontrados via as figuras 6,8,9,10,11,12 e 13 podemos notar a elevada capacidade preditiva dos modelos selecionados. Contudo, devido ao não ajuste das previsões ao longo do tempo, previsão condicionada em $t=31-12-2015$, e grandes modificações nos fundamentos não foram capturadas pelos modelos preditivos. Essa característica comentada pode ser vista na previsão para a taxa de câmbio Real/Dólar (Figura 7), onde o erro de previsão continua persistente. A seguir apresentamos uma figura com os resultados encontrados para o $R_{\text {oos }}^{2}$ do retorno acumulado para os ativos analisados, ressaltando que os valores encontrados são superestimados devido à magnitude da utilização dos resultados acumulados para cada ativo. 
Figura 14 - Avaliação da Capacidade Preditiva Para o Retorno Acumulado por Ativo.

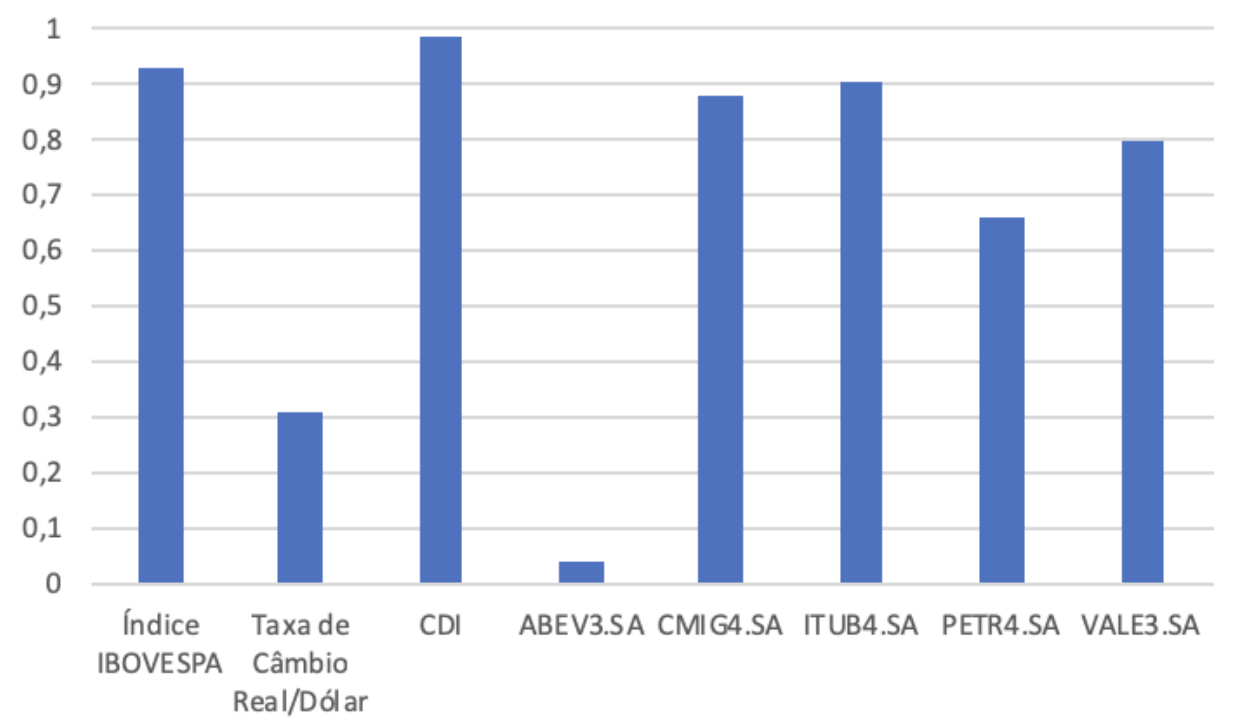

Legenda: $R_{\text {oos }}^{2}$ em Azul

Fonte: Elaborada pelos autores.

A figura 13 nos permitiu analisar a capacidade preditiva dos modelos selecionados e do modelo proposto para construção da estrutura a termo do retorno, para o grupo selecionado de ativos. Notamos que em muitos casos a estrutura desenvolvida não segue de fato o momentum dos retornos apresentados pelos ativos. A estrutura desenvolvida em alguns casos pode ser vista como uma tendência dos retornos esperados. Como resultado médio para $R_{\text {oos }}^{2}$ encontramos um total de $68,7 \%$, um percentual extremamente elevado quando comparado aos resultados encontrado na literatura (Fama e French (2008), Koijen e Nieuwerburgh (2011) e Rapach e Zhou (2013) , contudo novamente ressaltamos o problema com a métrica do $R_{o s}^{2}$. Uma análise realizada de forma adicional na pesquisa foi a construção de um nova série de dados feita através das diferenças encontradas entre as estruturas previstas e o retorno acumulado realizado. Em relação a esta nova série foram realizados testes para analisar se a mesma seria um ruído branco. Como resultados, encontramos que todas as séries construídas independentemente dos ativos analisado podem ser consideradas ruídos brancos, o teste utilizado foi de Nason e Savchev (2014), no qual testamos se a séries era um ruído branco utilizando wavelets.

Podemos notar um excelente caminho para exploração destes modelos na literatura, 
estes resultados serão melhores analisados em trabalhos posteriores pelos autores. 


\section{Aplicação: Alocação de Portfólios Via Ex-}

\section{tensão do Modelo Black e Litterman}

Retornando ao capítulo 2, em especial a seção 2.7, podemos relembrar da extensão proposta ao modelo de alocação de portfólio de Black e Litterman. Neste capítulo ressaltamos as principais variáveis de entrada para a construção do modelo proposto e os resultados encontrados. Com intuído de realizar uma breve revisão da extensão proposta, dividimos o conjunto informacional em dois grupos: priori e posterior.

Em relação à priori, a metodologia de Black e Litterman inclui as variáveis que propõem o equilíbrio de mercado ao longo do tempo para o retorno e para o relacionamento entre os ativos (matriz de covariâncias). Muitas metodologias são propostas na literatura, como utilização da média histórica, médias móveis, modelos CAPM, modelos FF, entre outros para a priori dos retornos. Em relação às modificações propostas para a matriz de covariâncias, as propostas existentes na literatura são extremamente abrangentes, por exemplo: utilização de matrizes de covariâncias de longo prazo, utilização de modelos para redução da dimensionalidade, modelos volatilidade estocástica, família ARCH e GARCH, entre outros. Contudo, não observamos nenhum modelo que obteve maior destaque ou resultados constantes de superioridade em relação aos demais, tanto para o retorno quanto para a matriz de covariâncias. Deste modo, a extensão proposta nesta pesquisa foi introduzir na literatura existente um novo modelo que permita através das previsões alcançadas com a pesquisa, extrair lucros extraordinários.

Como variável do retorno de equilibro do mercado no qual denominamos informação priori sobre o retorno, utilizamos a previsão mensal desagregada para retorno diário, $r_{i, t+1}^{\hat{M}}$. Para escolhermos qual previsão entre os 53 modelos propostos, consideramos o critério de selecionar o modelo preditivo que obteve o maior $R_{\text {oos }}^{2}$ analisando as 6 previsões anteriores a previsão de $R_{i, t+1}^{\hat{M}}$, i.e, utilizamos como amostra de validação os 6 últimos meses previstos de cada modelo. É extremamente importante ressaltar que todas as previsões analisas 
na amostra de validação e para $r_{i, t+1}^{\hat{M}}$ foram sempre condicionadas em $t$, assim sempre utilizamos dos dados com uma defasagem temporal em nossos modelos de previsão. O racional por trás da utilização da previsão de retorno desagregada mensal como variável priori, para o retorno de equilíbrio, atua em conjunto com a hipótese de que o retorno de um ativo é composto por dois fatores: o fator de desconto estocástico e um ruído informacional (não previsível). Utilizando do retorno desagregado mensal, buscamos uma alternativa, de equilíbrio para a previsão do retorno diário contaminado com ruído informacional. Adiante, explicamos como a posteriori adotada também atua na tentativa de redução do ruído informacional.

Como matriz de covariâncias, introduzimos como priori para nossa extensão de modelo de alocação de portfólio um conjunto de possibilidades, sendo essas: matriz de covariâncias amostral (CA), matriz de covariâncias de longo prazo de Andrews (1991) (A), matriz de covariâncias de longo prazo de Kiefer e Vogelsang (2005) (KV) e matriz de covariâncias estimadas via modelo fatorial de volatilidade estocástica baseado no artigo de Trucíos, Hotta e Pereira (2019) (FVE) . Desta forma, desenvolvemos para cada formato de matriz de covariâncias um resultado final do nosso modelo. Deixar tal critério amplo advém da tentativa de tentar capturar diferentes formulações e resultados para a pesquisa. Ainda em relação às priores do modelo proposto foi necessário a inclusão da variável de confiança (certeza) sobre os dados adicionados. Observando a literatura existente, utilizamos como variável de certeza o inverso do erro quadrático médio (RMSE) do modelo selecionado para a previsão do retorno de equilibro do mercado no período dos 6 últimos meses previstos pelo modelo.

Em relação a posteriori (visão do analista), aqui expressa pela matriz $I$, não consideramos o relacionamento entre os ativos analisados, apenas introduzimos na matriz as informações sobre a previsão do retorno esperado para $t+1, r_{i, \hat{t}+1}$, acrescendo a informação da certeza em relação a previsão utilizada. Mantendo a mesma metodologia utilizada para o desenvolvimento da priori, para a posteriori utilizamos a previsão do retorno diário desenvolvida pelo melhor modelo diário escolhido, ou seja, o maior $R_{\text {oos }}^{2}$ nas 21 previsões anteriormente estimadas. A posteriori em nossos modelos tem como objetivo introduzir 
uma informação adicional sobre a previsão diária considerando o amplo ruído informacional existente, i.e, uma possível correção as distorções sobre a informação da variável posterior. Podemos notar que todas variáveis utilizadas nessa extensão do modelo BL foram retiradas do conjunto informacional, gerados pelas previsões desenvolvidas na pesquisa que forneceu um arcabouço informacional completo. Com intuito de levar mais informações aos leitores, a seguir apresentamos as médias da confiança em relação as priores e posteriores por ativo analisado.

Tabela 10 - Médias da confiança em relação as priores e posteriores por ativo analisado.

\begin{tabular}{ccc}
\hline Variável & $\tau$ da Priori (Previsão Mensal) & $\tau$ da Posteriori (Previsão Diária) \\
\hline Índice IBOVESPA & $48,73 \%$ & $34,77 \%$ \\
Taxa de Câmbio Real/Dólar & $56,47 \%$ & $36,38 \%$ \\
CDI & $100,00 \% *$ & $100,00 \%^{*}$ \\
ABEV3.SA & $56,70 \%$ & $66,69 \%$ \\
CMIG4.SA & $32,20 \%$ & $25,13 \%$ \\
ITUB4.SA & $49,77 \%$ & $32,84 \%$ \\
PETR4.SA & $47,31 \%$ & $22,58 \%$ \\
VALE3.SA & $39,44 \%$ & $20,25 \%$ \\
\hline
\end{tabular}

Fonte: Elaborada pelos autores.

* indica que o nível de confiança encontrado foi superior a $100 \%$, desta forma para manter a racionalidade do modelo travamos o valor máximo em $100 \%$.

Em relação às carteiras desenvolvidas, dividimos a apresentação em dois grupos, o primeiro grupo foi formado por carteiras compostas apenas pelas ações presentes na pesquisa (ABEV3.SA, CMIG4.SA, ITUB4.SA, PETR4.SA e VALE3.SA). A única estratégia adotada foi a compra (Long-Only), e a carteira possui rebalanceamento diário, i.e, compramos o ativo na abertura e vendemos no fechamento do mesmo dia. Dada a caraterística anterior o custo de transação existente considerando custo de negociação e liquidação é de 0,024105\% por operação. Assim, a cada dia foi introduzida um nova informação posteriori $\left(r_{i, \hat{t}+1}\right)$ e a cada mês foi introduzida um nova priori $\left(r_{i, t+1}^{\hat{M}}\right)$, como também as informações referentes ao grau de certeza foram atualizadas na mesma frequência. Em relação este conjunto de ativos, comparamos os resultados com três benchmark, o primeiro foi em relação ao Índice IBOVESPA (Índice IBOVESPA), o segundo foi um índice construído através da média simples entre os ativos (20\% em ABEV3.SA, 20\% em CMIG4.SA, 20\% em ITUB4.SA, 20\% em PETR4.SA e 20\% em VALE3.SA), CR-PL. O terceiro benchmark foi um índice construído através da participação no Índice IBOVESPA de cada ativo 
(no total a soma da participação dos ativos no Índice IBOVESPA em 02/01/2016 foi de 34\%), CR-PI. Desta forma, os resultados apresentados a seguir são referentes ao conjunto de posições compradas com rebalanceamento diário no conjunto de ativos ABEV3.SA, CMIG4.SA, ITUB4.SA, PETR4.SA e VALE3.SA (doravante denominada carteira reduzida (CR)), de 02/01/2016 até 31/12/2017 (total de 482 dias de negociação).

Figura 15 - Retorno Acumulado Carteiras Reduzidas.

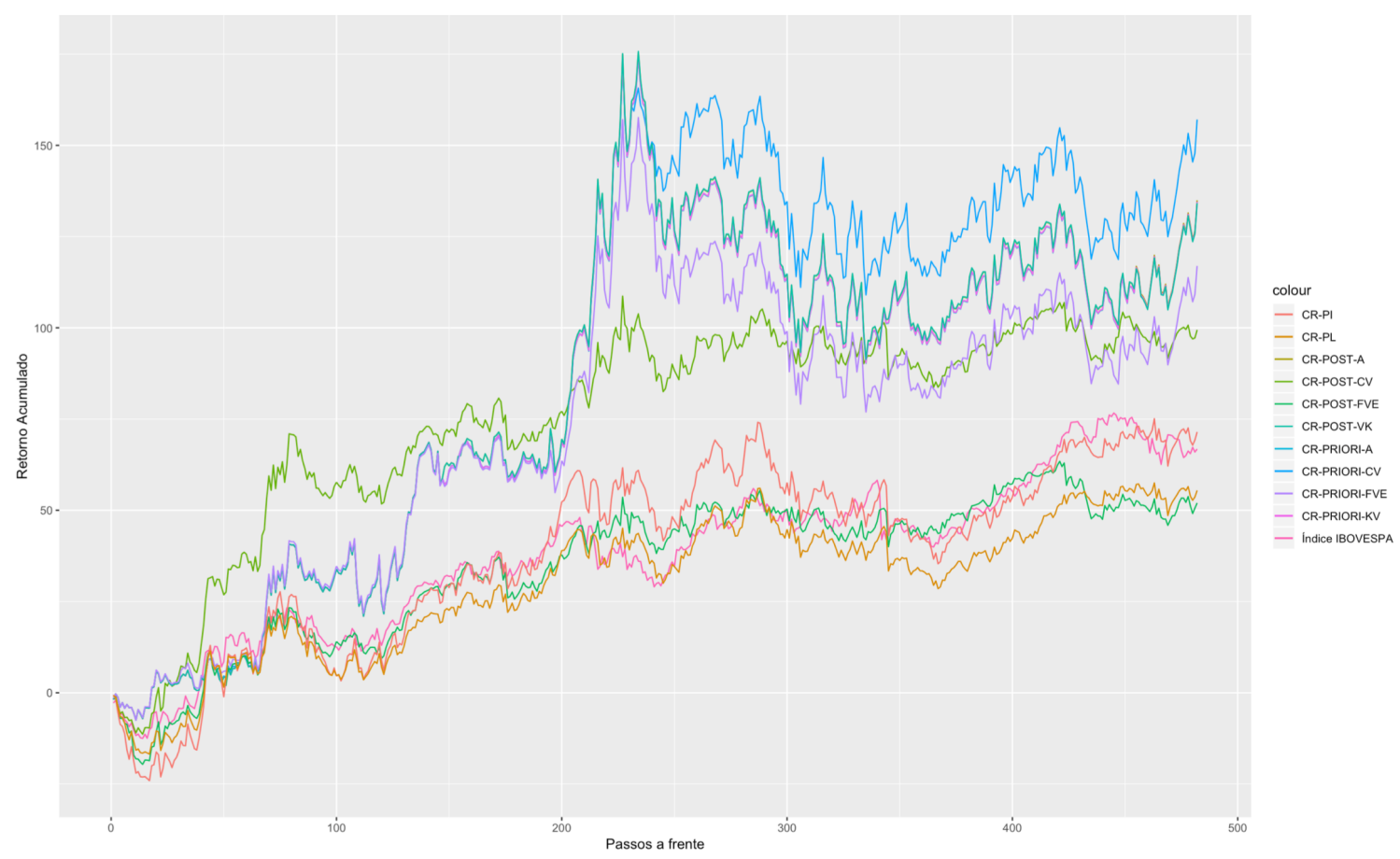

Fonte: Elaborada pelos autores e Economatica.

Onde CR-PRIORI-CV foi a carteira reduzida estimada utilizando apenas da informação da priori com matriz de covariâncias amostral. CR-POST-CV, foi a carteira reduzida estimada utilizando a combinação via BL da informação da priori e da posteriori com matriz de covariâncias amostral. As demais carteiras reduzidas desenvolvidas modificam a estimação da matriz de covariâncias, sendo CR-PRIORI-A e CR-POST-A para a matriz de covariâncias de longo prazo de Andrews (1991), e CR-PRIORI-KV e CR-POST-KV para a matriz de covariâncias de longo prazo de Kiefer e Vogelsang (2005) e CR-PRIORI-FVE e CR-POST-FVE para a matriz de covariâncias via modelo fatorial de volatilidade estocástica. Como podemos notar, entre os oito modelos propostos e desenvolvidos na dissertação apenas um CR-POST-KV não apresentou um resultado superior aos benchmarks utilizados como critério comparativo na pesquisa. A seguir apresentamos a tabela 11 que compara os 
principais resultados encontrados no conjunto de modelos.

Tabela 11 - Principais resultados encontrados.

\begin{tabular}{ccccc}
\hline Modelos de Carteira Reduzida & Índice Sharpe & Retorno Médio Mensal & Desvio Padrão Mensal & Retorno Acumulado \\
\hline CR-PRIORI-CV & 1,3096 & $4,01 \%$ & 0,1076 & $157,07 \%$ \\
CR-POST-CV & 1,1427 & $2,91 \%$ & 0,07501 & $99,41 \%$ \\
CR-PRIORI-A & 1,0936 & $3,61 \%$ & 0,1099 & $134,61 \%$ \\
CR-POST-A & 1,0950 & $3,62 \%$ & 0,1100 & $134,93 \%$ \\
CR-PRIORI-KV & 1,0931 & $3,61 \%$ & 0,1099 & $134,53 \%$ \\
CR-POST-KV & 1,0891 & $3,60 \%$ & 0,1100 & $134,18 \%$ \\
CR-PRIORI-FVE & 0,9537 & $3,27 \%$ & 0,1082 & $52,05 \%$ \\
CR-POST-KV & 0,4749 & $1,76 \%$ & 0,0715 & $71,46 \%$ \\
CR-PI & 0,5773 & $2,27 \%$ & 0,0971 & $55,44 \%$ \\
CR-PL & 0,5170 & $1,85 \%$ & 0,0734 & $66,76 \%$ \\
\hline
\end{tabular}

Fonte: Elaborada pelos autores.

Analisando os resultados anteriores, notamos o elevado potencial presente nos modelos desenvolvidos na pesquisa, mesmo considerando a presença de uma carteira reduzida formada por apenas cinco ativos. Comparando os resultados encontrados, observamos que o melhor resultado encontrado foi atingido pelo CR-PRIORI-CV, onde o retorno acumulado no período foi de 157,07\% com um índice Sharpe de 1,3096. Um ponto importante a ser ressaltado advém do resultado encontrado, onde as carteiras nas quais apenas utilizamos a priori apresentaram um resultado em todos os casos superiores as carteiras com a mesclas entre informações priori e posterior. Tal resultado foi ao encontro diretamente com a proposta da dissertação de utilizar uma informação que esteja exposta a um menor ruído informacional. Desta forma, a informação que obteve resultado superior foi a utilização da previsão mensal desagregada para retorno diário, $r_{i, t+1}^{\hat{M}}$, em relação a previsão do retorno esperado para $t+1, r_{i, \hat{t}+1}$. Um destaque adicional encontrado na pesquisa ocorre quando utilizamos as matrizes de covariâncias de longo prazo de Andrews (1991) e Kiefer e Vogelsang (2005), podemos notar que os resultados utilizando tanto informações da priori quando da priori em conjunto com a posterior apresentaram resultados extremamente semelhantes. Esse resultado, demostra que as matrizes de longo prazo atuam na redução do ruído informacional realizando uma uniformização entre os conjuntos informacionais.

O segundo grupo foi formado por carteiras compostas pelas ações presentes na pesquisa (ABEV3.SA, CMIG4.SA, ITUB4.SA, PETR4.SA e VALE3.SA) e pelos ativos: Índice IBOVESPA, taxa de câmbio Real/Dólar e CDI. As estratégias adotadas foram as 
de compra (Long-Only) e carteiras Long-Short. As carteiras possuem rebalanceamento diário, i.e, compramos o ativo na abertura e vendemos no fechamento do mesmo dia, o mesmo processo foi realizado para de venda (operações Short). Dada a caraterística anterior o custo de transação existente considerando custo de negociação e liquidação é de 0,024105\% por operação. Em relação as variáveis utilizadas nos modelos de alocação de portfólio, as mesmas seguem exatamente os procedimentos adotados no primeiro grupo de carteiras propostas anteriormente. Em relação as estratégias de investimentos denominadas Long-Short seguimos a tradição no mercado de fundos Long-Short, com um total 100\% alocado em CDI, 30\% em na carteira Long e 30\% em na carteira Short. Lembramos que todo dia as posições tomadas foram encerradas no final do mesmo dia. Como critério comparativo utilizamos o Índice IBOVESPA. Uma outra escolha natural poderia ser a utilização de fundos consagrados de mercado. Contudo, não foi interesse da pesquisa tal comparação devido a possibilidade limitada de ativos negociados no modelo proposto.

Figura 16 - Retorno Acumulado Carteiras Completas

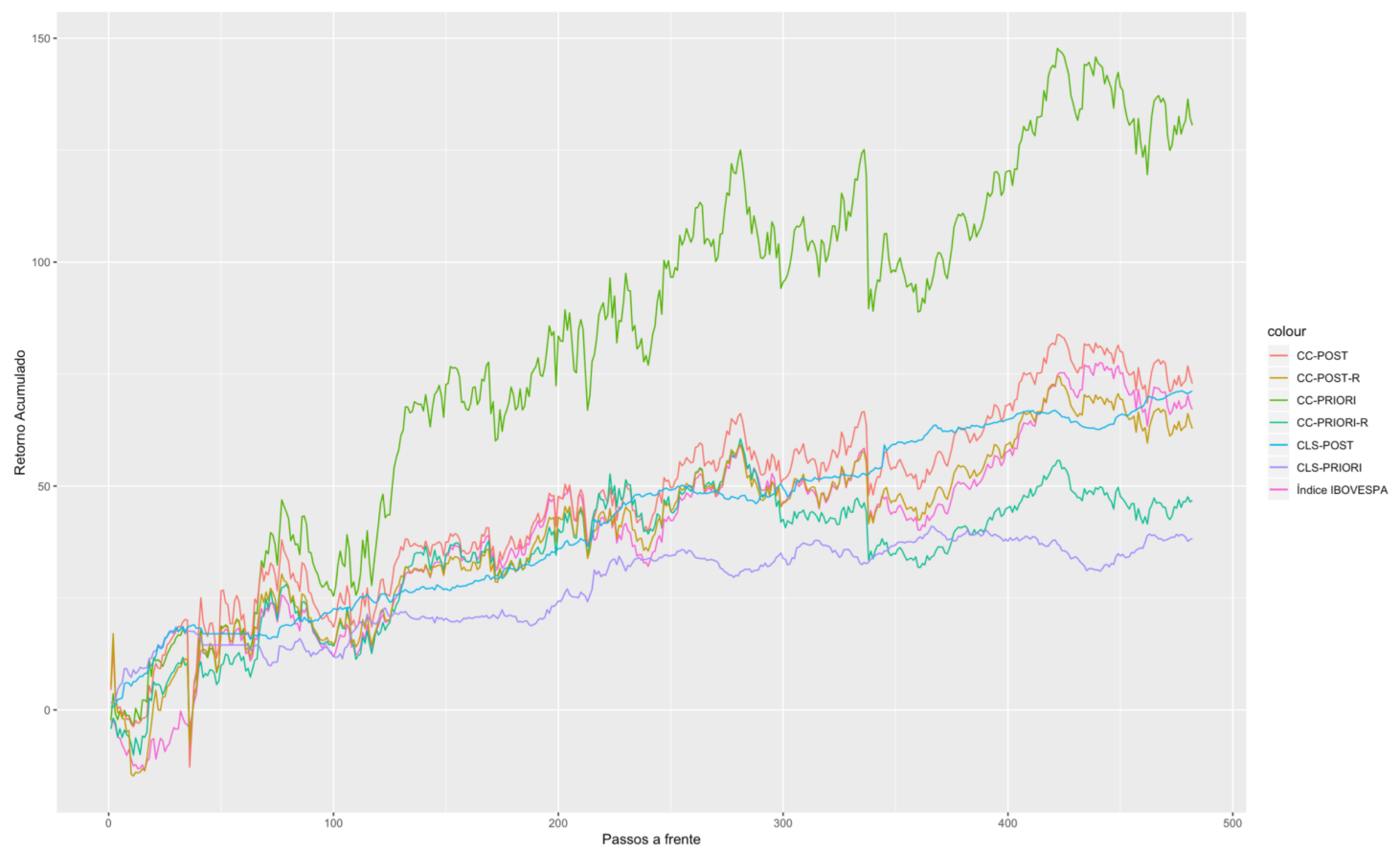

Fonte: Elaborada pelos autores e Economatica.

Onde CC-PRIORI, é a carteira completa estimada utilizando apenas da informação da priori com matriz de covariâncias amostral; CC-POST é a carteira completa estimada utilizando a combinação via BL da informação da priori e da posteriori. Temos que CC- 
PRIORI-R é a carteira restrita onde delimitamos o tamanho de cada ativos em $20 \%$ e o somatório total de ações em $67 \%$ para controle de risco e exposição da carteira ao mercado. CC-POST-R, segue o mesmo processo da carteira restrita, utilizando a combinação via BL da informação da priori e da posteriori. A carteira CLS-PRIORI é a carteira LongShort utilizando apenas da informação da priori com matriz de covariâncias amostral, e CLS-POST é a carteira Long-Short utilizando a combinação via BL da informação priori e da posteriori. Em relação às matrizes de covariâncias, para não estender muito a pesquisa, acabamos adotando uma janela rolante com uma matriz de covariâncias amostral, a janela é de 512 observações. Como podemos notar, entre os seis modelos propostos e desenvolvidos na dissertação com esse conjunto de ativos, temos que as duas carteiras completas sem restrição obtiveram um resultado superior ao benchmark. Em relação as carteiras restritas devido à restrição os resultados apresentados foram inferiores ao benchmark, contudo obtiveram um melhor resultado em relação a volatilidade. Em relação as carteiras Long-Short notamos que os resultados são elevados e controlam o risco no formato de longo prazo. A seguir apresentamos uma tabela (tabela 12) comparativa para com os principais resultados encontrados no conjunto de carteiras.

Tabela 12 - Principais resultados encontrados nas carteiras completas .

\begin{tabular}{ccccc}
\hline Modelos de Carteira Reduzida & Índice Sharpe & Retorno Médio Mensal & Desvio Padrão Mensal & Retorno Acumulado \\
\hline CC-PRIORI & 1,003 & $3,54 \%$ & 0,2618 & $130,56 \%$ \\
CC-POST & 0,589 & $2,30 \%$ & 0,2368 & $72,89 \%$ \\
CC-PRIORI-R & 0,398 & $1,61 \%$ & 0,1755 & $46,85 \%$ \\
CC-POST-R & 0,575 & $2,05 \%$ & 0,1981 & $62,83 \%$ \\
CLS-PRIORI & 0,739 & $1,35 \%$ & 0,0603 & $38,26 \%$ \\
CLS-POST & 3,030 & $2,26 \%$ & 0,0445 & $71,21 \%$ \\
Índice IBOVESPA & 0,8077 & $2,15 \%$ & 0,0629 & $66,76 \%$ \\
\hline
\end{tabular}

Fonte: Elaborada pelos autores.

Observando os resultados apresentados anteriormente, continuamos animados com o potencial de retornos encontrados nos modelos estudados, mesmo considerando a presença de uma carteira reduzida em relação ao número de ativos incluídos. Comparando os resultados encontrados, podemos notar que o melhor resultado encontrado foi atingido pelo CC-PRIORI, onde o retorno acumulado no período foi de 130,56\%, com um índice Sharpe de 1,003. Entretanto, quando consideramos o critério índice de Sharpe, a carteira CLS-POST apresentou um resultado $(3,030)$ extremamente elevado comparado as demais carteiras. 
Tal resultado já esperado para um carteira Long-Short, em que o objetivo postulado é estar dinheiro-neutro ao mercado e ter um redução considerável na volatilidade, dado o resultado final comprado e vendido da carteira. Ainda em relação as carteiras Long-Short, notamos que o resultado superior foi apresentado pelas carteiras com a mescla entre informações priori e posterior. Na visão dos autores, tal fato advém que a informação incluída em $r_{i, \hat{t}+1}$ possui maior poder preditivo em relação ao ruído, dado sua maior frequência. Portanto, uma carteira de combinações de compra e venda tende a apresentar maior retorno. Os resultados das demais carteiras seguem o padrão apresentado pelos modelos de carteiras reduzidas. A informação que obteve resultado superior foi a utilização da previsão mensal desagregada para retorno diário, $r_{i, t+1}^{\hat{M}}$, em relação à previsão do retorno esperado para $t+1, r_{i, \hat{t}+1}$.

Os resultados encontrados nesta aplicação são extremamente motivadores e abrem um novo caminho para modelos de combinação de precificação de ativos e alocação de carteiras. O modelo de alocação de portfólios de BL teve um bom ajuste às premissas e variáveis utilizadas no modelo cumprindo de forma correta sua tarefa. 


\section{Conclusão}

Propomos uma nova maneira de estimar modelos de precificação de ativos para previsão de retornos individuais de ações que podem tirar proveito da grande quantidade de informações existentes. Para esse propósito, utilizamos de um extenso arcabouço de modelos de Machine Learning linear, composto por modelos de pré-seleção, PCA, PLS, VAR, BVAR, combinação entre métodos de pré-seleção com PCA e SPCA. Nossa inovação crucial é a inclusão de uma condição de não arbitragem como parte dos algoritmos de precificações de ativos para modelos de Machine Learning linear e paramétricos. Estimamos os fatores de desconto estocástico comuns entre os ativos e características específicas que explicam os retornos das ações dada as restrições de momento condicional implícitas pela não arbitragem. Nosso FDS é um portfólio de todas as séries temporais com pesos variados no tempo, que são funções gerais das variáveis observáveis e não observáveis específicas da empresa, macroeconômicas e microeconômicas. Nosso modelo nos permitiu entender quais são os principais fatores que impulsionam os preços dos ativos, identificam a precificação incorreta das ações e geram um portfólio eficiente. Nosso trabalho se posiciona de forma contemporânea as principais pesquisas da área de precificação de ativos em alta dimensão, por exemplo Fama e French (2015), Lettau e Pelger (2018), Kozak, Nagel e Santosh (2018), Gu, Kelly e Xiu (2018) e Chen, Pelger e Zhu (2019).

Foram sete as nossas principais conclusões. Primeiro, reforçamos o potencial de ML, no processo de precificação de ativos, em linha com os trabalhos de Gu, Kelly e Xiu (2018) e . Os modelos desenvolvidos foram capazes de identificar os principais fatores que impulsionam os retornos dos ativos e a forma funcional dessa relação em um nível de generalidade e com uma precisão que não era possível com os métodos econométricos tradicionais. Segundo, incluímos uma condição de não arbitragem na estimativa dos modelos de precificação de ativos de Machine Learning que geraram resultados preditivos elevados. A condição de não arbitragem mesmo que simples gera resultados relevantes a literatura de predição e precificação de ativos. Desta forma, mencionamos a conclusão de Chen, Pelger 
e Zhu (2019) que um uso bem-sucedido dos métodos de Machine Learning em finanças requer conhecimento específico sobre o assunto e uma implementação técnica de última geração. Terceiro, os dados financeiros têm uma dimensão temporal que deve ser levada em consideração de acordo com ativo analisado, a utilização de diferentes frequências temporais na pesquisa permitiu expor com consistência tal resultado. Concluímos que os melhores preditivos para retornos diários não são os melhores preditores para retorno mensal, trimestral ou anual. Nossos resultados têm benefícios práticos diretos para pesquisadores de precificação de ativos que vão além de nossas descobertas empíricas. Primeiro, fornecemos um novo conjunto de variáveis de teste de referência para pesquisas no mercado de ativos Brasileiro, como também referências para futuras pesquisas em critérios comparativos. Esses ativos de teste incorporaram as informações de todas as características e informações macroeconômicas em um pequeno número de fatores. Segundo, forcemos a literatura um conjunto de novos modelos para o desenvolvimento de modelos de SPCA, utilizando métodos de pré-seleção antes do PCA, que apresentou resultados superiores aos demais modelos. Terceiro, em nossas aplicações forcemos a literatura de estruturas a termo do excesso de retorno esperado e modelos de alocação de portfólios de Black-Litterman extensões valiosas e com bons resultados empíricos. Por último, mas não menos importante, nosso modelo é diretamente valioso para investidores e gestores de portfólio vide as aplicações encontradas.

Uma extensão não desenvolvida na pesquisa, contudo que foi proposta foi a introdução dentro dos 53 modelos de previsão de uma matriz covariância estimada através de um modelo fatorial de volatilidade estocástica via MCMC. Tal método não foi utilizado devido a extensiva utilização de capacidade computacional. Como já ressaltamos o processo estimar sempre em $t$ para $t+1$ as 892 previsões diárias, 48 previsões mensais, 16 previsões trimestrais e 4 anuais, utilizando sempre como critério de escolha minimização do RMSE e maximização do $R_{o o s}^{2}$ tornou o processo de estimação extremamente custoso em termos computacionais, calculamos que todas as previsões condicionais foram rodadas em 558 horas utilizando de um amplo poder computacional. Deixamos como extensões futuras o melhor desenvolvimento das aplicações presentes na pesquisa e extensão dos modelos 
para demais ativos do mercado acionário brasileiro. Como objetivo dos autores iremos explorar em futuros trabalho as modificações ao longo do tempo e extração de momentos da curva em formato comparativo da estrutura a termo do retorno esperado, incorporar novas variáveis presentes nas pesquisas de Gu, Kelly e Xiu (2018) e Chen, Pelger e Zhu (2019), incluir novos modelos de Machine Learning e a expansão do número e horizonte das variáveis previstas pelos modelos.

Encerrando, acreditamos que o sucesso geral dos algoritmos de Machine Learning para previsão de retorno traz promessas para a modelagem econômica e para aspectos práticos da escolha do portfólio. Com uma melhor medição através do Machine Learning, os prêmios de risco são menos encobertos pelo erro de estimativa, portanto, o desafio de identificar mecanismos econômicos confiáveis por trás dos fenômenos de precificação de ativos se torna menos acentuados. Por fim, nossas descobertas ajudam a justificar o crescente papel do Machine Learning em toda a arquitetura da crescente indústria de fintech. 


\section{Referências}

ACHARYA, V. V.; PEDERSEN, L. H. Asset pricing with liquidity risk. Journal of financial Economics, Elsevier, v. 77, n. 2, p. 375-410, 2005.

ANDREWS, D. W. Heteroskedasticity and autocorrelation consistent covariance matrix estimation. Econometrica: Journal of the Econometric Society, JSTOR, p. 817-858, 1991.

BAI, J.; NG, S. Determining the number of factors in approximate factor models. Econometrica, Wiley Online Library, v. 70, n. 1, p. 191-221, 2002.

BERNANKE, B. S.; BOIVIN, J.; ELIASZ, P. Measuring the effects of monetary policy: a factor-augmented vector autoregressive (favar) approach. The Quarterly journal of economics, MIT Press, v. 120, n. 1, p. 387-422, 2005.

BERNANKE, B. S.; MIHOV, I. What does the bundesbank target? European economic review, Elsevier, v. 41, n. 6, p. 1025-1053, 1997.

BIANCHI, D. et al. Modeling systemic risk with markov switching graphical sur models. Journal of econometrics, Elsevier, v. 210, n. 1, p. 58-74, 2019.

BLACK, F.; LITTERMAN, R. Global portfolio optimization, financial analysis journal. 1992.

BOLlERSLEV, T.; CHOU, R. Y.; KRONER, K. F. Arch modeling in finance: A review of the theory and empirical evidence. Journal of econometrics, Elsevier, v. 52, n. 1-2, p. 5-59, 1992.

CHEN, L.; PELGER, M.; ZHU, J. Deep learning in asset pricing. Available at SSRN 3350138, 2019.

DAVIS, R. A.; ZANG, P.; ZHENG, T. Sparse vector autoregressive modeling. Journal of Computational and Graphical Statistics, Taylor \& Francis, v. 25, n. 4, p. 1077-1096, 2016.

DIEBOLD, F.; MARIANO, R. Comparing predictive accuracy. journal of business and economics statistics, v. 13. 1995.

DOAN, T.; LITTERMAN, R.; SIMS, C. Forecasting and conditional projection using realistic prior distributions. Econometric reviews, Taylor \& Francis, v. 3, n. 1, p. 1-100, 1984.

ELLIOTT, G.; ROTHENBERG, T.; STOCK, J. keffi cient tests for an autoregressive unit root, leconometrica. 1996.

FAMA, E. F.; FRENCH, K. R. Dissecting anomalies. The Journal of Finance, Wiley Online Library, v. 63, n. 4, p. 1653-1678, 2008.

FAMA, E. F.; FRENCH, K. R. A five-factor asset pricing model. Journal of financial economics, Elsevier, v. 116, n. 1, p. 1-22, 2015.

FENG, W.; WANG, Y.; ZHANG, Z. Informed trading in the bitcoin market. Finance Research Letters, Elsevier, v. 26, p. 63-70, 2018. 
FREYBERGER, J.; NEUHIERL, A.; WEBER, M. Nonparametric dissection of the cross-section of expected stock returns. NBER working paper, v. 23227, 2017.

GALÍ, J.; LÓPEZ-SALIDO, J. D.; VALLÉS, J. Understanding the effects of government spending on consumption. Journal of the european economic association, Oxford University Press, v. 5, n. 1, p. 227-270, 2007.

GRANGER, C. W. Investigating causal relations by econometric models and cross-spectral methods. Econometrica: journal of the Econometric Society, JSTOR, p. 424-438, 1969.

GU, S.; KELLY, B.; XIU, D. Empirical asset pricing via machine learning. [S.l.], 2018.

GU, S.; KELLY, B. T.; XIU, D. Autoencoder asset pricing models. Available at SSRN, 2019 .

HAMILTON, J. D.; SUSMEL, R. Autoregressive conditional heteroskedasticity and changes in regime. Journal of econometrics, North-Holland, v. 64, n. 1-2, p. 307-333, 1994.

HARVEY, C. R.; LIU, Y. A census of the factor zoo. Available at SSRN 3341728, 2019.

HASTIE, T.; TIBSHIRANI, R.; WAINWRIGHT, M. Statistical learning with sparsity: the lasso and generalizations. [S.l.]: CRC press, 2015.

HE, Z.; KELLY, B.; MANELA, A. Intermediary asset pricing: New evidence from many asset classes. Journal of Financial Economics, Elsevier, v. 126, n. 1, p. 1-35, 2017.

ISMAILOV, A.; ROSSI, B. Uncertainty and deviations from uncovered interest rate parity. Journal of International Money and Finance, Elsevier, v. 88, p. 242-259, 2018.

JENTER, D.; LEWELLEN, K. Ceo preferences and acquisitions. The Journal of Finance, Wiley Online Library, v. 70, n. 6, p. 2813-2852, 2015.

KADIYALA, K. R.; KARLSSON, S. Numerical methods for estimation and inference in bayesian var-models. Journal of Applied Econometrics, Wiley Online Library, v. 12, n. 2, p. 99-132, 1997.

KALMAN, R. E. et al. Contributions to the theory of optimal control. Bol. soc. mat. mexicana, v. 5, n. 2, p. 102-119, 1960.

KASTNER, G.; FRÜHWIRTH-SCHNATTER, S.; LOPES, H. F. Efficient bayesian inference for multivariate factor stochastic volatility models. Journal of Computational and Graphical Statistics, Taylor \& Francis, v. 26, n. 4, p. 905-917, 2017.

KIEFER, N. M.; VOGELSANG, T. J. A new asymptotic theory for heteroskedasticityautocorrelation robust tests. Econometric Theory, Cambridge University Press, v. 21, n. 6, p. 1130-1164, 2005.

KOIJEN, R. S.; NIEUWERBURGH, S. V. Predictability of returns and cash flows. Annu. Rev. Financ. Econ., Annual Reviews, v. 3, n. 1, p. 467-491, 2011.

KOZAK, S.; NAGEL, S.; SANTOSH, S. Interpreting factor models. The Journal of Finance, Wiley Online Library, v. 73, n. 3, p. 1183-1223, 2018. 
KRISTENSEN, D.; SALANIÉ, B. Higher-order properties of approximate estimators. Journal of econometrics, Elsevier, v. 198, n. 2, p. 189-208, 2017.

LETTAU, M.; PELGER, M. Factors that fit the time series and cross-section of stock returns. [S.1.], 2018.

LITTERMAN, R. Hot spots and hedges. Journal of Portfolio Management, Euromoney Institutional Investor PLC, p. 52, 1996.

MARKOWITZ, H. The utility of wealth. Journal of political Economy, The University of Chicago Press, v. 60, n. 2, p. 151-158, 1952.

MESSMER, M.; AUDRINO, F. The (adaptive) lasso in the zoo-firm characteristic selection in the cross-section of expected returns. Available at SSRN 2930436, 2017.

MOL, C. D.; GIANNONE, D.; REICHLIN, L. Forecasting using a large number of predictors: Is bayesian shrinkage a valid alternative to principal components? Journal of Econometrics, Elsevier, v. 146, n. 2, p. 318-328, 2008.

NASON, G. P.; SAVCHEV, D. White noise testing using wavelets. Stat, Wiley Online Library, v. 3, n. 1, p. 351-362, 2014.

PELGER, M.; XIONG, R. Interpretable proximate factors for large dimensions. arXiv preprint arXiv:1805.03373, 2018.

PRADO, M. L. D. Advances in financial machine learning. [S.1.]: John Wiley \& Sons, 2018.

RAPACH, D.; ZHOU, G. Forecasting stock returns. In: Handbook of economic forecasting. [S.l.]: Elsevier, 2013. v. 2, p. 328-383.

ROBERTSON, J. C.; TALLMAN, E. W. Vector autoregressions: forecasting and reality. Economic Review-Federal Reserve Bank of Atlanta, Federal Reserve Bank of Atlanta, v. 84, n. 1, p. 4, 1999.

SIMON, N. et al. A sparse-group lasso. Journal of computational and graphical statistics, Taylor \& Francis Group, v. 22, n. 2, p. 231-245, 2013.

SIMS, C. A. Macroeconomics and reality. Econometrica: journal of the Econometric Society, JSTOR, p. 1-48, 1980.

SIMS, C. A. Interpreting the macroeconomic time series facts: The effects of monetary policy. European economic review, Elsevier, v. 36, n. 5, p. 975-1000, 1992.

SIMS, C. A.; ZHA, T. Bayesian methods for dynamic multivariate models. International Economic Review, JSTOR, p. 949-968, 1998.

TIAO, G. C.; BOX, G. E. Modeling multiple time series with applications. journal of the American Statistical Association, Taylor \& Francis Group, v. 76, n. 376, p. 802-816, 1981.

TIBSHIRANI, R. Regression shrinkage and selection via the lasso. Journal of the Royal Statistical Society: Series B (Methodological), Wiley Online Library, v. 58, n. 1, p. 267-288, 1996. 
TRUCÍOS, C.; HOTTA, L. K.; PEREIRA, P. L. V. On the robustness of the principal volatility components. Journal of Empirical Finance, Elsevier, v. 52, p. 201-219, 2019.

WANG, H.; LENG, C. A note on adaptive group lasso. Computational statistics 86 data analysis, Elsevier, v. 52, n. 12, p. 5277-5286, 2008.

ZOU, H. The adaptive lasso and its oracle properties. Journal of the American statistical association, Taylor \& Francis, v. 101, n. 476, p. 1418-1429, 2006. 


\section{Anexo A}

Nas próximas tabelas apresentamos um resumo das séries temporais utilizadas na dissertação em diferentes frequências temporais. Para reduzir a extensão das tabelas a serem apresentadas, retiramos delas todos os fechamentos das ações participantes do índice IBOVESPA nas frequências diária, mensal, trimestral e anual, como também retiramos o índices de momentum para cada ativo presente no índice IBOVESPA nas frequências anteriormente mencionadas. Para também facilitar a apresentação das séries temporais indexamos para algumas variáveis. 
Tabela 13 - Variáveis incluídas na pesquisa (1).

\begin{tabular}{|c|c|c|c|c|c|}
\hline Código.Variável & Nome.da.Variável & Banco.de.Dados & Perído & Frequência & \\
\hline 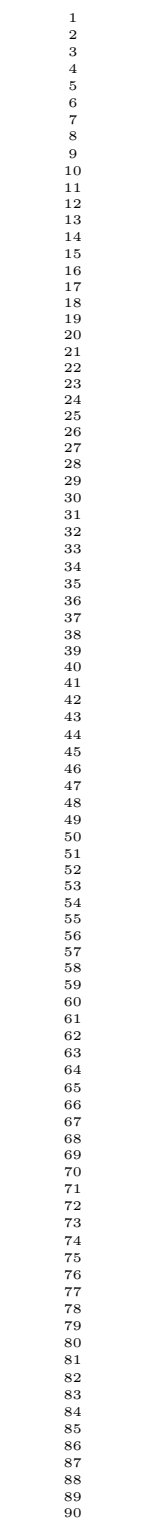 & 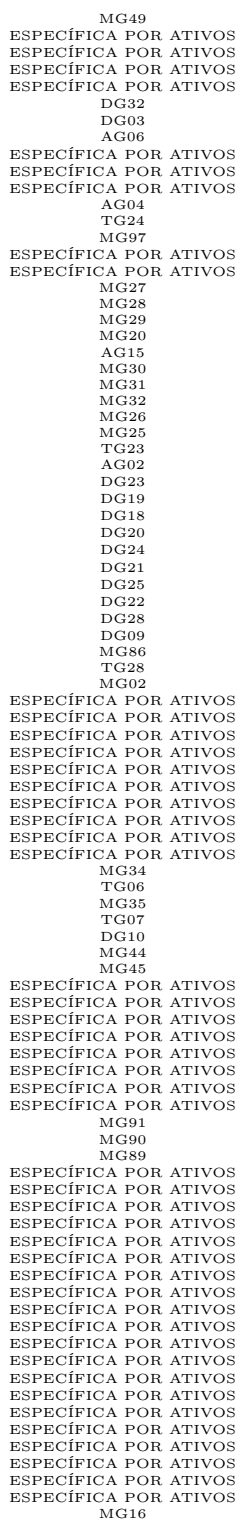 & 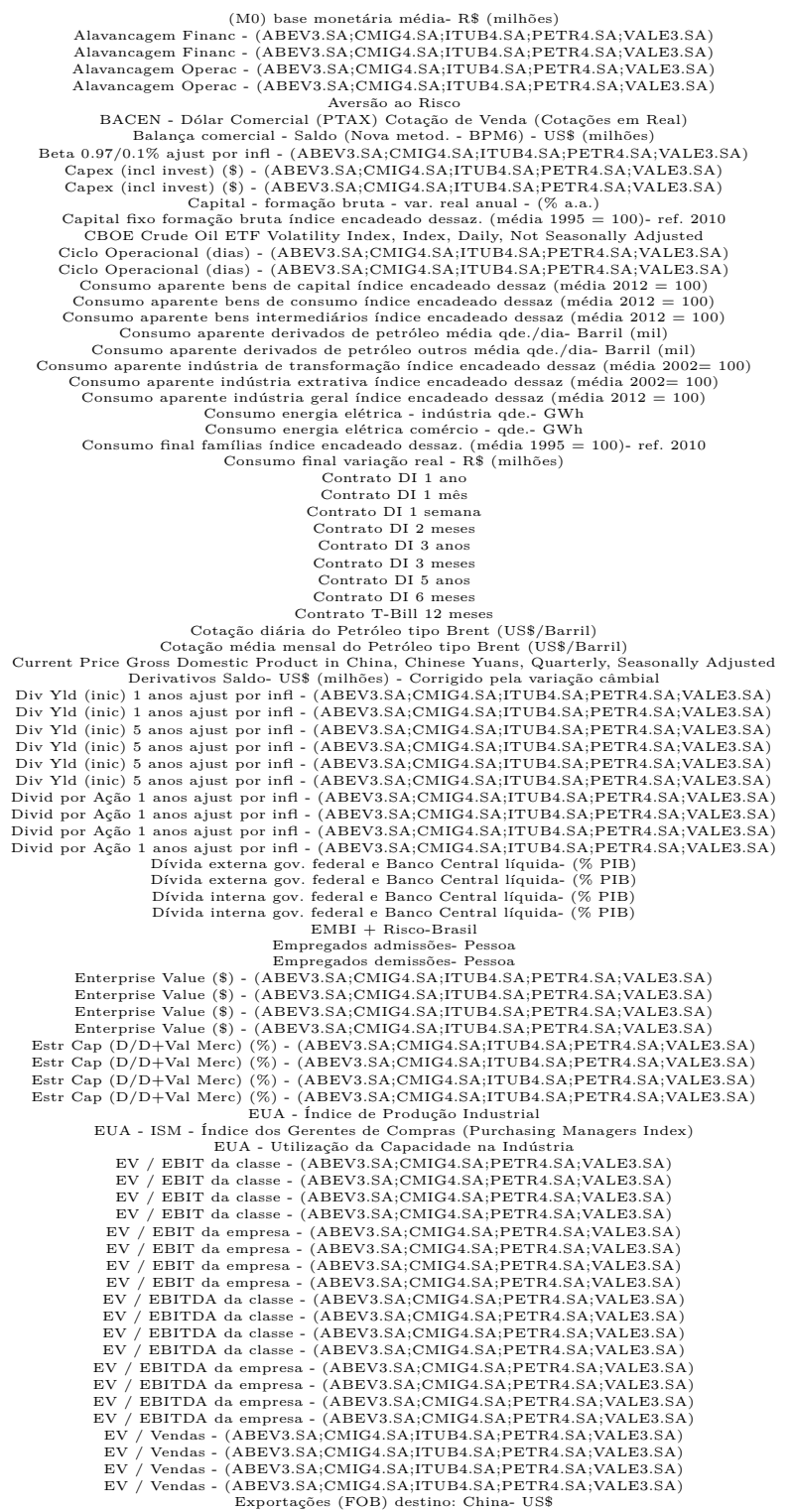 & 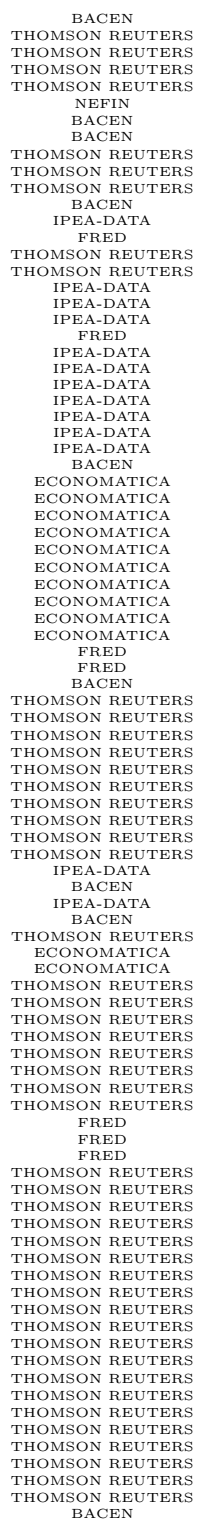 & 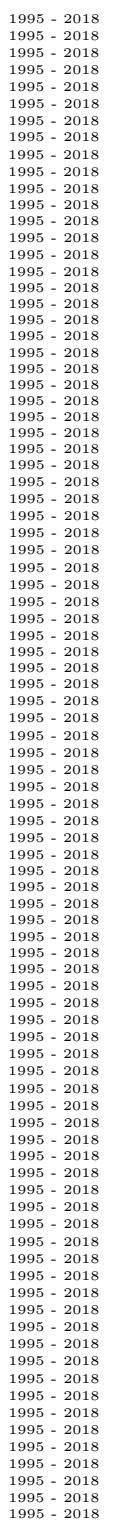 & 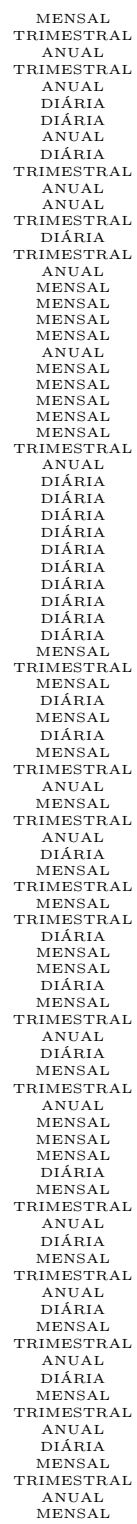 \\
\hline
\end{tabular}

Fonte: Elaborada pelos autores. 
Tabela 14 - Variáveis incluídas na pesquisa (2).

\begin{tabular}{|c|c|c|c|c|c|}
\hline Jódigo, Variável & Nome.da.Variável & Banco.de.Dados & Periodo & Frequência & \\
\hline $\begin{array}{l}91 \\
{ }_{1}\end{array}$ & $\begin{array}{l}\text { MG17 } \\
\text { MG } 08\end{array}$ & $\begin{array}{l}\text { Exportaçōes (FOB) destino: Estados Unidos- US\$ } \\
\text { Fxportaçes (FOB): }\end{array}$ & $\begin{array}{l}\text { BACEN } \\
\text { BACEN }\end{array}$ & $\begin{array}{l}018 \\
018 \\
0_{18}\end{array}$ & \\
\hline & & 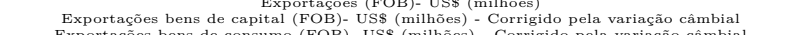 & & & \\
\hline $\begin{array}{c}94 \\
95 \\
95\end{array}$ & MTG10 & 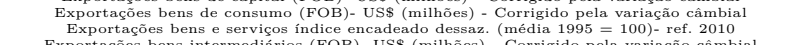 & 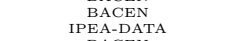 & $\begin{array}{l}1995-2018 \\
1995-2018\end{array}$ & $\begin{array}{c}\text { MENAL } \\
\text { TRIMESTRAL } \\
\text { TRES }\end{array}$ \\
\hline $\begin{array}{c}96 \\
97 \\
98 \\
98\end{array}$ & $\begin{array}{l}\text { MG11 } \\
\text { DGO02 } \\
\text { MGC23 }\end{array}$ & 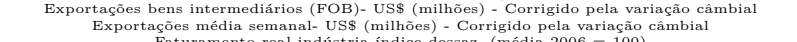 & $\begin{array}{c}\text { BAAEN } \\
\text { BACEN } \\
\text { PACENG }\end{array}$ & $\begin{array}{l}1995-2018 \\
1995-2018\end{array}$ & $\begin{array}{c}\text { MENAAL } \\
\text { DIARIA } \\
\text { DIARA }\end{array}$ \\
\hline $\begin{array}{c}98 \\
99 \\
100\end{array}$ & $\begin{array}{l}\text { MGG3 } \\
\text { MG63 } \\
\text { TG10 }\end{array}$ & 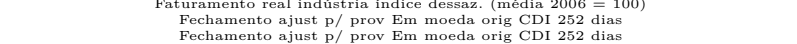 & $\begin{array}{l}\text { IPEADAAA } \\
\text { ECONOATICA } \\
\text { ECONOATICA }\end{array}$ & \begin{tabular}{l}
\multicolumn{1}{c}{$1995-2018$} \\
1995 \\
1995
\end{tabular} & 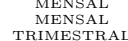 \\
\hline $\begin{array}{l}101 \\
102\end{array}$ & $\begin{array}{l}\text { AG07 } \\
\text { AG55 }\end{array}$ & 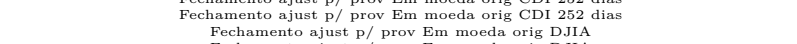 & $\begin{array}{l}\text { ECONOMATICA } \\
\text { ECONOMATIA }\end{array}$ & $\begin{array}{l}1995-2018 \\
1995-2018\end{array}$ & 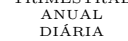 \\
\hline $\begin{array}{l}103 \\
104\end{array}$ & MG13 & $\begin{array}{l}\text { Fechamento a aust p/ p/ prov Emm moeda orig DDJA } \\
\text { Fechamento ajust p/ prov Em moeda orig DJIA }\end{array}$ & $\begin{array}{l}\text { ECONOMAICA } \\
\text { ECONOMATICA }\end{array}$ & $\begin{array}{l}1995-2018 \\
1995-2018\end{array}$ & $\begin{array}{c}\text { MENAL } \\
\text { TRIMESTRAL } \\
\text { TREST }\end{array}$ \\
\hline $\begin{array}{l}105 \\
106 \\
107\end{array}$ & 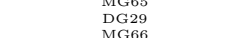 & 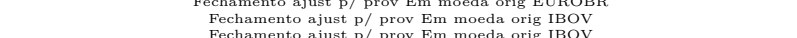 & $\begin{array}{l}\text { THOMSON REUTERS } \\
\text { ECONOMATCAS }\end{array}$ & $\begin{array}{l}1995-2018 \\
1995 \\
1905\end{array}$ & $\begin{array}{l}\text { MENAL } \\
\text { DARIA } \\
\text { MENAL }\end{array}$ \\
\hline $\begin{array}{l}108 \\
109\end{array}$ & $\begin{array}{l}\text { TG11 } \\
\text { AG08 }\end{array}$ & 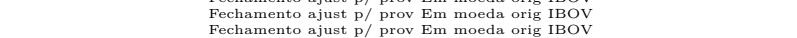 & $\begin{array}{l}\text { ECONOMATICA } \\
\text { ECONOMATCA }\end{array}$ & $\begin{array}{l}1995-2018 \\
1995-2018\end{array}$ & $\begin{array}{l}\text { TRIMESTRAL } \\
\text { ANUAL }\end{array}$ \\
\hline $\begin{array}{l}110 \\
111\end{array}$ & $\begin{array}{l}\text { DG56 } \\
\text { MG67 }\end{array}$ & $\begin{array}{l}\text { Fechamento ajust t p prov Em moeda orig NASDAQ } \\
\text { Fechamento a ajust p/ prov Em moeda orig NASDAQ }\end{array}$ & $\begin{array}{l}\text { ECONOMATICA } \\
\text { ECONOMATICA }\end{array}$ & $\begin{array}{l}1995-2018 \\
1995-2018\end{array}$ & 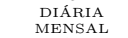 \\
\hline $\begin{array}{ll}112 \\
113 \\
113\end{array}$ & 08 & $\begin{array}{l}\text { Fechamento ajust p/ prov Em moeda orig oZ1D } \\
\text { Fechamento a just p/ prov Em moeda original OZ1D }\end{array}$ & $\begin{array}{l}\text { ECONOMATICA } \\
\text { ECONOMATICA }\end{array}$ & $\begin{array}{l}1995-2018 \\
1995-2018\end{array}$ & $\begin{array}{c}\text { DIÁRIA } \\
\text { MENAL }\end{array}$ \\
\hline $\begin{array}{ll}114 \\
115\end{array}$ & 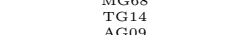 & 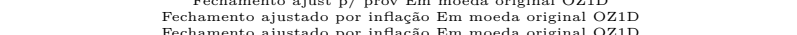 & $\begin{array}{l}\text { ECONOMATLA } \\
\text { ECONOMATICA } \\
\text { ECONONATICA }\end{array}$ & $\begin{array}{lll}1995-2018 \\
1995\end{array}$ & $\begin{array}{l}\text { TRIMESTRAL } \\
\text { TRESTR }\end{array}$ \\
\hline $\begin{array}{l}115 \\
116 \\
116\end{array}$ & $\begin{array}{l}\text { AG9o ATIVOS } \\
\text { ESPECCIFA POR ATIOS } \\
\text { ESPECHCA POR ATV }\end{array}$ & 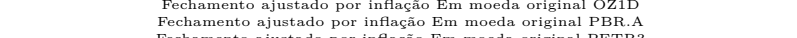 & $\begin{array}{l}\text { ECONMATICA } \\
\text { ECONOMATICA }\end{array}$ & $\begin{array}{l}1995-2018 \\
1995-2018\end{array}$ & $\begin{array}{c}\text { ANAAL } \\
\text { MENSAL }\end{array}$ \\
\hline $\begin{array}{l}1178 \\
119 \\
119\end{array}$ & 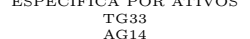 & 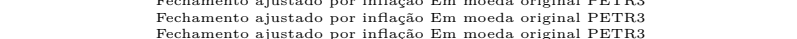 & $\begin{array}{l}\text { ECNOMATIA } \\
\text { ECNOMATIA } \\
\text { ECNOMATICA }\end{array}$ & $\begin{array}{l}1995-2018 \\
1995-2018 \\
1995-2018\end{array}$ & $\begin{array}{l}\text { MRINSARRAL } \\
\text { ANUAL }\end{array}$ \\
\hline $\begin{array}{l}120 \\
121\end{array}$ & $\begin{array}{l}\text { MG69 } \\
\text { TG12 }\end{array}$ & 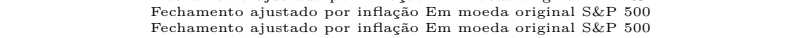 & $\begin{array}{l}\text { ECONOMATICA } \\
\text { ECONOMATICA }\end{array}$ & $\begin{array}{l}1995-2018 \\
1995-2018\end{array}$ & $\begin{array}{l}\text { MENAL } \\
\text { TRIMESTRAL }\end{array}$ \\
\hline 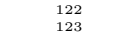 & $\begin{array}{l}\mathrm{A} G 100 \\
\mathrm{DG} 26\end{array}$ & & $\begin{array}{l}\text { MAATCA } \\
\text { NREUTERS }\end{array}$ & $\begin{array}{l}1995-2018 \\
1995-2018\end{array}$ & $\begin{array}{l}\text { ANUAL } \\
\text { DIÁRIA }\end{array}$ \\
\hline $\begin{array}{l}124 \\
125 \\
125\end{array}$ & $\begin{array}{l}\text { MG70 } \\
\text { MGT15 }\end{array}$ & 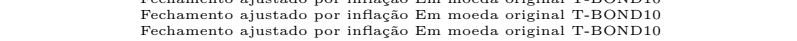 & $\begin{array}{l}\text { ECONOMATICA } \\
\text { ECONOMATICA } \\
\text { ECOA }\end{array}$ & $\begin{array}{l}1995-2018 \\
1995-2018\end{array}$ & $\begin{array}{l}\text { MENSAL } \\
\text { TRMESTRAL } \\
\text { TRMEST }\end{array}$ \\
\hline $\begin{array}{l}126 \\
127\end{array}$ & $\begin{array}{c}\mathrm{A} \text { AG1 } \\
\mathrm{D} 127\end{array}$ & 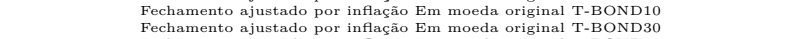 & $\begin{array}{l}\text { ECONOMATIIA } \\
\text { THOMSON REUTERS }\end{array}$ & $\begin{array}{l}1995-2018 \\
1995-2018\end{array}$ & $\begin{array}{c}\text { ANULL } \\
\text { DIAAIA }\end{array}$ \\
\hline $\begin{array}{l}128 \\
129 \\
129\end{array}$ & $\begin{array}{l}\text { MG71 } \\
\text { MG72 }\end{array}$ & 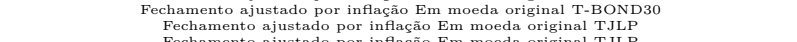 & $\begin{array}{l}\text { IATICA } \\
\text { IATICA }\end{array}$ & $\begin{array}{l}1995-2018 \\
1995-2018\end{array}$ & $\begin{array}{c}\text { MENSAL } \\
\text { MENSAL }\end{array}$ \\
\hline${ }_{131}^{130}$ & 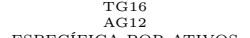 & 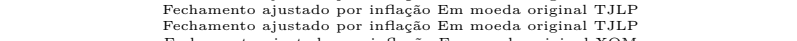 & $\begin{array}{l}\text { ECONOMATCA } \\
\text { ECONOMATICA }\end{array}$ & 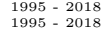 & $\begin{array}{l}\text { TRIMESTRAI } \\
\text { ANUAL }\end{array}$ \\
\hline $\begin{array}{l}132 \\
133\end{array}$ & $\underset{\text { ESPECÍFICA POR ATIVOS }}{\text { TG34 }}$ & 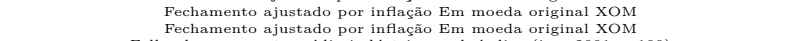 & $\begin{array}{c}\text { ECONOMAICA } \\
\text { ECONOMATICA }\end{array}$ & $\begin{array}{l}1995-2018 \\
1995-2018\end{array}$ & $\begin{array}{c}\text { MENAL } \\
\text { TRIMESTRAL } \\
\text { TIMST }\end{array}$ \\
\hline $\begin{array}{l}134 \\
135\end{array}$ & $\begin{array}{l}\text { MG61 } \\
\text { DG44 }\end{array}$ & $\begin{array}{l}\text { Folha de pagamento média induśstria geral- indice (jan. } 2001=100 \text { ) } \\
\text { HML - FF }\end{array}$ & $\begin{array}{l}\text { IPEADAA } \\
\text { ECONOMATICA épria }\end{array}$ & $\begin{array}{l}1995-2018 \\
1995-2018\end{array}$ & $\begin{array}{l}\text { MENSAL } \\
\text { DIARIA }\end{array}$ \\
\hline $\begin{array}{l}136 \\
137 \\
137\end{array}$ & $\begin{array}{l}\text { MGG62 } \\
\text { MGG6 } \\
\text { MG } 744\end{array}$ & 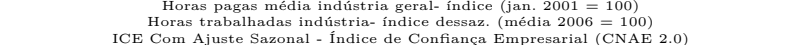 & $\begin{array}{l}\text { MPEADAA } \\
\text { ECONOATICA } \\
\text { IPEADATA }\end{array}$ & $\begin{array}{l}1995-2018 \\
1995 \\
1909\end{array}$ & $\begin{array}{l}\text { MENSAL } \\
\text { MENSAL } \\
\text { MENAAL }\end{array}$ \\
\hline $\begin{array}{l}138 \\
139 \\
130\end{array}$ & M M 176 & 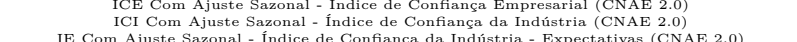 & $\begin{array}{l}\text { IFA-DAA } \\
\text { IFEA-DAAA } \\
\text { IPEA-DTA }\end{array}$ & $\begin{array}{lll}1995-2018 \\
1995-2018\end{array}$ & $\begin{array}{l}\text { MESSAL } \\
\text { MENSAL }\end{array}$ \\
\hline 140 & $\begin{array}{l}\text { MGG77 } \\
\text { MG75 }\end{array}$ & 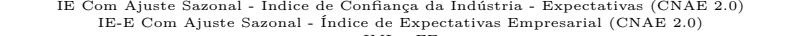 & & $\begin{array}{l}1995-2018 \\
1995-2018\end{array}$ & MENSAL \\
\hline 142 143 & $\begin{array}{l}\text { DGG6 } \\
\text { MG19 }\end{array}$ & $\begin{array}{l}\text { IML- FF } \\
\text { Importaçóns (FOB) origem: China- } t\end{array}$ & $\begin{array}{l}\text { A e Própria } \\
N\end{array}$ & $\begin{array}{l}1995-2018 \\
1995-2018\end{array}$ & IAA \\
\hline 14: & $\begin{array}{l}\text { MGG18 } \\
\text { MG12 }\end{array}$ & 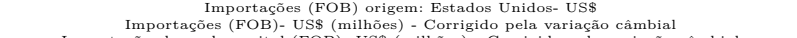 & 焉ACEN & $\begin{array}{l}1995-2018 \\
1995-2018\end{array}$ & $\begin{array}{l}\text { MENSAL } \\
\text { MENSAL }\end{array}$ \\
\hline & $\begin{array}{l}\text { MG13 } \\
\text { MG14 }\end{array}$ & 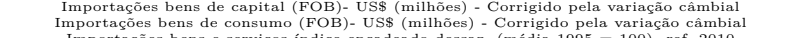 & BA & $\begin{array}{l}1995-2018 \\
1995-2018\end{array}$ & MENSAL \\
\hline 14: & $\begin{array}{l}\text { TGG66 } \\
\text { MG15 }\end{array}$ & 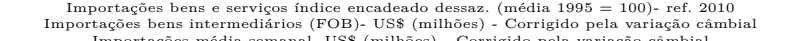 & $\begin{array}{l}\text { IPEA-DAAA } \\
\text { BACEN }\end{array}$ & $\begin{array}{l}1995-2018 \\
1995-2018\end{array}$ & MIMESTRAL \\
\hline 151 & $\begin{array}{l}\text { DG01 } \\
\text { DG30 }\end{array}$ & 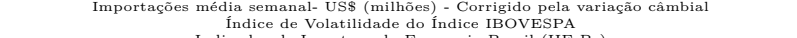 & $\begin{array}{l}\text { BAEEN } \\
\text { NEFIN }\end{array}$ & $\begin{array}{l}1995-2018 \\
1995-2018\end{array}$ & $\begin{array}{l}\text { DIARAA } \\
\text { DIARIA }\end{array}$ \\
\hline 15 & ${ }_{\mathrm{MG} 333}^{\mathrm{MG} 33}$ & 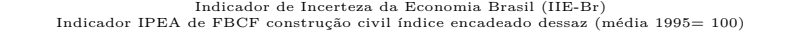 & ${ }_{\mathrm{IP}}^{\mathrm{FG}}$ & $\begin{array}{l}1995-2018 \\
1995-2018\end{array}$ & $\begin{array}{l}\text { MENSAL } \\
\text { MENSAL }\end{array}$ \\
\hline $\begin{array}{l}15 \\
15\end{array}$ & DC & $\begin{array}{l}\text { Indice CBOE Brasil ETF } \\
\text { ice }\end{array}$ & REUTERS & $\begin{array}{l}1995-2018 \\
1095 \\
102018\end{array}$ & $\begin{array}{l}\text { DIARAA } \\
\text { DIARA }\end{array}$ \\
\hline 15 & $\begin{array}{l}\text { MG79 } \\
\text { MG88 }\end{array}$ & 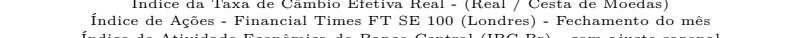 & & $\begin{array}{lll}1995-2018 \\
1995-2018\end{array}$ & $\begin{array}{l}\text { MENSAL } \\
\text { MENSAL } \\
\text { MENSL }\end{array}$ \\
\hline & 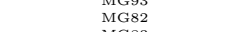 & 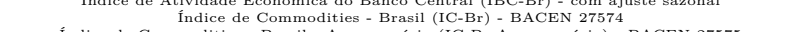 & $\begin{array}{l}\text { BACEN } \\
\text { BACEN }\end{array}$ & $1995-2018$ & $\begin{array}{l}\text { MENSAL } \\
\text { MENSAL }\end{array}$ \\
\hline 16 & & $\begin{array}{l}\text { opecuária (IC-Br Agropecuária) - } \\
\text { Energia - (CI-Br Energia) - BAC }\end{array}$ & & 1995 & $\begin{array}{l}\text { MENSAL } \\
\text { MENSAL }\end{array}$ \\
\hline & & $\begin{array}{l}\text { commodities } \\
\text { Comdic de. } \\
\text { indic de }\end{array}$ & & & \\
\hline 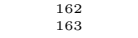 & $\begin{array}{l}\text { MG24 } \\
\text { MG80 }\end{array}$ & $\begin{array}{l}\text { Indice de c } \\
\text { Indice d. }\end{array}$ & & $\begin{array}{l}995-2018 \\
995-2018\end{array}-20$ & $\begin{array}{l}\text { MENSAL } \\
\text { MENSAL }\end{array}$ \\
\hline 16: 16. & $\begin{array}{l}\text { MG81 } \\
\text { DG57 }\end{array}$ & 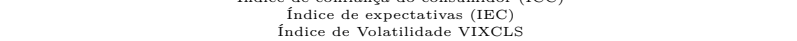 & $\begin{array}{l}\text { FGV-DADOS } \\
\text { ECONOMATC }\end{array}$ & $\begin{array}{l}1995-2018 \\
1995-2018\end{array}$ & $\begin{array}{l}\text { MENSAL } \\
\text { DIAAIA }\end{array}$ \\
\hline 16 & & 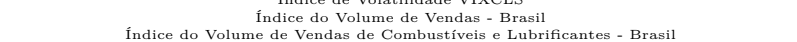 & & $995-2018$ & \\
\hline 16. & $\begin{array}{l}\text { MG99 } \\
\text { DG54 }\end{array}$ & $\begin{array}{l}\text { Índice do Volume de Vendas de } \\
\text { indic }\end{array}$ & $\begin{array}{l}\text { IPEA } \\
\text { ECONC }\end{array}$ & $\begin{array}{l}\begin{array}{l}1995-2018 \\
1995-2018\end{array} \\
\end{array}$ & $\begin{array}{l}\text { MENSAL } \\
\text { DIARIA }\end{array}$ \\
\hline 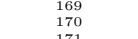 & G55 & $\begin{array}{l}\text { a.m.t. } \\
\% \\
\% \\
\text { a.m.m. }\end{array}$ & & $\begin{array}{l}\begin{array}{l}1995-2018 \\
1995-2018\end{array} \\
1909\end{array}$ & $\begin{array}{l}\text { MENSAL } \\
\text { MENSAL }\end{array}$ \\
\hline & 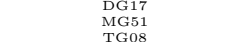 & 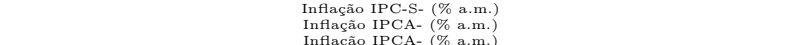 & $\begin{array}{l}\text { IPEA-ATAA } \\
\text { BACEN } \\
\text { BACEN }\end{array}$ & $\begin{array}{l}1995-2018 \\
1995-2018\end{array}$ & $\begin{array}{l}\text { MARIA } \\
\text { MENAL } \\
\text { TRINSTRA }\end{array}$ \\
\hline $\begin{array}{l}17 . \\
17 \\
17\end{array}$ & 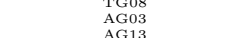 & 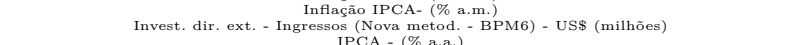 & $\begin{array}{l}\text { BACN } \\
\text { BACEN } \\
\text { BCEN }\end{array}$ & $\begin{array}{l}1995-2018 \\
1995-2018\end{array}$ & $\begin{array}{l}\text { TRRMESRAL } \\
\text { ANUAL } \\
\text { ANUAL }\end{array}$ \\
\hline & & $\begin{array}{l}\text { IPCA (Fa.a. } \\
\text { IPG211111CS } \\
\text { IPG }\end{array}$ & $\begin{array}{l}\text { BACEN } \\
\text { FRED }\end{array}-1-30$ & & \\
\hline 17 & $\begin{array}{l}\text { vos } \\
\text { vos }\end{array}$ & aаăo - (AAEV3.SA;CMIG4.SA;TUBA4.SA & $\mathrm{T}_{\mathrm{T}}^{\mathrm{T}}$ & & \\
\hline & $\begin{array}{c}\text { DG13 } \\
\text { DG16 }\end{array}$ & $\begin{array}{l}\text { LTN - } 1 \text { mes - (\%) o.a.) } \\
\text { LTN }-12 \text { meses }-(\% \text { a.a. }\end{array}$ & $\begin{array}{l}\text { AMBMMA } \\
\text { AMBIMA }\end{array}$ & $\begin{array}{l}1995-2018 \\
1995-2018\end{array}$ & 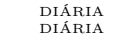 \\
\hline
\end{tabular}

Fonte: Elaborada pelos autores. 
Tabela 15 - Variáveis incluídas na pesquisa (3).

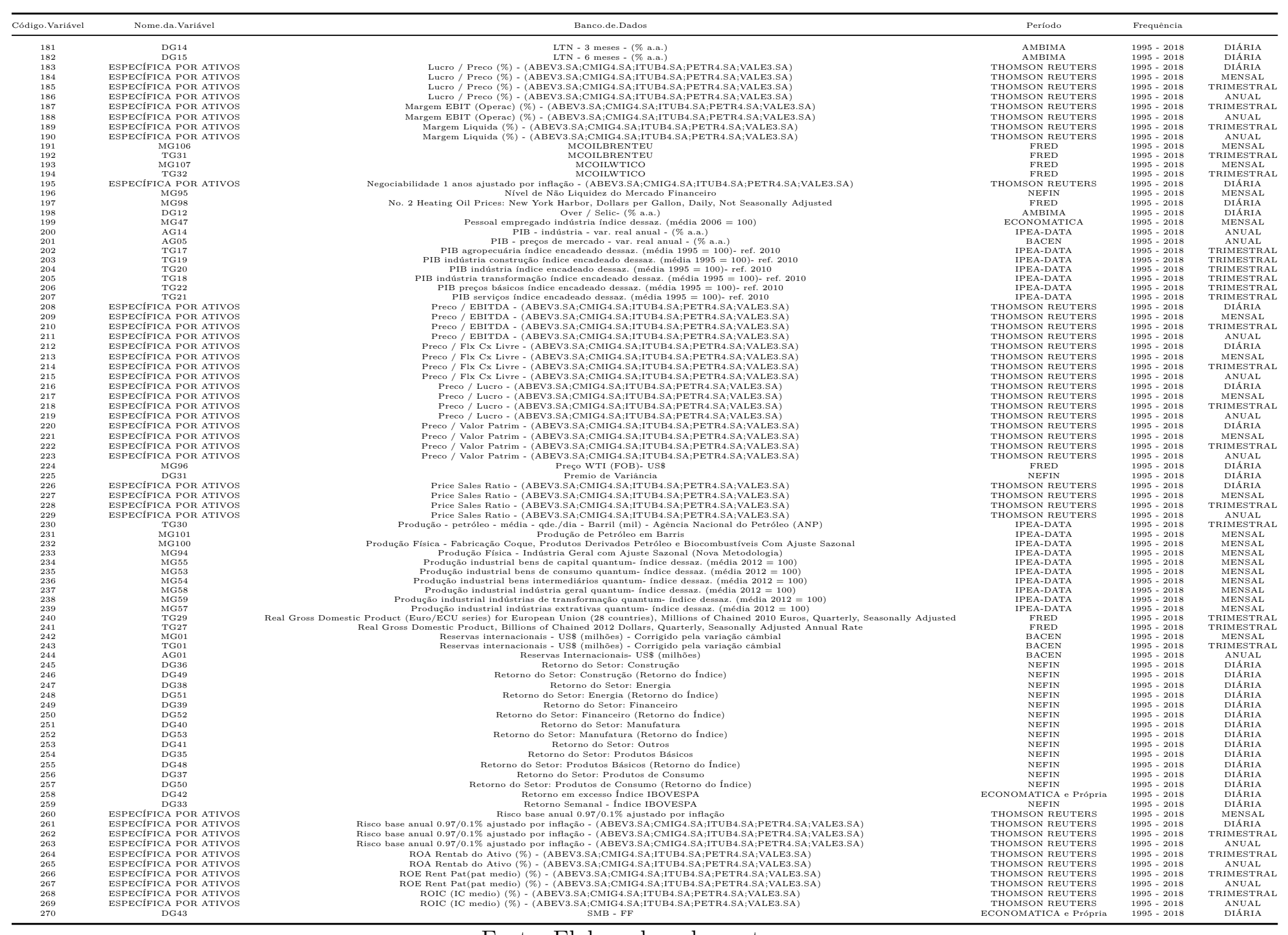

Fonte: Elaborada pelos autores. 
Tabela 16 - Variáveis incluídas na pesquisa (4).

\begin{tabular}{|c|c|c|c|c|c|}
\hline igo.Var & me.da. Variável & Banco.de.Dados & $\begin{array}{l}\text { Período } \\
\end{array}$ & requência & \\
\hline 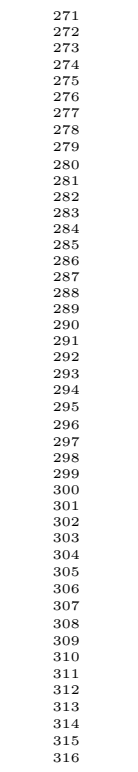 & $\begin{array}{l}\text { ESPECIFICA POR ATIVOS } \\
\text { MG103 } \\
\text { MG102 } \\
\text { MG 104 } \\
\text { MG105 } \\
\text { ESPECIFICA POR ATIVO } \\
\text { ESPECIFICA POR ATIVOS } \\
\text { DG45 ATIVOS } \\
\text { DG } 07\end{array}$ & 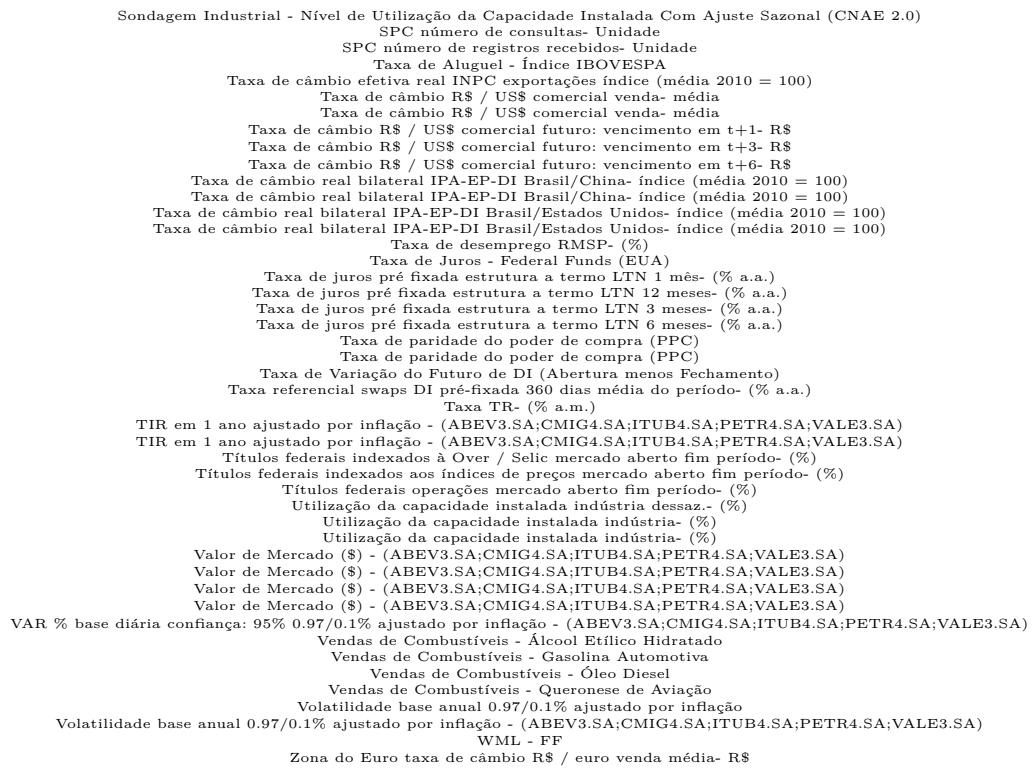 & 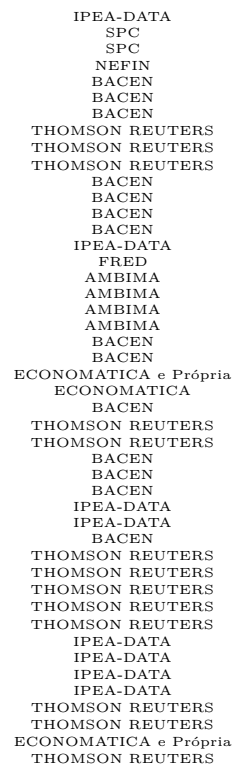 & 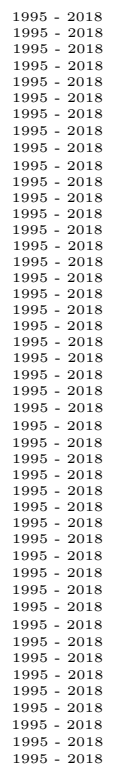 & 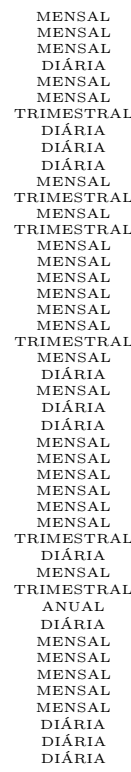 \\
\hline
\end{tabular}

Fonte: Elaborada pelos autores. 


\section{Anexo B}

Nas seções a seguir poderemos observar um resumo dos principais algorítimos utilizados nos modelos desenvolvidos na pesquisa. Todos os modelos foram desenvolvido no software R.

\subsection{Modelos de Penalização Linear}

A estrutura base utilizada para o desenvolvimento do código apresentado a seguir, foi o pacote glmnet.R, as modificações atribuídas ocorrem no processo de estimação e maximização do $R_{\text {oos }}^{2}$.

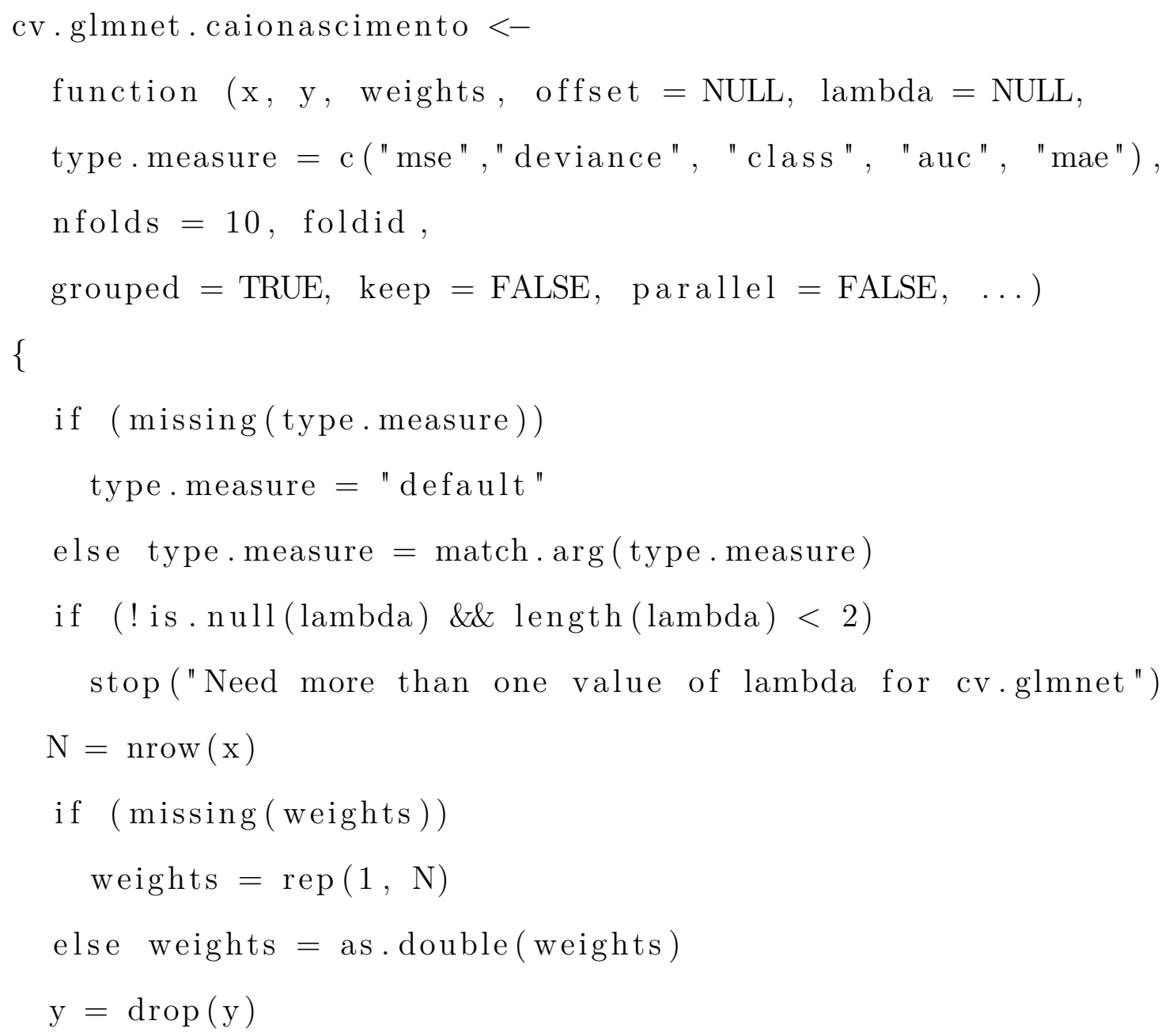


glmnet. call = match. call (expand.dots $=$ TRUE)

which $=$ match $(\mathrm{c}$ ("type.measure", "nfolds", "foldid ", "grouped ",

"keep"), names(glmnet.call), F)

if $(\operatorname{any}($ which $))$

glmnet.call = glmnet.call [-which $]$

glmnet.call $[[1]]=$ as .name ("glmnet")

glmnet. object $=\operatorname{glmnet}(\mathrm{x}, \mathrm{y}$, weights $=$ weights, offset $=$ offset ,

lambda $=$ lambda,$\ldots$ )

glmnet.object $\$$ call = glmnet. call

subclass=class (glmnet. object) [ [1] ]

type. measure=crtype (type. measure, subclass )

is. offset $=$ glmnet. object $\$$ offset

\#\#\#Next line is commented out so each call generates its own

lambda sequence

\# lambda=glmnet. object $\$$ lambda

if (inherits (glmnet.object, "multnet") \&\& ! glmnet.object\$grouped) \{ $\mathrm{nz}=\operatorname{predict}($ glmnet. object, type $=$ "nonzero" $)$

$\mathrm{nz}=\operatorname{sapply}(\mathrm{nz}$, function $(\mathrm{x}) \operatorname{sapply}(\mathrm{x}, \operatorname{length}))$

$\mathrm{nz}=\operatorname{ceiling}(\operatorname{apply}(\mathrm{nz}, 1, \operatorname{median}))$

\}

else $n z=$ sapply $($ predict $($ glmnet.object, type $=$ "nonzero"),

length)

if $(\operatorname{missing}($ foldid $))$

foldid $=\operatorname{sample}(\operatorname{rep}(\operatorname{seq}(\operatorname{nfolds}), \operatorname{length}=\mathrm{N}))$

else $n f o l d s=\max ($ foldid $)$

if $($ nfolds $<3)$

stop ("nfolds must be bigger than 3; nfolds=10 recommended")

outlist $=$ as.list $(\operatorname{seq}($ nfolds $))$

if (parallel) \{ 
\# if (parallel \&\& require (foreach)) \{

outlist $=$ foreach $(i=\operatorname{seq}($ nfolds $), \quad$ packages $=c("$ glmnet $")) \% \operatorname{dopar} \%$ \{

which $=$ foldid $=\mathrm{i}$

$\#$

if (is . matrix $(y))$

if $(\operatorname{length}(\operatorname{dim}(y))>1)$

$\mathrm{y} \_$sub $=\mathrm{y}[$ ! which,$\quad]$

else y_sub $=y[$ ! which $]$

if (is.offset)

offset_sub = as.matrix ( offset) [! which, ]

else offset_sub $=$ NULL

glmnet $(x[$ ! which,, drop $=$ FALSE $]$, y_sub, lambda = lambda, offset $=$ offset_sub, weights = weights [! which $]$, ...)

\}

\}

else \{

for (i in seq $(n$ folds $))\{$

which $=$ foldid $=\mathrm{i}$

if (is . matrix (y))

$\mathrm{y} \_$sub $=\mathrm{y}[$ ! which,$\quad]$

else y_sub $=y[$ ! which $]$

if (is.offset)

offset_sub = as.matrix ( offset) [! which, ]

else offset_sub $=$ NULL

outlist $[[\mathrm{i}]]=\operatorname{glmnet}(\mathrm{x}[$ ! which,, drop $=$ FALSE $]$,

y_sub, lambda $=$ lambda, offset $=$ offset_sub,

weights $=$ weights $[$ ! which $], \ldots$ ) 


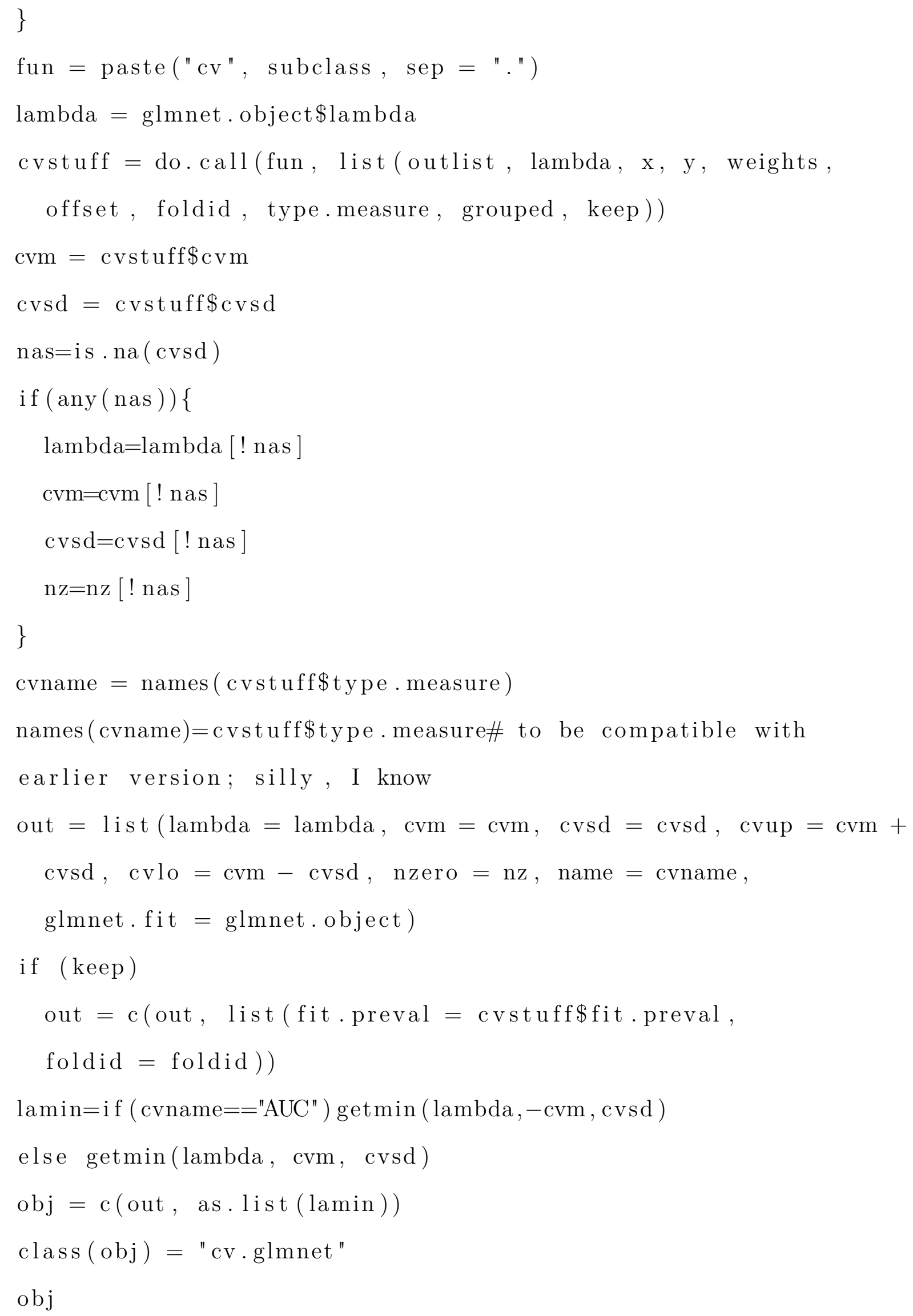




\subsection{VAR Esparso}

O primeiro algorítimo a ser apresentado é o algorítimo gerador do modelo VAR-SL, tal algoritmo tem inspiração no pacote BigVar.R, onde podemos encontrar as principais funções auxiliares.

SparseGroupLassoVAR <-function (beta, groups, Y,Z, gamm, alpha, IN Iactive , eps , q1a , p,MN, dual=FALSE, C1, in tercept )

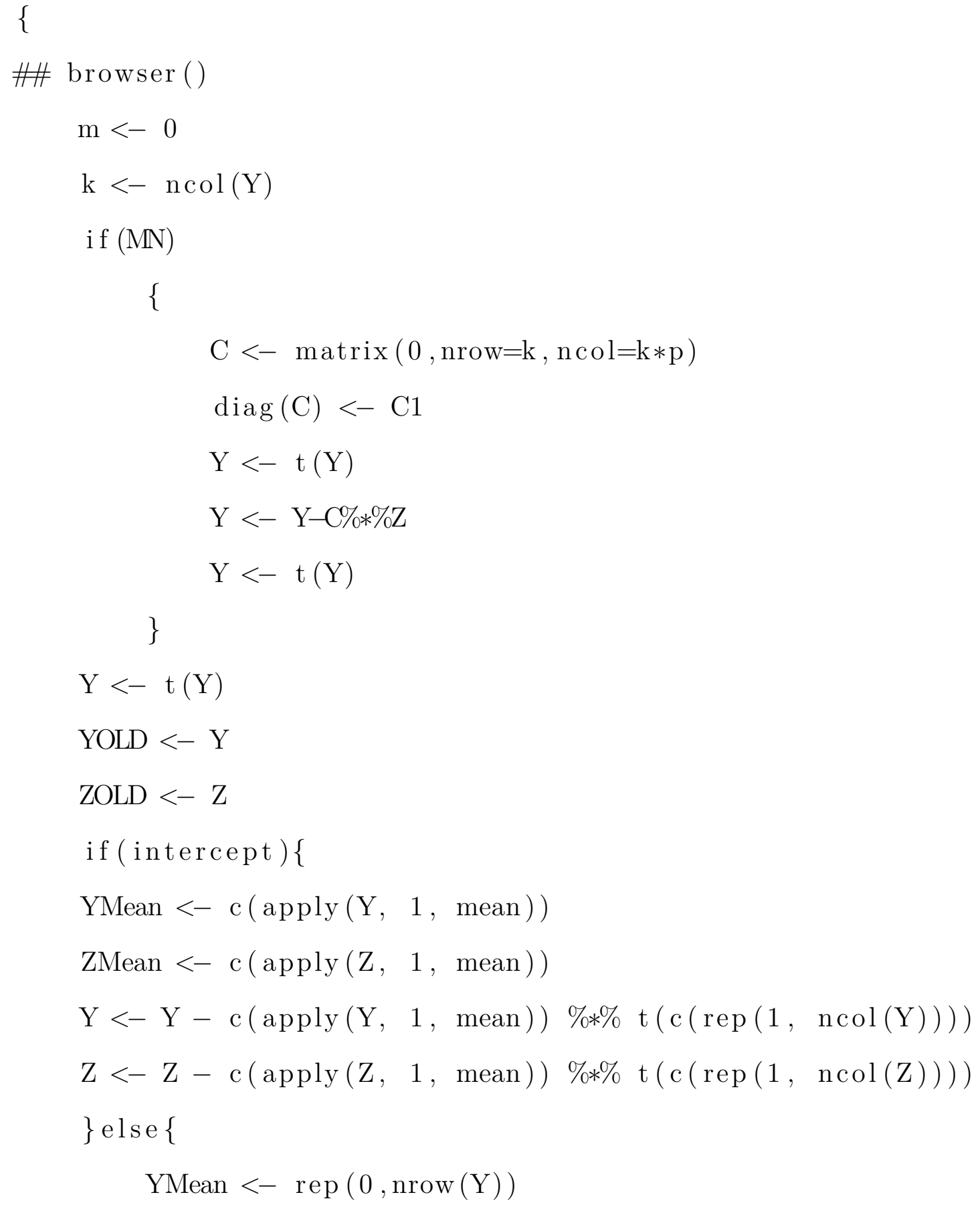




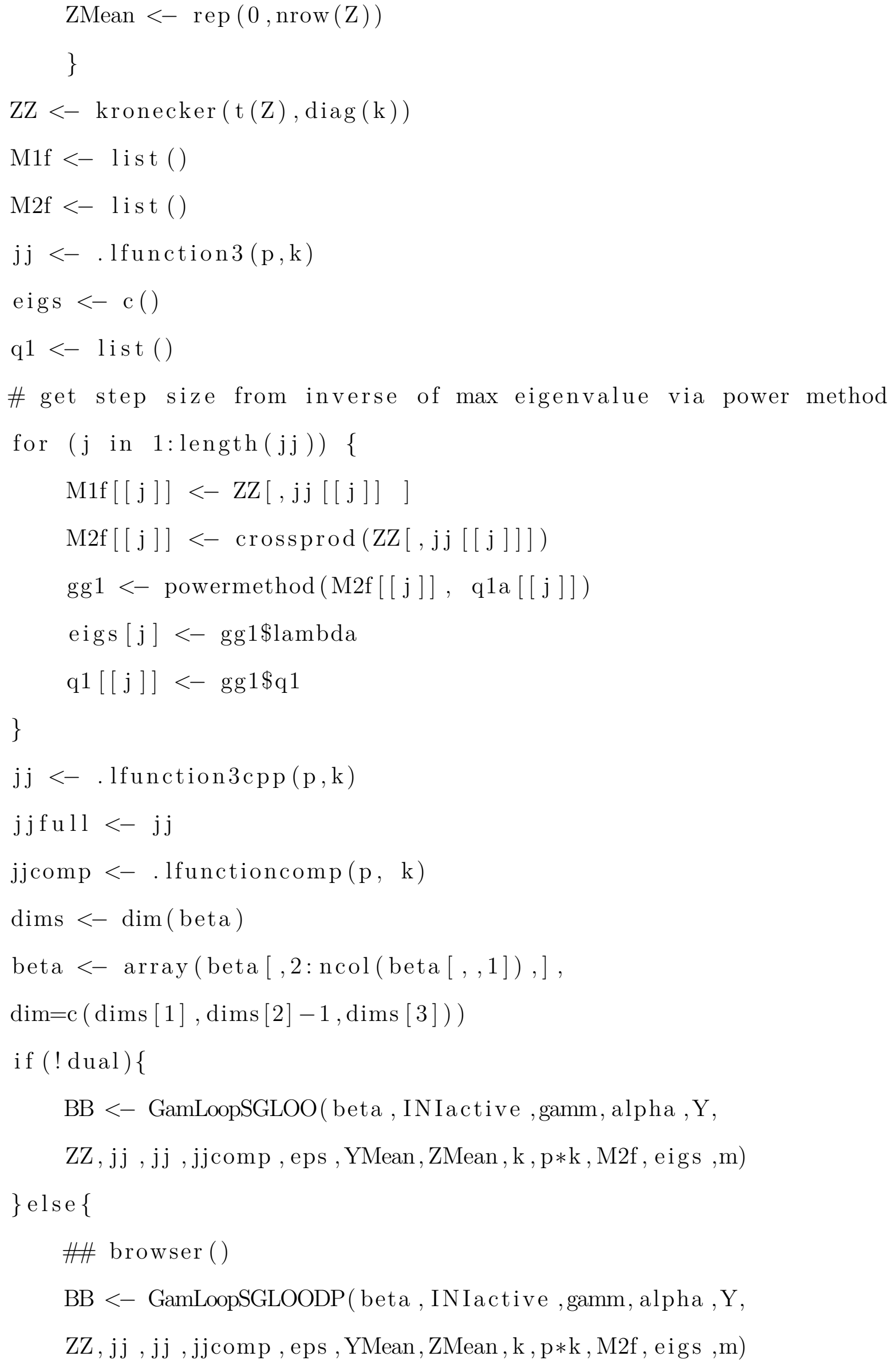




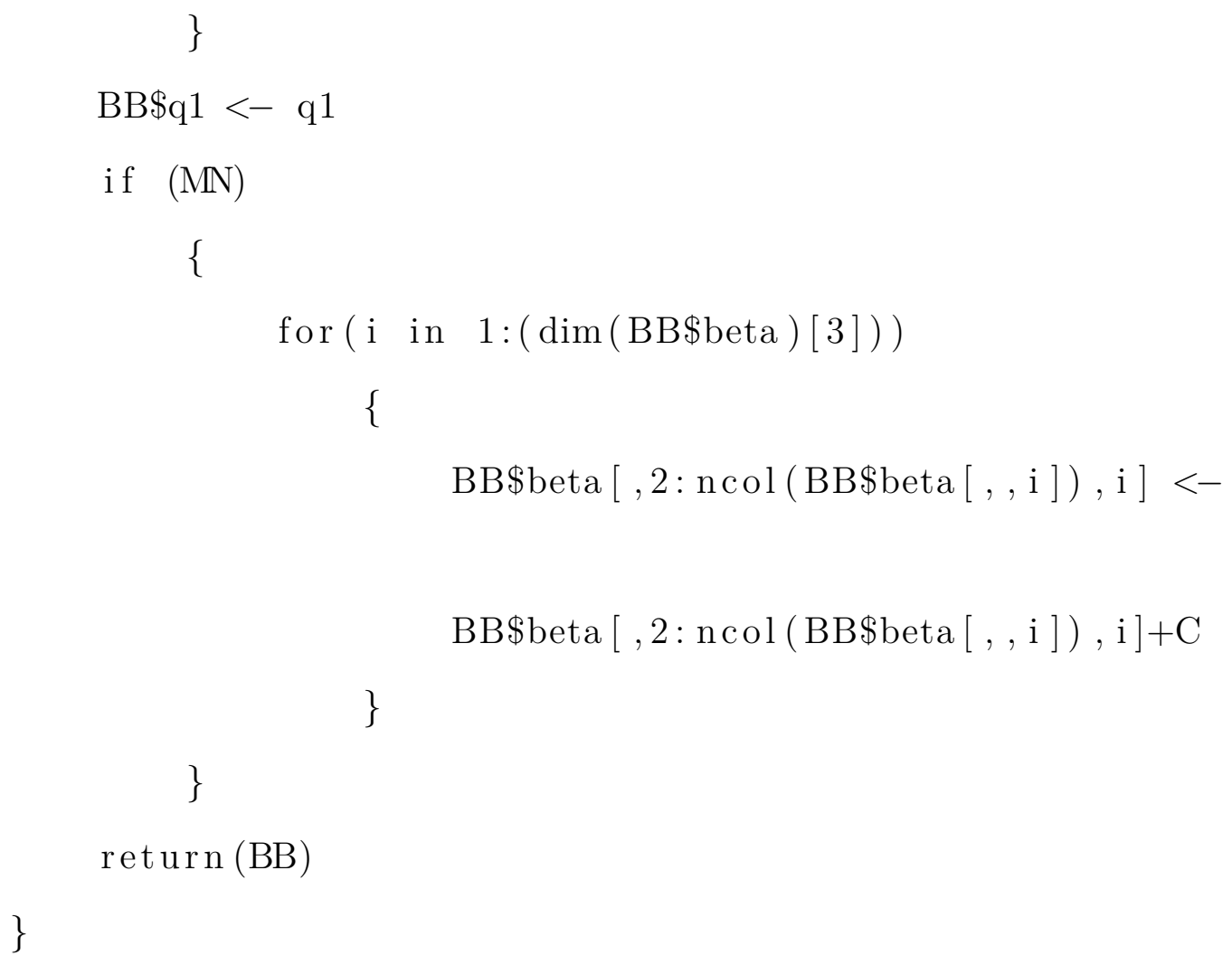

O algoritmo apresentado a seguir é uma extensão do algoritmo acima apresentado, com intuito de gerar esparcidade através da defasagem temporal.

SparseGroupLassoVAR<-function (beta, groups, Y,Z, gamm, alpha , IN Iactive, eps, q1a, p,MN, C1, intercept)

\{

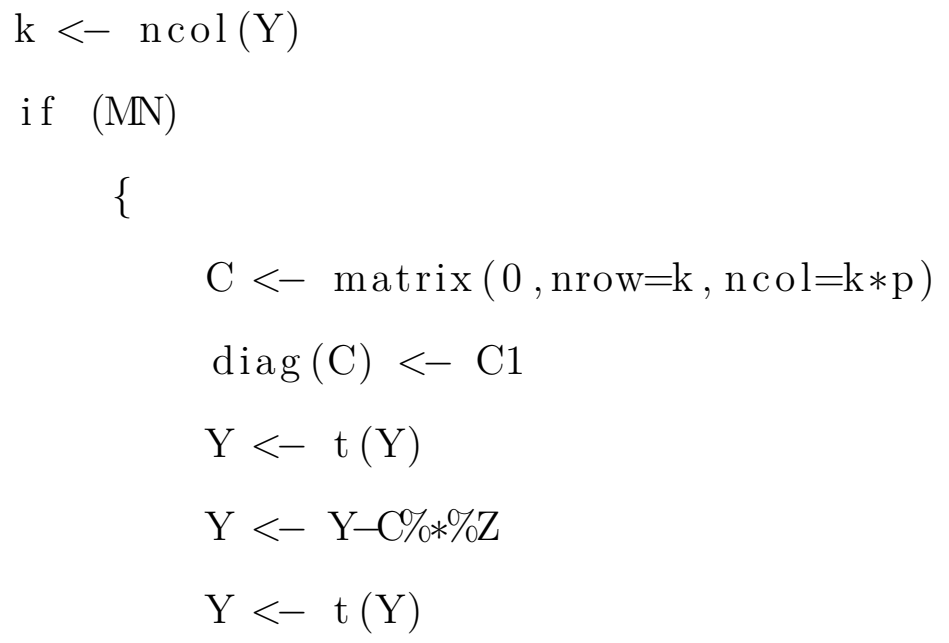




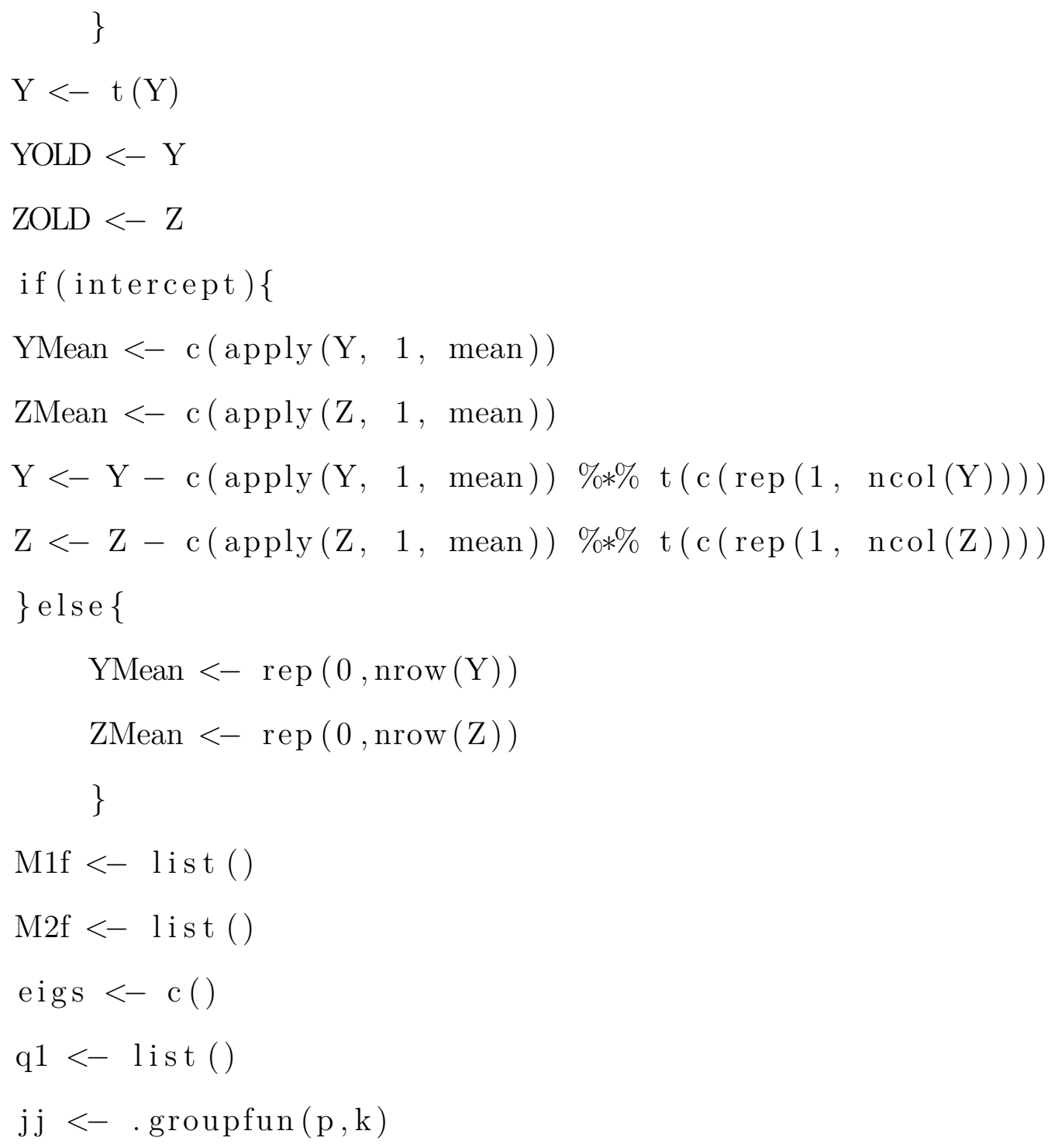

\# get step size from inverse of max eigenvalue via power method

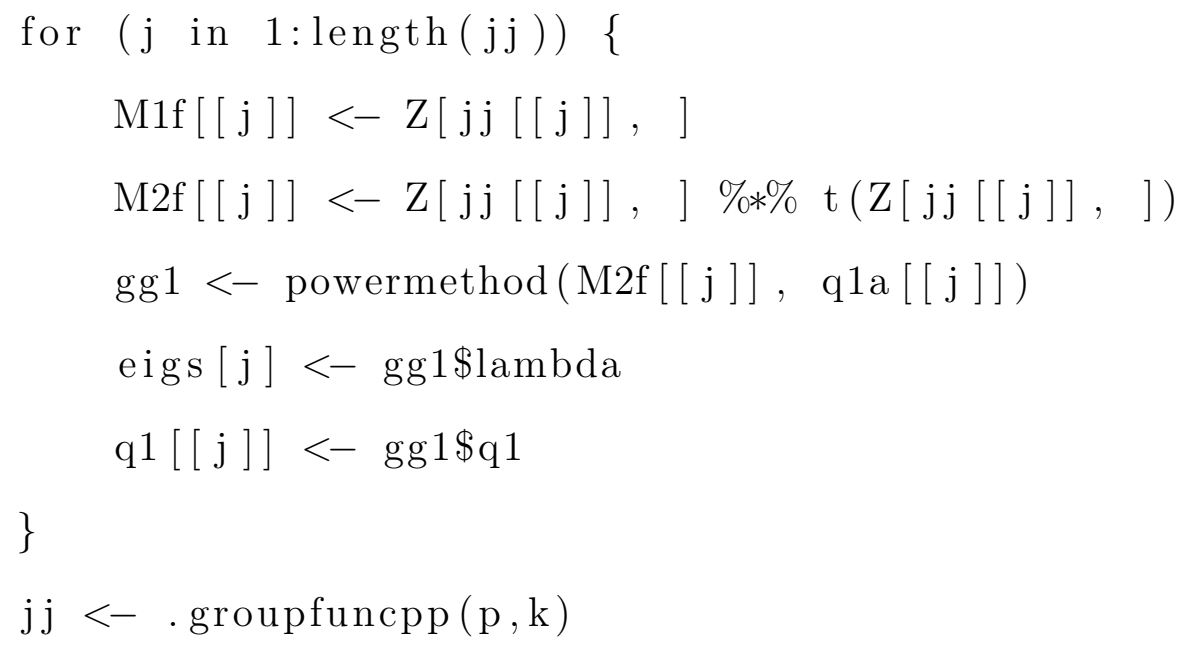




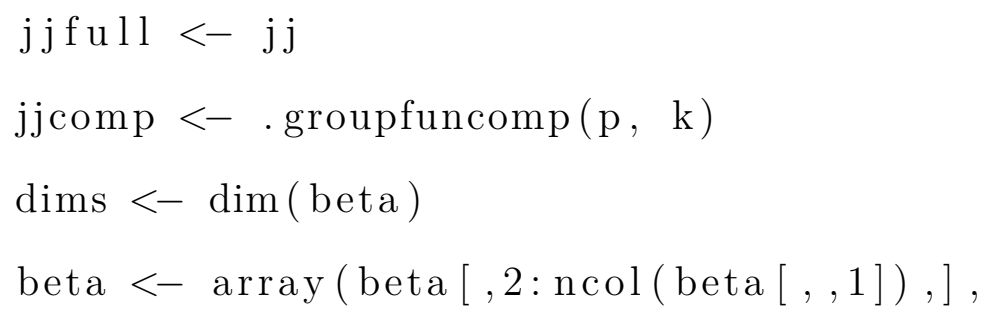

$\operatorname{dim}=c(\operatorname{dims}[1], \operatorname{dims}[2]-1, \operatorname{dims}[3]))$

\#\# browser ()

\#\# beta $<-\operatorname{beta}[, 2: \operatorname{ncol}(\operatorname{beta}[,, 1])$,

BB $<-$ GamLoopSGL( beta, IN Iactive , gamm, alpha, Y, Z, jj ,

jjfull, jjcomp, eps, YMean, as . matrix (ZMean), k, p*k, M1f, M2f, eigs )

$\mathrm{BB} \$ \mathrm{q} 1<-\mathrm{q} 1$

if $(\mathrm{MN})$

\{

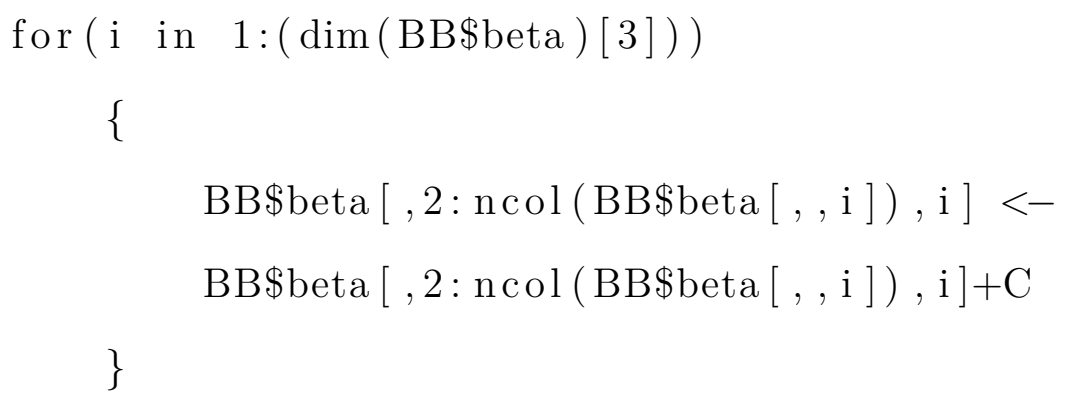

O último modelo a ser apresentado nesta seção é o BVAR-S, novamente ressaltamos que as funções auxiliares podem ser encontradas no pacote BigVar.R. 
BVARLitterman <- function $(Y, Z, p$, tau , mu, H,iRW)

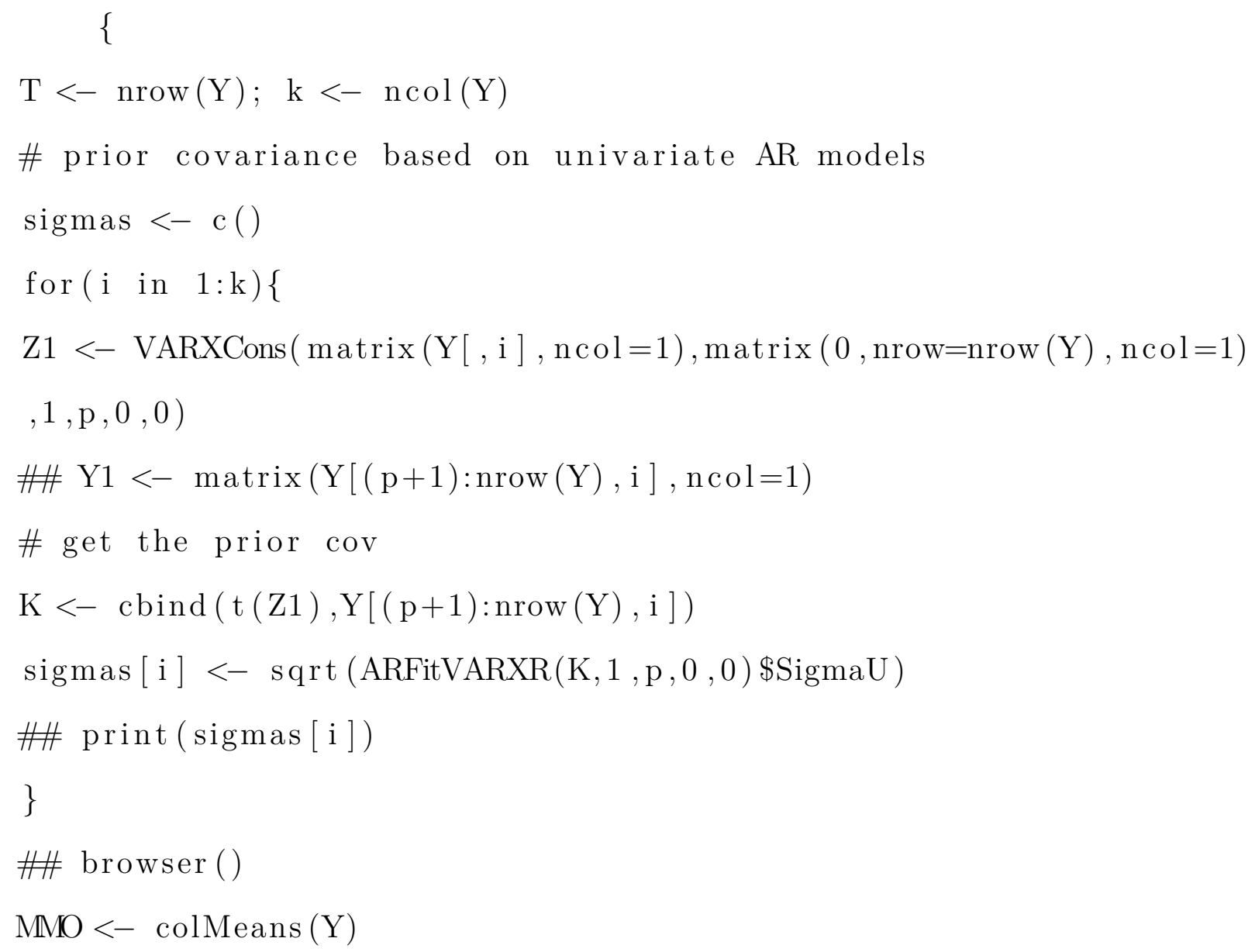


\# create dummy for intercept

epsilon $=1 \mathrm{e}-5$

Ycs $<-1 \mathrm{e}-5 *$ matrix $(0$, nrow $=1, \mathrm{ncol}=\mathrm{k})$

Zcs $<-$ epsilon $* \operatorname{cbind}(\operatorname{matrix}(0, \operatorname{ncol}=\mathrm{k} * \mathrm{p}$, nrow $=1), 1)$

\# dummy on the sums of coefficients

Ylr $<-\operatorname{mu} * \operatorname{diag}(\mathrm{MMO} * \mathrm{iRW})$

Zlr $1<-\operatorname{kronecker}(\operatorname{matrix}(1$, nrow $=1$, ncol $=$ p $)$, diag $(\mathrm{MMO}) * \mathrm{RW})$

Zlr $<-\operatorname{mu} *(\operatorname{cbind}(Z \operatorname{lr} 1, \operatorname{matrix}(0$, nrow $=\mathrm{k}, \operatorname{ncol}=1)))$

\# Dummy for residual covariance matrix

Ycv $<-\operatorname{diag}(\operatorname{sigmas})$

Zcv $<-$ matrix $(0$, nrow $=\mathrm{k}, \mathrm{ncol}=\mathrm{k} * \mathrm{p}+1)$

Yprior $<-$ rbind (Yrw, Ylr, Ycv, Ycs)

Zprior $<-$ rbind $($ Zrw, Zlr, Zcv, Zcs)

\#\# Zp2 <- rev $($ Zprior $[(\operatorname{nrow}($ Zprior $))]$,

\#\# Zp3 <- Zprior [1:( nrow $($ Zprior $)-1)$,

\#\# Zp3 <- rbind $(\mathrm{Zp} 2, \mathrm{Zp} 3)$

\#\# ZZI2 <- solve (t (Zp3)\%*\%Zp3+t (Z)\%*\%Z)

\#\# $\operatorname{dim}($ ZZI2)

Tstar $<-\operatorname{nrow}($ Yprior $)$

\#\# $\operatorname{dim}($ Zprior $)$

\#\# \# posterior

\#\# $\operatorname{dim}(\mathrm{Z})$

\#\# browser ()

$\mathrm{Z}<-\mathrm{t}(\mathrm{Z})$ 
$\mathrm{Z}<-\operatorname{cbind}(\mathrm{Z}[, 2: \operatorname{ncol}(\mathrm{Z})], 1)$

\#\# $\operatorname{dim}($ Yprior $)$

\#\# browser ()

\#\# kappa(crossprod (Z))

ZZinv $<-$ solve (t ( Zprior)\%*\%Zprior $+\mathrm{t}(\mathrm{Z}) \% * \% \mathrm{Z})$

$\mathrm{ZY}<-\mathrm{t}(\mathrm{Zprior}) \% * \%$ Yprior $+\mathrm{t}(\mathrm{Z}) \% * \% \mathrm{Y}$

beta $<-$ ZZinv\%*\%ZY

\#\# browser ()

\#\# preds $<-\mathrm{Z}[\operatorname{nrow}(\mathrm{Z})] \% * \$,$% beta$

$\operatorname{return}(\mathrm{t}($ beta $))$

\}

\subsection{PCA}

Para o desenvolvimento da análise de componentes principais utilizamos a função prcomp presente no conjunto básico de funções do $\mathrm{R}$, a única modificação realizada foi uma rotação nos componentes principais.

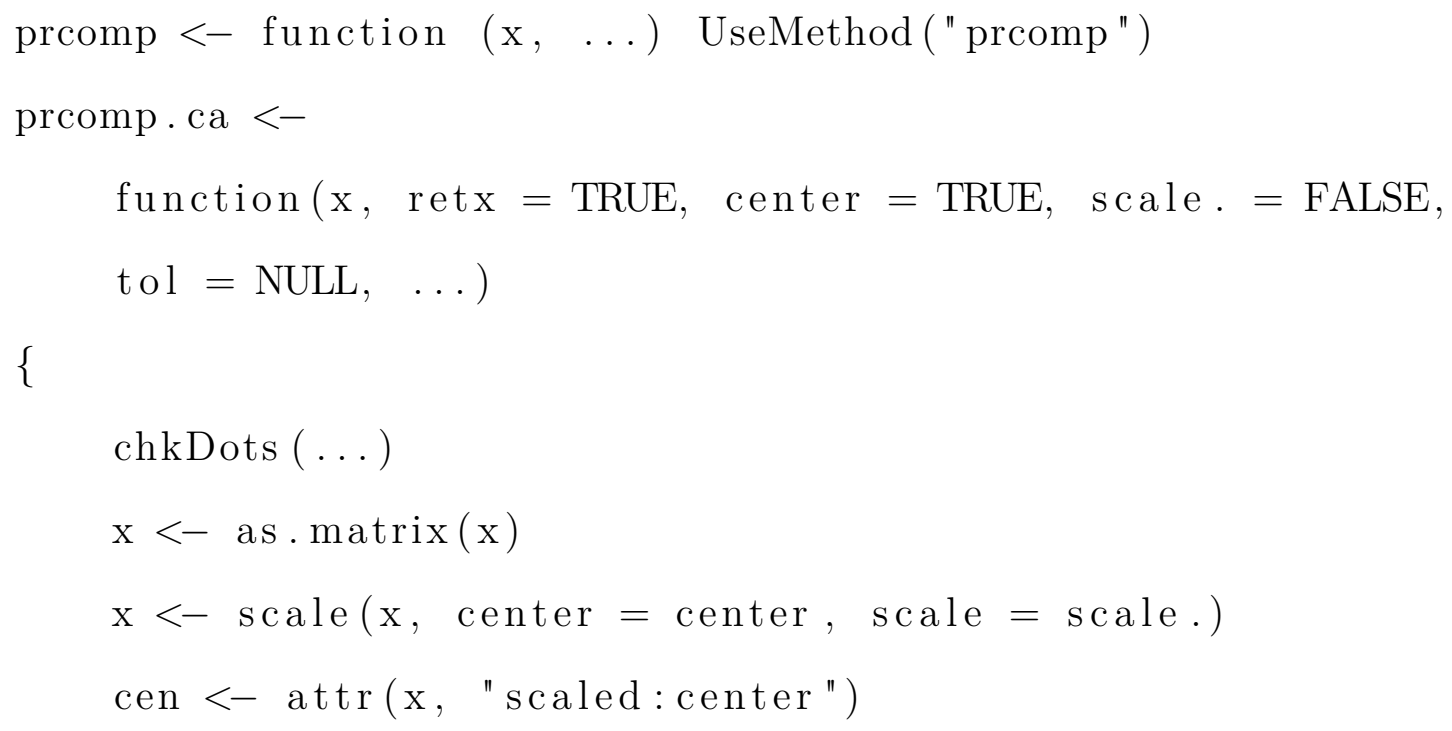




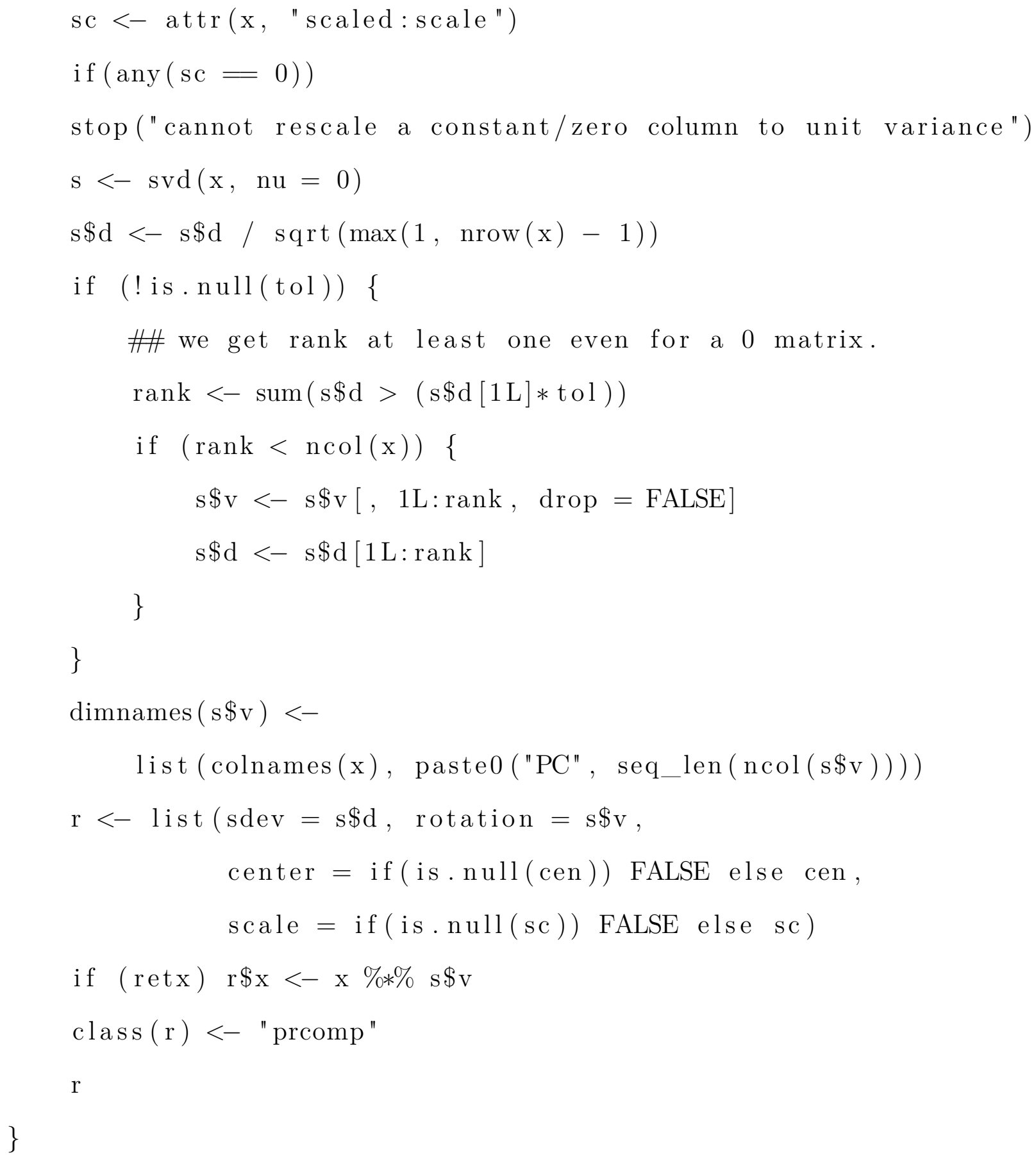

\subsection{SPCA}

Para o desenvolvimento do SPCA, utilizamos a função $S P C A$ presente no pacote elasticnet.R, apenas realizamos um modificação em uma função auxiliar para se encaixar no objetivo da pesquisa de maximizar o $R_{\text {oos }}^{2}$. 


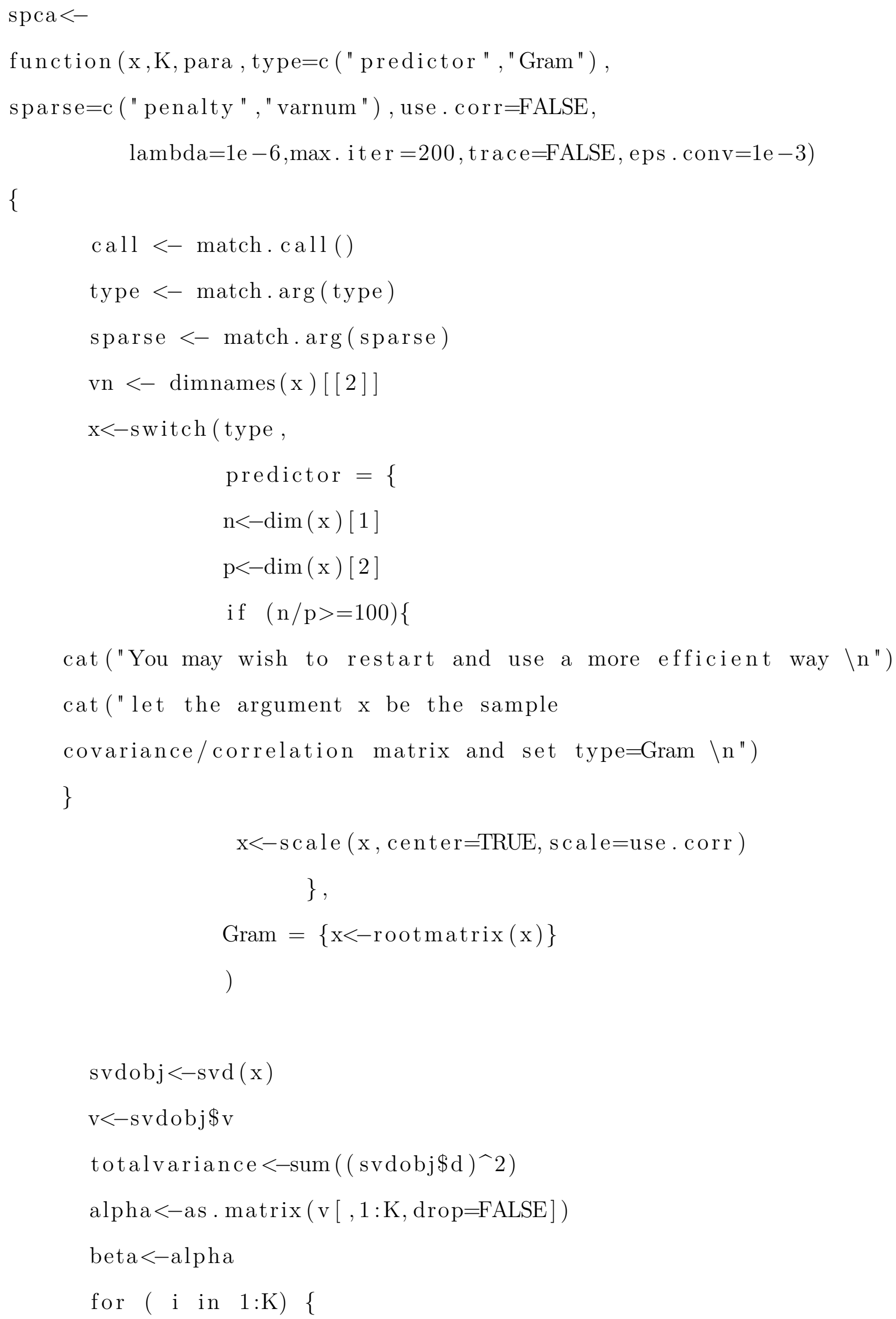




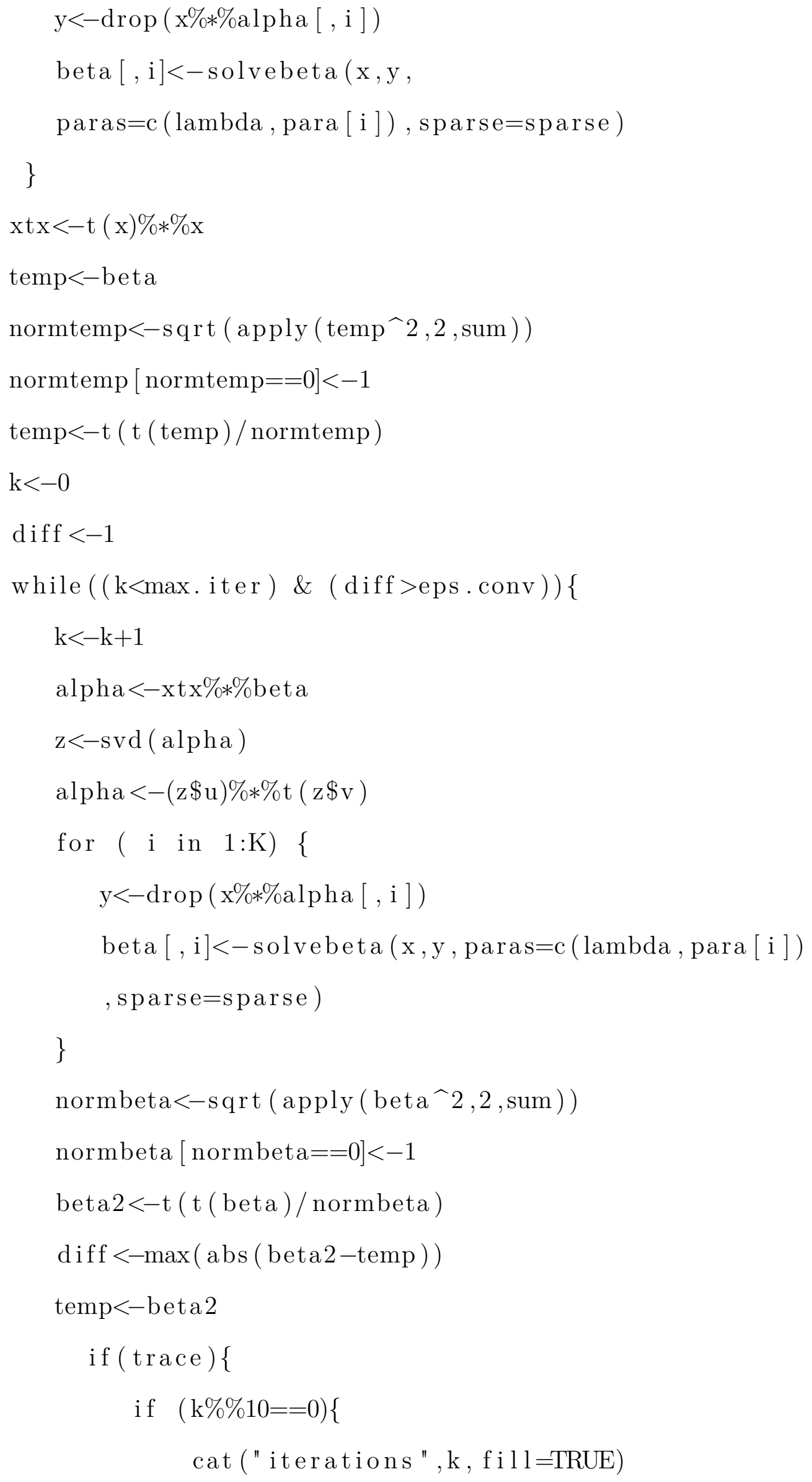




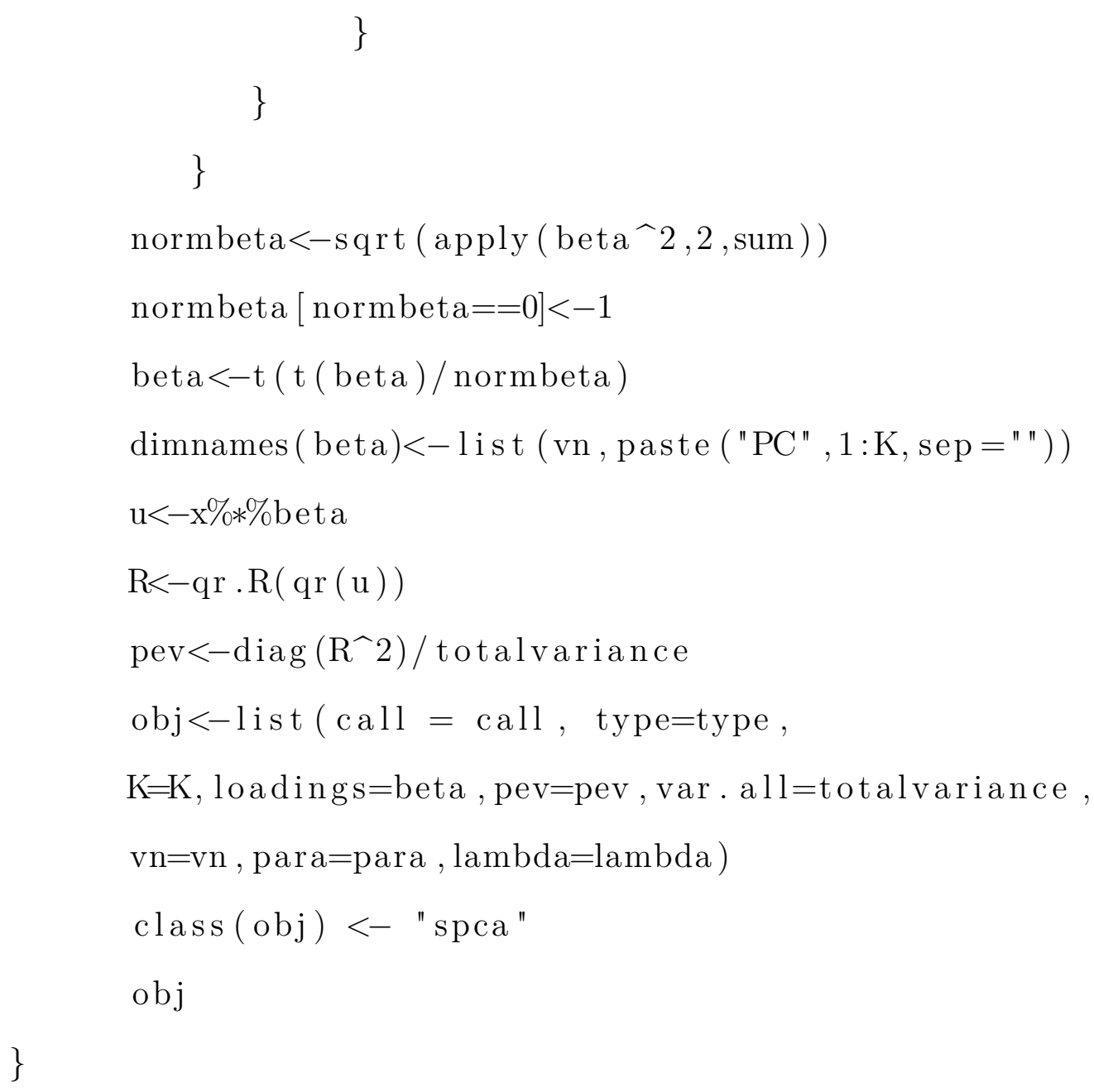

\subsection{PLS}

O algoritmo utilizados na pesquisa para o desenvolvimento do mínimos quadrados parciais foi estruturado sobre o pacote pls.

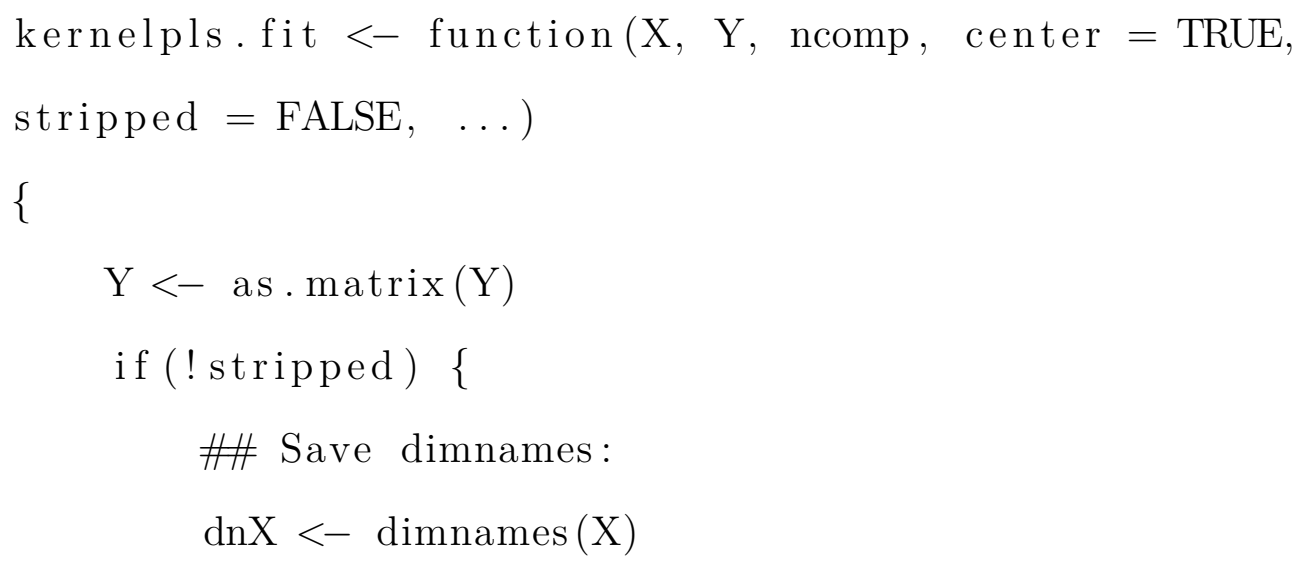




$$
\operatorname{dn} \mathrm{Y}<- \text { dimnames }(\mathrm{Y})
$$

\}

\#\# Remove dimnames during calculation. (Doesn't seem to make a \#\# difference here (2.3.0).)

$\operatorname{dimnames}(\mathrm{X})<-\operatorname{dimnames}(\mathrm{Y})<-$ NULL

$$
\begin{aligned}
& \operatorname{nobj}<-\operatorname{dim}(\mathrm{X})[1] \\
& \operatorname{npred}<-\operatorname{dim}(\mathrm{X})[2] \\
& \operatorname{nresp}<-\operatorname{dim}(\mathrm{Y})[2]
\end{aligned}
$$

\#\# Center variables:

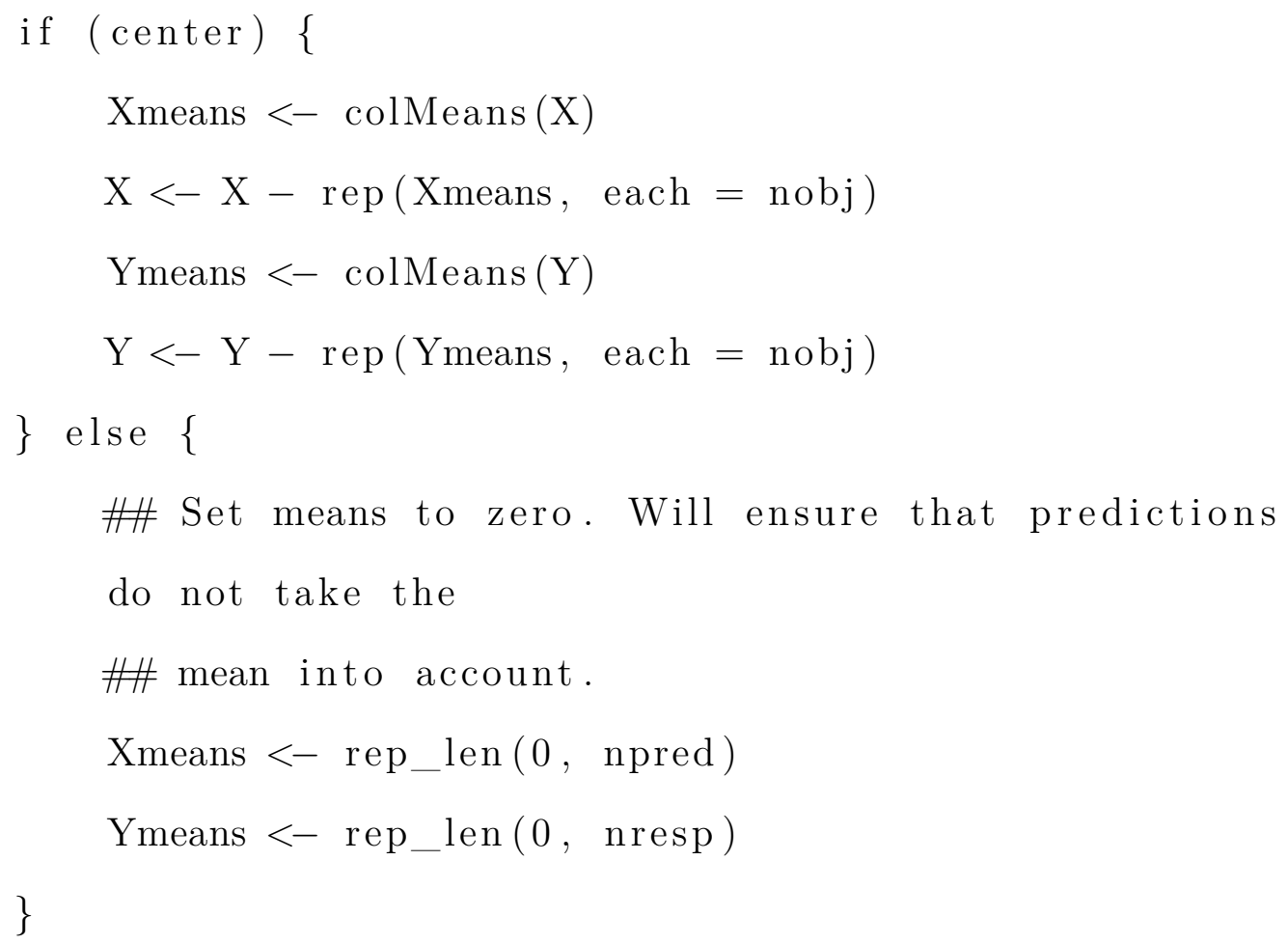




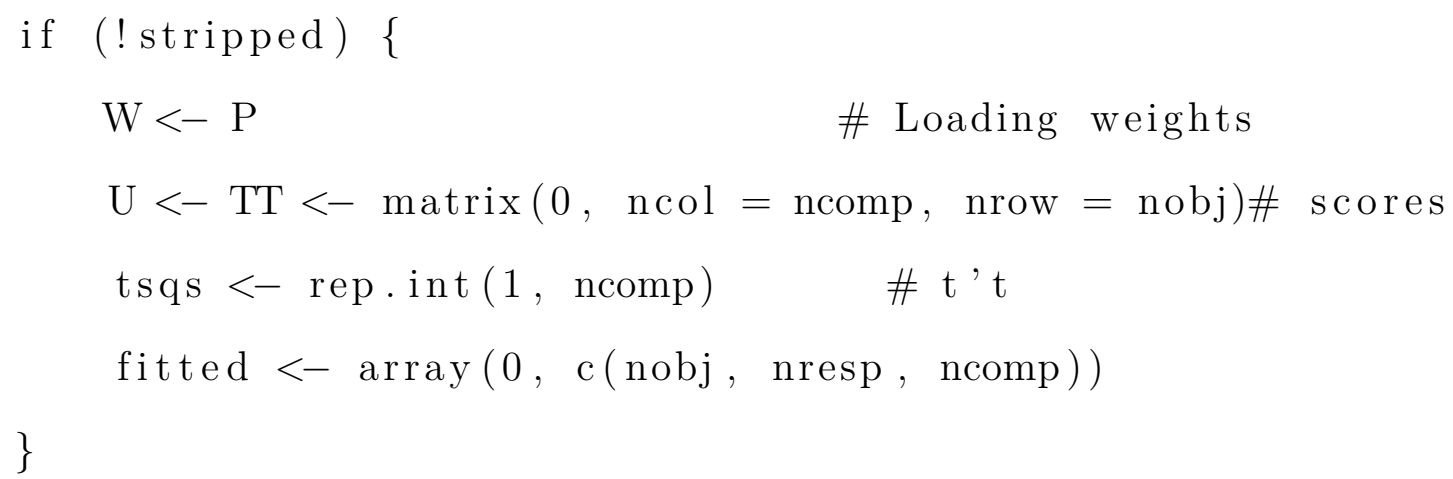

\#\# 3. 


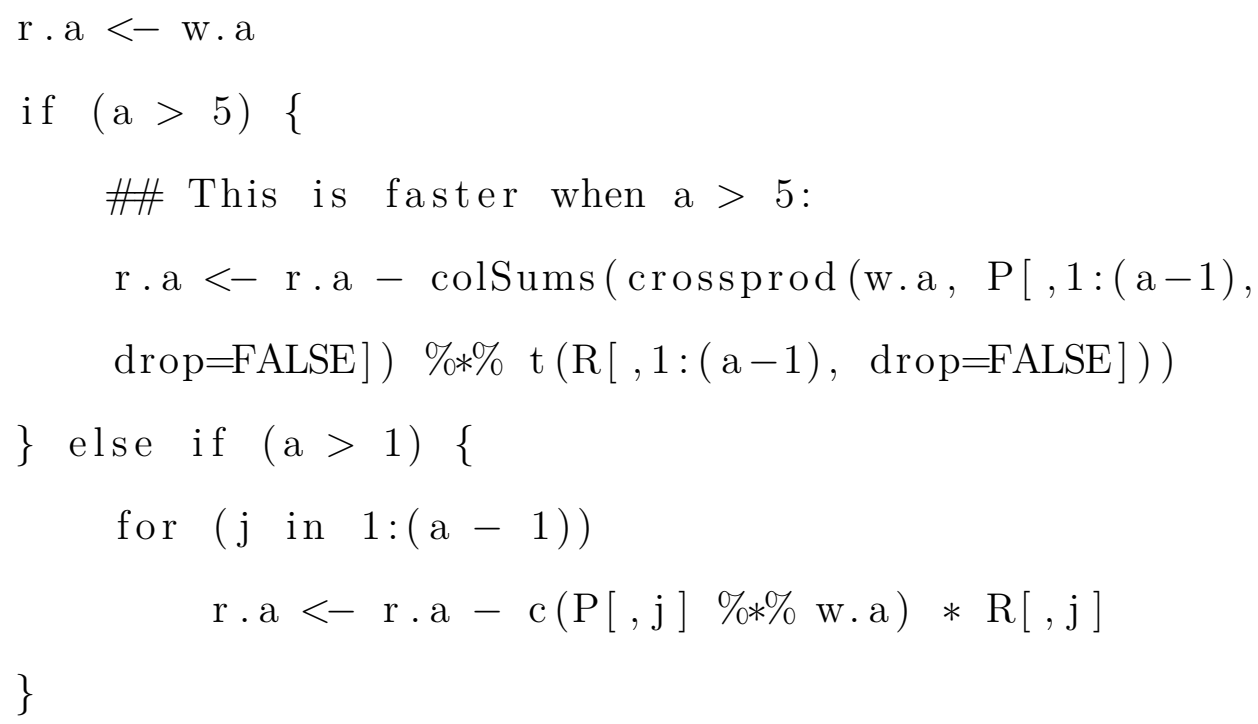

\#\# 4 .

t. a $<-\mathrm{X} \% * \%$ r. a

tsq $<-c(\operatorname{crossprod}($ t.a $))$

p.a $<-\operatorname{crossprod}(X$, t.a $) /$ tsq

q.a $<-$ crossprod (XtY, r.a) / tsq

\#\# 5 .

$\mathrm{XtY}<-\mathrm{XtY}-(\mathrm{tsq} * \mathrm{p} \cdot \mathrm{a}) \% * \%$ t $(\mathrm{q} \cdot \mathrm{a})$

\#\# 6.-8.

$\mathrm{R}[, \mathrm{a}]<-\mathrm{r} \cdot \mathrm{a}$

$\mathrm{P}[, \mathrm{a}]<-\mathrm{p} \cdot \mathrm{a}$

$\mathrm{tQ}[\mathrm{a}]<,-\mathrm{q} \cdot \mathrm{a}$

$\mathrm{B}[, \mathrm{a}]<-\mathrm{R}[, 1: \mathrm{a}, \mathrm{drop}=\mathrm{FALSE}] \% * \%$ tQ $[1: \mathrm{a},, \mathrm{drop}=\mathrm{FALSE}]$

if (! stripped) \{

$\operatorname{tsqs}[\mathrm{a}]<-\operatorname{tsq}$

\#\# Extra step to calculate Y scores:

u. a $<-$ Y \%*\% q.a $/ \mathrm{c}(\operatorname{crossprod}(\mathrm{q} \cdot \mathrm{a}))$ \# Ok for nresp $=1$

\#\# make u orth to previous X scores: 


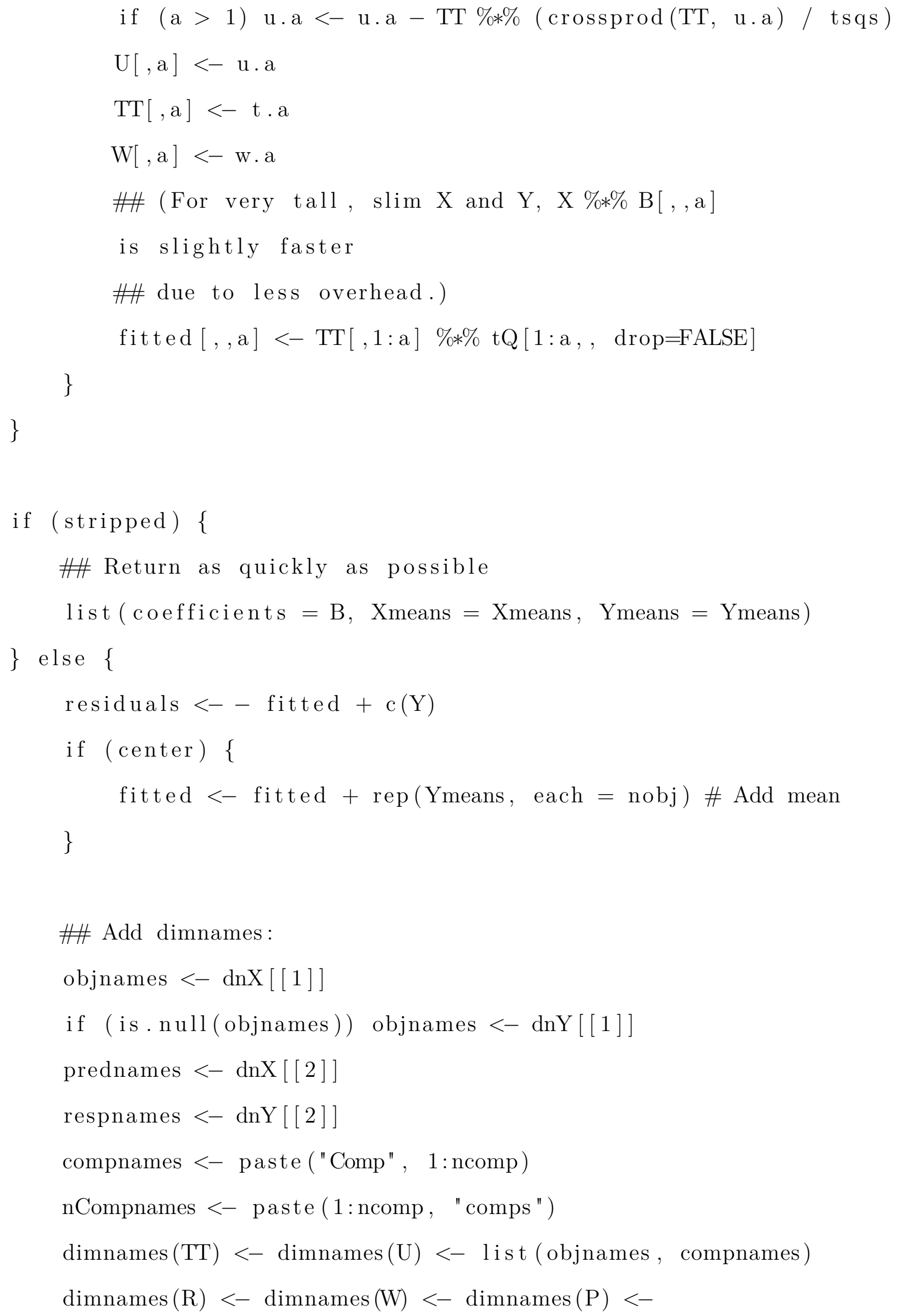

\#\# Add dimnames:

objnames $<-\operatorname{dnX}[[1]]$ 


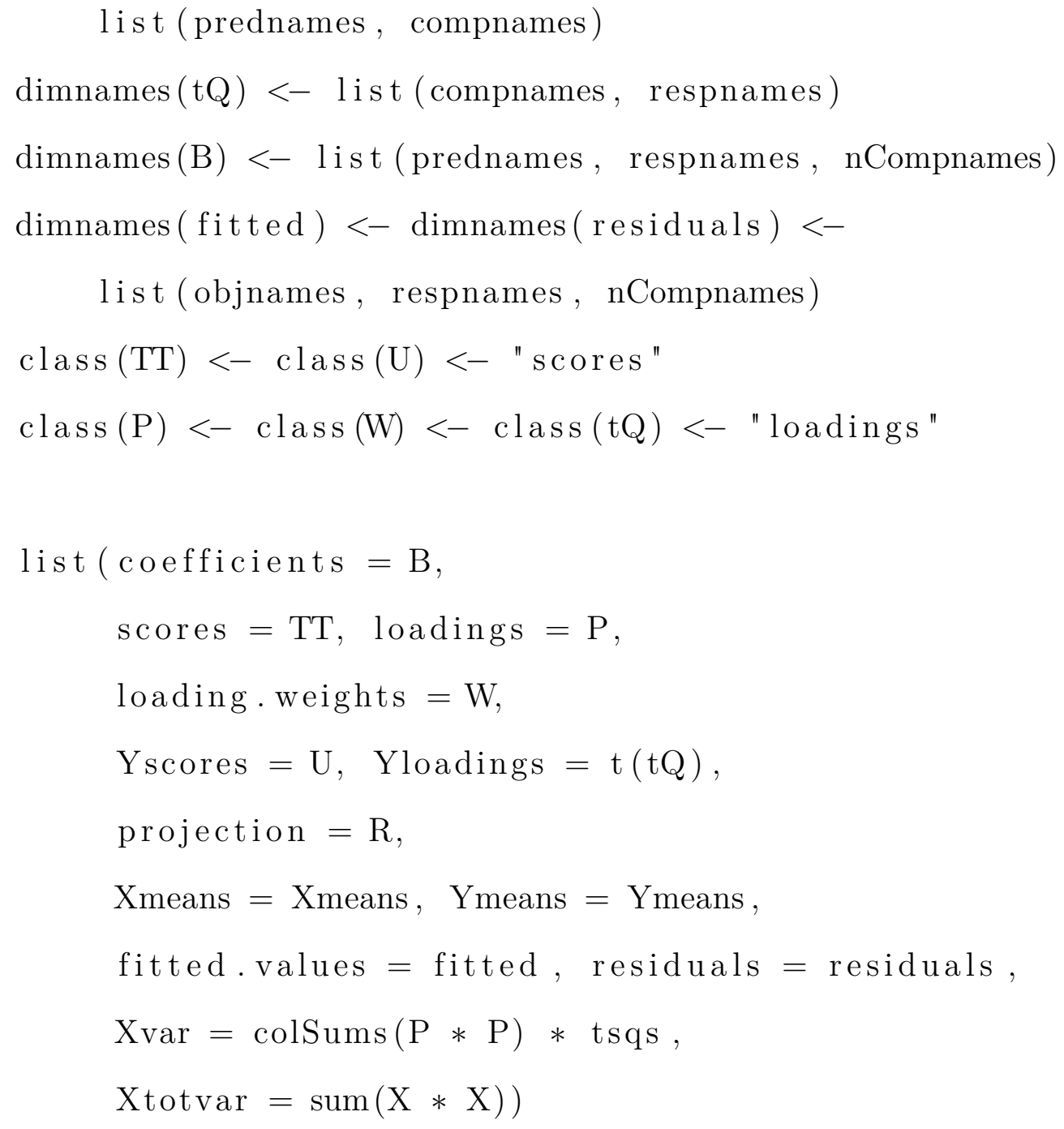

